\title{
Adapting Direct Services for Telehealth: A Practical Tutorial
}

\author{
Samantha Bergmann ${ }^{1}$ (D) Karen A. Toussaint $^{1}$ (D) $\cdot$ Haven Niland $^{1,2} \cdot$ Elizabeth M. Sansing $^{1,2} \cdot$ Gabriel Armshaw $^{1,2}$. \\ Marla Baltazar ${ }^{1,2}$
}

Accepted: 5 November 2020 / Published online: 12 October 2021

(C) Association for Behavior Analysis International 2021

\begin{abstract}
Due to the pandemic brought on by the novel coronavirus (COVID-19), consumers of applied behavior-analytic interventions may be experiencing disrupted access to services. In response to the need for services, behavior analysts and therapists may find themselves treading unchartered waters as they use telehealth to provide direct intervention to consumers. Direct service provision via telehealth extends beyond the bounds of existing telehealth research, which primarily focuses on caregiver training and consultation. In the transition to telehealth, behavior analysts can consider how to adapt an existing evidence base of behavioranalytic strategies from a face-to-face format to intervention via a teleconferencing platform (i.e., Zoom). In this tutorial, we provide practice recommendations, task analyses, and a curated list of Zoom walk-throughs to help behavior analysts construct conceptually systematic learning opportunities in their direct telehealth services. Leveraging teleconferencing features to provide behavior-analytic intervention directly to consumers could spur future research to support these need-inspired practices and guide telehealth applications during and beyond the current pandemic.
\end{abstract}

Keywords Applied behavior analysis · Autism · COVID-19 · Direct services $\cdot$ Telehealth

On March 13, 2020, the United States declared a state of emergency related to the novel coronavirus (COVID-19) pandemic. As we write this article, the world continues to be consumed by this public health crisis. Many individuals are experiencing insufficient access to medically necessary health care, including behavioral health services, due to imposed restrictions and recommendations to curtail the spread of COVID-19 through social distancing and personal protective equipment (Centers for Disease Control and Prevention [CDC], 2020b; World Health Organization [WHO], 2020). In many states, applied behavior analysis (ABA) for individuals with autism spectrum disorder (ASD) is recognized as an essential service and may continue despite shelter-in-place orders and phased openings (Association of Professional Behavior Analysts, 2020; Council of Autism Service Providers [CASP], n.d.).

Haven Niland and Elizabeth M. Sansing contributed equally to this work.

Samantha Bergmann

sam.bergmann@unt.edu

1 Department of Behavior Analysis, University of North Texas, 1155 Union Circle \#310919, Denton, TX 76203, USA

2 UNT Kristin Farmer Autism Center, University of North Texas, Denton, TX, USA
Although services may continue in some states, behavior analysts are encouraged to engage in a decision-making process to mitigate risk for consumers and staff (Colombo, Wallace, \& Taylor, 2020; Cox, Plavnick, \& Brodhead, 2020; LeBlanc, Lazo-Pearson, Pollard, \& Unumb, 2020); the decision may include pausing face-to-face services for some.

As a result, many health care providers have turned to telehealth to limit person-to-person contact, a necessary step to reduce the risk of exposure. Access to telehealth services may be eased by the U.S. Department of Health and Human Services temporarily relaxed requirements around the potential breach of protected health information by permitting the use of technology that is not compliant with the Health Insurance Portability and Accountability Act (HIPAA; Office for Civil Rights, 2020). Additionally, several third-party payors increased the breadth of telehealth coverage to respond to the needs of consumers with ASD. Therefore, Board Certified Behavior Analysts (BCBAs) may find themselves pivoting from face-to-face services (e.g., those provided in the clinic, home, and school) to telehealth-mediated interventions.

Telehealth applications and research in behavior analysis predate the pandemic (Tomlinson, Gore, \& McGill, 2018; Vismara, McCormick, Young, Nadhan, \& Monlux, 2013). Ferguson, Craig, and Dounavi (2019) conducted a systematic review of the literature on behavior-analytic intervention services provided 
via telehealth; they identified that $86 \%$ of interventionists were caregivers implementing assessment or intervention procedures under the supervision of a behavior analyst. These caregivermediated interventions typically address a limited number of target behaviors, such as reducing challenging behavior (Wacker et al., 2013a, 2013b) or increasing manding (Neely, Rispoli, Gerow, \& Hong, 2016). However, many individuals with ASD require comprehensive intervention services in which all relevant skill domains are addressed. Comprehensive intervention models are typically provided by a behavior professional (often referred to as a behavior therapist or behavior technician) who employs numerous operant-learning procedures directly with the consumer for an average of $30 \mathrm{hr}$ per week for $2-$ 3 years (Smith, 2012). With social-distancing measures and the current scope of behavior-analytic telehealth services, individuals with ASD are likely experiencing disrupted comprehensive intervention services (CASP, 2020a).

One solution to remediate disrupted services is to extend telehealth technologies to include intervention services provided directly to the client by a behavior professional. However, there are barriers to this expansion. First, this model has technology barriers that are common to all telehealth models (e.g., high technology support requirements for the provider and families, issues with remote viewing, disruptive environment; Lerman et al., 2020; Zoder-Martell, Markelz, Floress, Skriba, \& Sayyah, 2020). Second, this model has practical limitations above and beyond technological barriers. Although the therapist would be interacting primarily with the learner, the caregiver may need to facilitate components of the intervention to assist with technology use or to reduce competing variables in the home environment. Given the intensity of hours associated with comprehensive services, caregiver facilitation may be challenging to arrange regularly. Parents may be motivated to continue ABA intervention for their child with ASD; however, their participation may be limited due to multiple factors, including work demands and the need to care for other children in the home. Before the pandemic, parents of children with ASD reported higher stress levels than parents of children without ASD (Quintero \& McIntyre, 2010). The onset of the pandemic brought additional stressors to families, including lost jobs, forced transitions to work from home, closure of schools and clinics, limited respite care, reduced support from family members, reduction or discontinuation of ABA therapy, and difficulty obtaining household supplies. These difficulties are understandable during these uncertain times, so a BCBA should work with the caregivers to assess the requirements of direct services via telehealth and identify solutions to remove barriers to effective intervention (Behavior Analyst Certification Board [BACB], 2014, Section 4.07).

Third, there is no empirical support for direct service provision of ABA via telehealth. A BCBA should make decisions on their professional activities based on available support in the science and practice of behavior analysis (BACB, 2014, Section 1.01). Therefore, the lack of research on direct services to the client through telehealth needs to be considered carefully, especially regarding a client's right to effective treatment (BACB, 2014, Section 2.09a). Despite the lack of research, many third-party payors approved coverage of ABA delivered directly to the consumer through telehealth; a BCBA should be aware of organizational pressures to identify revenue sources under reduced service hours. When considering telehealth as an option, a BCBA should pursue it only if it is in the client's best interest (BACB,2014, Section 2.02).

Even with these barriers, behavior analysts should be knowledgeable of existing technologies to determine which may allow for an adaptation of empirically supported interventions to telehealth models on a case-by-case basis to help minimize disruptions in services (BACB, 2014, Section 2.15; BACB, 2020), given the extreme situation of the COVID-19 pandemic. A BCBA considering the provision of direct services via telehealth should consult several resources that provide recommendations for decision guides and assessments to determine whether direct services through telehealth are likely to benefit the learner (Blanco, Meisels, Blair, \& Leonard, 2020; CASP, 2020b; Rodriguez, 2020).

As behavior analysts shift to providing telehealth services to meet the needs of clients and their families, service providers would benefit from information on how to utilize a teleconferencing platform to deliver behavior-analytic interventions. Teleconferencing platforms allow individuals to meet virtually with others from different locations with the use of electronic devices, such as a computer or a smartphone. Virtual meetings often offer video, voice, text chat, and screen-sharing capabilities to facilitate interactions between meeting participants. One teleconferencing platform used by health care providers is Zoom (Archibald, Ambagtsheeer, Casey, \& Lawless, 2019), which has a version for free and a HIPAA-compliant version for purchase.

Given the capabilities of Zoom, we believe that the Zoom platform is relevant to behavior analysts providing telehealth services. Zoom offers videos and guides to help users navigate its many features. These resources are helpful, but the behavioranalytic community could benefit from specific information on how to leverage features within Zoom to create an analogue of a traditional learning environment. Therefore, this tutorial provides task analyses ${ }^{1}$

\footnotetext{
${ }^{1}$ The examples and task analyses in this tutorial display features using computers; however, the Zoom application is compatible with a variety of devices. Some features of Zoom discussed in this tutorial may not be available on all devices. Visit the Zoom Help Center to determine the compatibility of specific devices and Zoom features mentioned in this tutorial (https://support.zoom.us/ hc/en-us/articles/360027397692-Desktop-client-mobile-app-and-web-clientcomparison).
} 
and a curated list of Zoom walk-throughs (see Table 1) to construct interventions that are conceptually consistent with ABA (BACB, 2014, Section 4.04).

In addition to the Zoom suggestions in this tutorial, we provide guidance on how to create a direct services telehealth model that adapts many of the components and strategies that are present during behavior-analytic interventions to maintain treatment integrity (Rodriguez, 2020). As an organizing framework, we utilized the three-term contingency - a defining feature of operant-learning procedures. Even with the three-term contingency as a guide, a perfect analogue to face-to-face intervention is unlikely; therefore, we have delineated some of the technological limitations in this tutorial. We designed the task analyses in this tutorial to help behavior analysts and therapists deliver instructional antecedents, assess learners' responses, and provide appropriate consequences.

\section{Tutorial}

\section{Presenting Stimuli}

Learning opportunities in face-to-face intervention begin when a therapist presents a stimulus (discriminative stimulus $\left[\mathrm{S}^{\mathrm{D}}\right]$ ) — an image, video, vocal question, or written instruction - and ends when the therapist presents a reinforcer before the intertrial interval (Smith, 2001). To maintain these discrete events in telehealth services, a therapist will need to present a variety of stimuli to serve as $\mathrm{S}^{\mathrm{D}} \mathrm{S}$ and reinforcers. The Zoom platform has sharing features that allow a therapist to present auditory stimuli and two-dimensional visual stimuli (e.g., pictures, GIFs, videos) much like they would when implementing intervention in a face-to-face format.

To present auditory stimuli, the therapist can share sound by using the Share Computer Sound feature (see Screen Share - Computer Sound - Table 1). To present two-dimensional visual stimuli, we recommend that therapists utilize the Zoom Screen Share ${ }^{2}$ feature rather than holding stimuli up to their webcam (see Screen Share Table 1). Through Zoom, Screen Share allows the therapist to show the learner any screen that is open on the therapist's computer. Screen Share may provide the learner with a clear view of the stimuli, as the feature is equipped with high-resolution capabilities (720p, 1080p, 4K; see Screen Share - Resolution - Table 1), and the

\footnotetext{
$\overline{2}$ Zoom offers three types of Screen Share: full screen, specific program, and portion of screen - many of the strategies described in this tutorial can be used with all three. We will use Screen Share when all options are applicable, and we will specify the type of Screen Share when required to use the strategies.
}

size of the presented stimuli may be larger on the learner's screen than if they are shown in the therapist's webcam. With Screen Share, the stimuli available for antecedents and consequences may broaden because the therapist is not required to have access to the stimuli in their physical environment. A therapist can use Screen Share to present videos with audio and visual components via Zoom (see Screen Share - Optimize Video and Sound - Table 1); these settings will share the video sound automatically. The therapist can select "Optimize Screen Sharing for Video Clip" to maximize the quality of the shared video.

Although there are myriad ways to present stimuli using the Screen Share and Share Computer Sound features on Zoom, we suggest using presentation software to present visual and prerecorded auditory stimuli (see the task analysis "Presenting Visual Stimuli Using Presentation Software"). Presentation software (e.g., Microsoft PowerPoint, Google Slides, Keynote) allows the therapist to organize and arrange visual and auditory stimuli into a slideshow to share on the learner's device. The slideshow is analogous to presenting stimuli on flash cards during a face-to-face intervention. Slideshows have built-in features that permit a behavior analyst to prearrange and individualize instructional components (e.g., error correction, reinforcers; see Cummings \& Saunders, 2019; Mattson et al., 2020; Niland, 2019). The therapist can insert media, toggle between slides to begin trials, and embed reinforcers (see Mattson et al., 2020; Niland, 2019). There are several different types of presentation software available: Microsoft PowerPoint, Google Slides, and Keynote. We recommend presenting the slideshow in an individual window rather than opening it in full-screen, presentation mode, because other files or programs on the computer will remain accessible while you are presenting the slide show. In addition to slideshows, therapists may use the Whiteboard feature within Zoom's Screen Share to create and present visual stimuli (see Whiteboard - Table 1). The Whiteboard feature is analogous to a chalkboard or whiteboard in a face-to-face setting, and it allows the therapist to quickly create and erase visual stimuli, such as text, shapes, lines, stamps, and drawings.

While presenting stimuli to the learner with Screen Share, the therapist can use other programs on the same device simultaneously. For example, the therapist may wish to share the $S^{D}$ with the learner using Google Slides while preparing to collect data on the learner's response using Microsoft Word and preparing a funny video on YouTube as a reinforcer. Using multiple programs without impacting the stimuli shown to the learner requires the therapist to share only one specific program on their screen (e.g., just the presentation software and not 
desktop) or use the Portion of Screen Share feature (see Portion of Screen Share - Table 1). Sharing portions of the therapist's screen means the learner views only the stimuli within the screen-sharing box, which is outlined in lime green and can be repositioned and resized (see Portion of Screen Share - Table 1 and the "Portion of Screen Share" task analysis). This feature is also useful when the therapist presents a YouTube video or part of a website, and they do not want to show the surrounding, irrelevant features of the site.

There are a number of different types of presentation software available: Microsoft PowerPoint, Google Slides, and Keynote. We recommend presenting the slideshow in an individual window rather than opening it in full-screen presentation mode, which makes other files or programs on the computer inaccessible while you are presenting the slideshow.

\section{Presenting Visual Stimuli Using Presentation Software}

1. To do this in Microsoft PowerPoint, open the presentation in an individual window and share only that program with Screen Share.

a. Click the Slide Show tab (Fig. 1).

b. Click "Set Up Slide Show" (see Fig. 1).

c. Click "Browsed by an individual (window)" and "OK" (Fig. 1).

d. Click "From Beginning" in the Slide Show tab to play the slideshow from the first slide (Fig. 1).

e. Share the slideshow window with your learner, and use the rest of your screen space to your advantage. Fig. 2.

2. For Windows users, presenting a Google Slides slideshow as an individual window can be accomplished by opening

Table 1 Index of Zoom Tutorials

\begin{tabular}{|c|c|c|}
\hline Zoom feature & Section & Link \\
\hline Annotate & Presenting Stimuli, Prompts, Token Economies & https://support.zoom.us/hc/en-us/articles/115005706806- \\
\hline Annotate - Draw & Attending to Visual and Auditory Stimuli, Token Economies & Using-annotation-tools-on-a-shared-screen-or-whiteboard \\
\hline Annotate - Draw Arrow & Attending to Visual and Auditory Stimuli & \\
\hline Annotate - Draw Box & Prompts, Error Correction & \\
\hline Annotate - Highlight Stimuli & Attending to Visual and Auditory Stimuli & \\
\hline Annotate - Spotlight & Attending to Visual and Auditory Stimuli & \\
\hline Annotate - Stamp & Presenting Stimuli, Token Economies & \\
\hline Annotate - Text Prompt & Prompts & \\
\hline Host Privileges & Reducing Distractions & $\begin{array}{l}\text { https://support.zoom.us/hc/en-us/articles/201362603- } \\
\text { Host-and-co-host-controls-in-a-meeting }\end{array}$ \\
\hline Mirror Image & Prompts & $\begin{array}{l}\text { https://support.zoom.us/hc/en-us/articles/115002595343- } \\
\text { Touch-Up-My-Appearance }\end{array}$ \\
\hline Portion of Screen Share & $\begin{array}{l}\text { Presenting Stimuli, Prompts, Identifying Preferred Stimuli, } \\
\text { Immediacy of Reinforcer Delivery, Token Economies }\end{array}$ & $\frac{\text { https://support.zoom.us/hc/en-us/articles/201362153- }}{\text { Sharing-your-screen }}$ \\
\hline Remote Access & Learner's Response, Distribution of Reinforcers & $\begin{array}{l}\text { https://support.zoom.us/hc/en-us/articles/201362673- } \\
\text { Requesting-or-giving-remote-control }\end{array}$ \\
\hline Rotate Camera & Attending to the Screen, Identifying Preferred Stimuli & $\begin{array}{l}\text { https://support.zoom.us/hc/en-us/articles/115005859366- } \\
\text { Manually-Rotate-Camera }\end{array}$ \\
\hline $\begin{array}{l}\text { Settings and Controls - Hide } \\
\text { Non-video Participants }\end{array}$ & Reducing Distractions & $\begin{array}{l}\text { https://support.zoom.us/hc/en-us/articles/201362323- } \\
\text { How-Do-I-Change-The-Video-Layout-Participants. }\end{array}$ \\
\hline $\begin{array}{l}\text { Settings and Controls - Turn } \\
\text { Off Participant Camera }\end{array}$ & Reducing Distractions & $\begin{array}{l}\text { https://support.zoom.us/hc/en-us/articles/115005759423- } \\
\text { Managing-participants-in-a-meeting }\end{array}$ \\
\hline Screen Share & $\begin{array}{l}\text { Presenting Stimuli, Prompts, Error Correction, Distribution of } \\
\text { Reinforcers }\end{array}$ & $\begin{array}{l}\text { https://support.zoom.us/hc/en-us/articles/201362153- } \\
\text { Sharing-your-screen-in-a-meeting }\end{array}$ \\
\hline $\begin{array}{l}\text { Screen Share - Computer } \\
\text { Sound }\end{array}$ & Presenting Stimuli & $\begin{array}{l}\text { https://support.zoom.us/hc/en-us/articles/201362643- } \\
\text { Sharing-Computer-Sound-During-Screen-Sharing }\end{array}$ \\
\hline $\begin{array}{l}\text { Screen Share - Optimize } \\
\text { Video and Sound }\end{array}$ & Presenting Stimuli & $\begin{array}{l}\text { https://support.zoom.us/hc/en-us/articles/202954249- } \\
\text { Optimizing-a-shared-video-clip-in-full-screen }\end{array}$ \\
\hline $\begin{array}{l}\text { Screen Share Screen - } \\
\text { Resolution }\end{array}$ & Presenting Stimuli & $\begin{array}{l}\text { https://support.zoom.us/hc/en-us/articles/203727929- } \\
\text { Screen-Sharing-with-Zoom-Rooms }\end{array}$ \\
\hline Test and Adjust Audio & Attending to Visual and Auditory Stimuli & $\begin{array}{l}\text { https://support.zoom.us/hc/en-us/articles/201362283- } \\
\text { Testing-computer-or-device-audio }\end{array}$ \\
\hline Virtual Background & Attending to the Screen, Identifying Preferred Stimuli & $\begin{array}{l}\text { https://support.zoom.us/hc/en-us/articles/210707503- } \\
\text { Virtual-Background }\end{array}$ \\
\hline Virtual Reactions & Identifying Preferred Stimuli & $\begin{array}{l}\text { https://support.zoom.us/hc/en-us/articles/360038311212- } \\
\text { Meeting-reactions }\end{array}$ \\
\hline Whiteboard & Presenting Stimuli, Identifying Preferred Stimuli & $\begin{array}{l}\text { https://support.zoom.us/hc/enus/articles/205677665- } \\
\text { Sharing-a-whiteboard }\end{array}$ \\
\hline
\end{tabular}

Note. Complete Zoom walk-through references are available in the Supplemental Materials. 


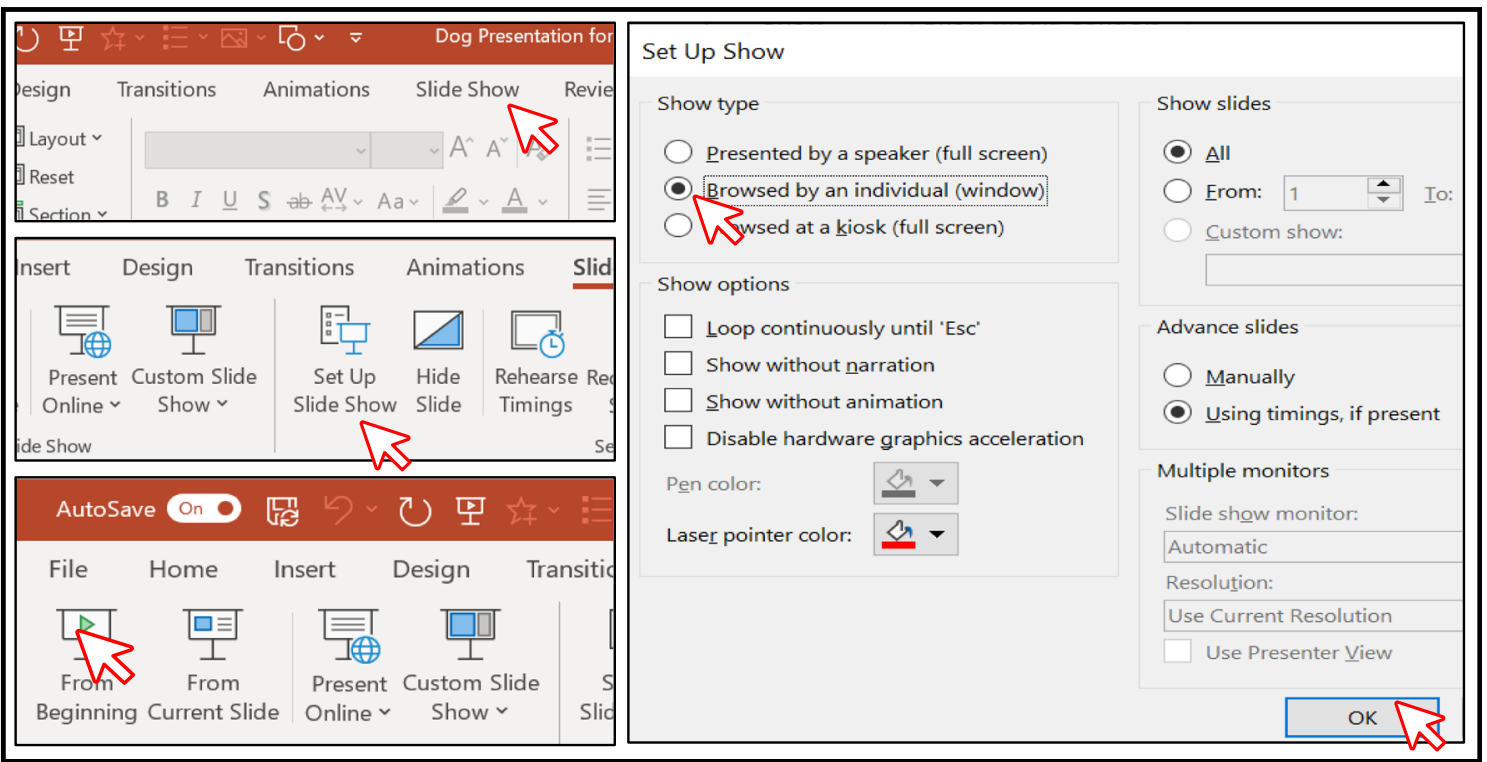

Fig. 1 Accessing slideshow presentation option (top left panel), setting up the slideshow (middle left panel), browsing the slideshow by individual window (bottom left panel), and starting the slideshow from the beginning (bottom right panel)

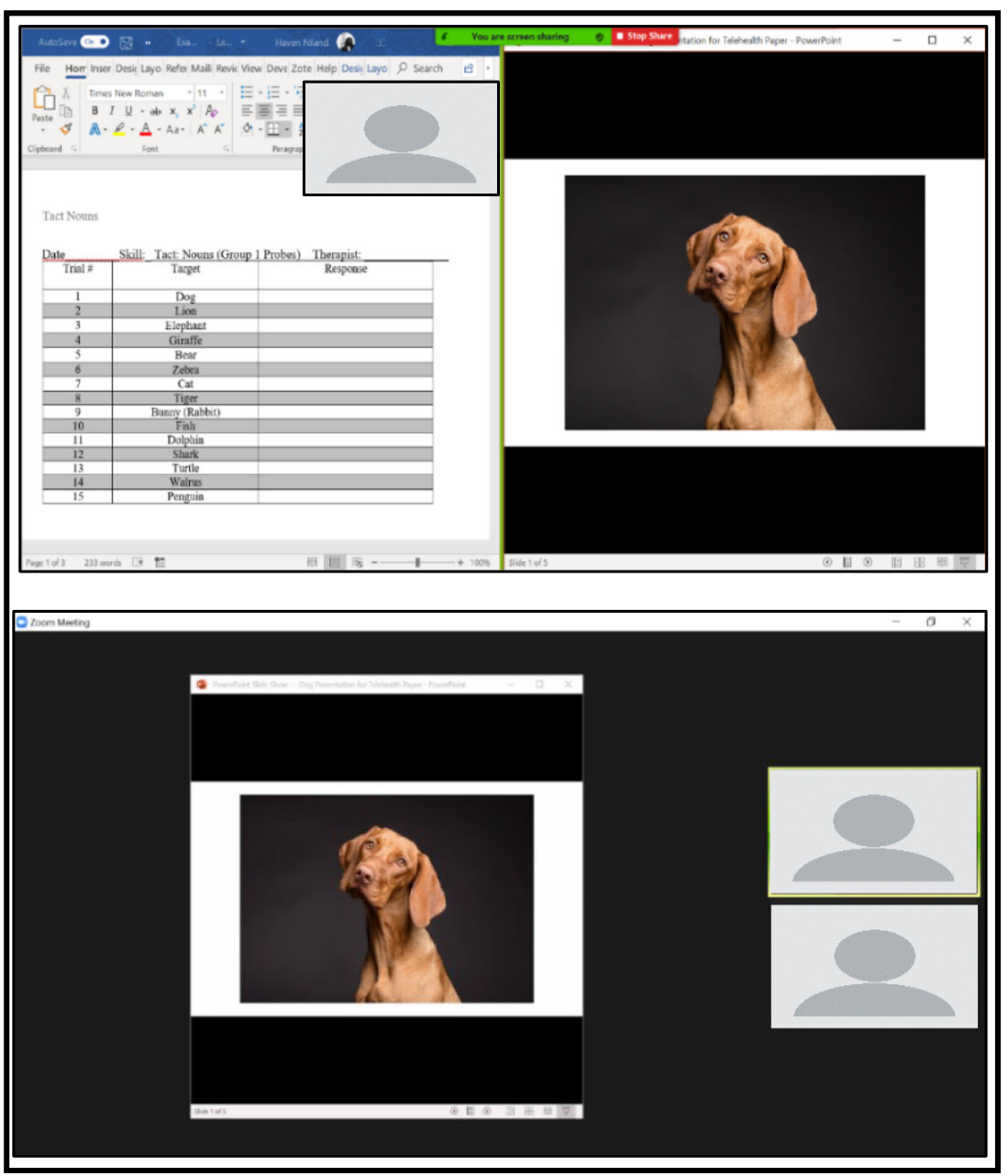

Fig. 2 Presenting the Slideshow in an Individual Window: Therapist (top panel) and Learner Views (bottom panel) 


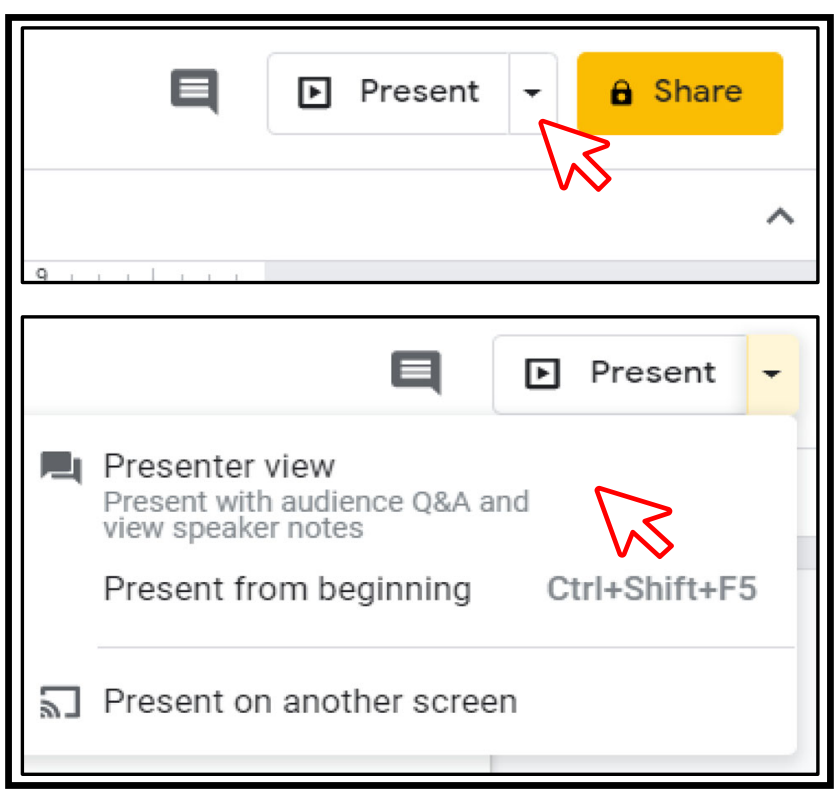

Fig. 3 Presenting a Slideshow in Google Slides

the slideshow in Presenter view.

a. Click the down arrow next to (Fig. 3).

b. Click "Presenter view" (Fig. 3).

i. The slideshow will open in a new browser tab, and a Presenter view controls window will open (Fig. 4).

ii. Close the Presenter view controls box (Fig. 5).

c. Share the slideshow window with your learner (Fig. 6).

3. To share a presentation using a Mac, click "Present" (see Step 2 in the "Presenting Visual Stimuli Using Presentation Software" section). The Google Slides slideshow will automatically open in a full-screen version on a new desktop.

4. Access the new desktop by pressing the F3 key and toggle between desktops as needed using your cursor (Fig. 7).

5. Use Steps 1-2 in the "Portion of Screen Share" section to access Zoom's Screen Share options. Use the Basic tab to

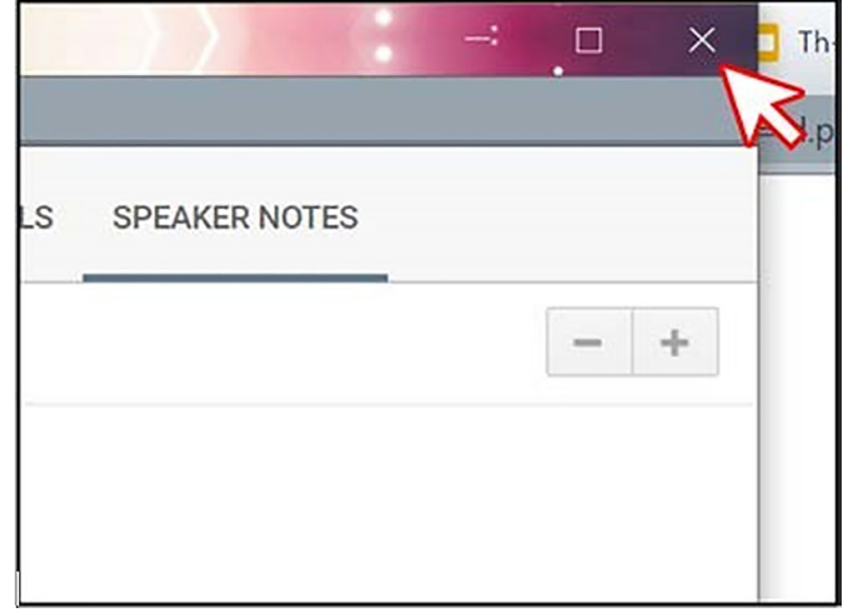

Fig. 5 Closing the Presenter View Controls Box

select the secondary desktop for the Google Slides presentation for sharing (Fig. 8).

6. Keynote does not offer the option to present a slideshow in an individual window; therefore, using the Portion of Screen Share tool and placing the Screen Share box over the slides in editing mode will still allow the therapist to share full-screen slides with their learner while having other program windows open if necessary (Fig. 9).

\section{Portion of Screen Share}

1. On the Zoom toolbar, click "Share Screen" (see Fig. 10, top panel).

2. Click "Advanced" (Fig. 10, middle panel).

3. Click "Portion of Screen" (Fig. 10, bottom panel).

4. A green box will appear on your screen. Anything within the green box will be shared with your learner (Fig. 11). Move and resize the box by clicking on the green border or hovering over it until the size arrow appears. The box will turn yellow when moved, and screen sharing will

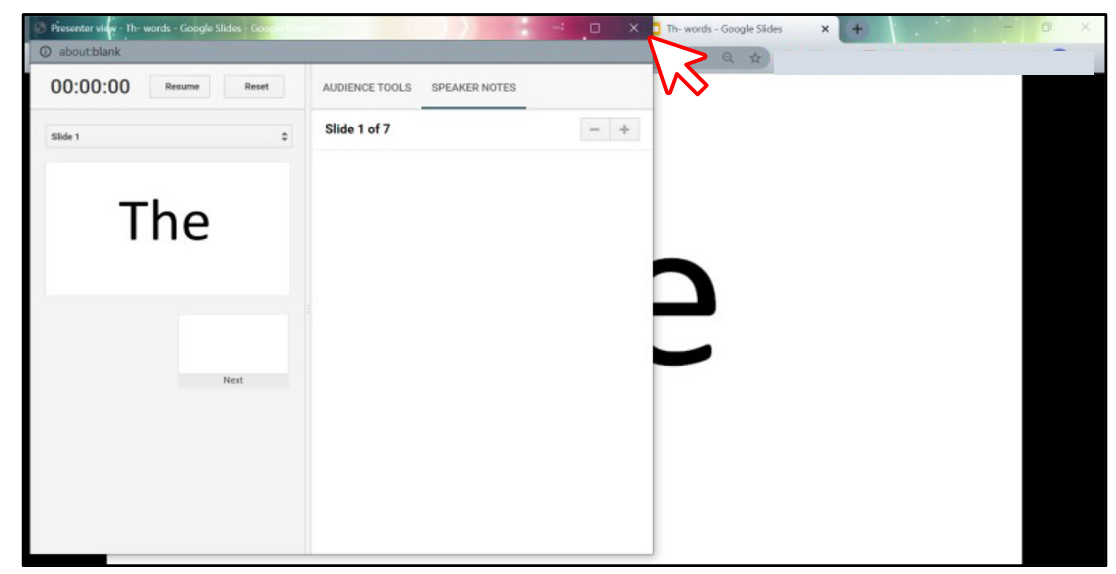

Fig. 4 Presenter view control box 


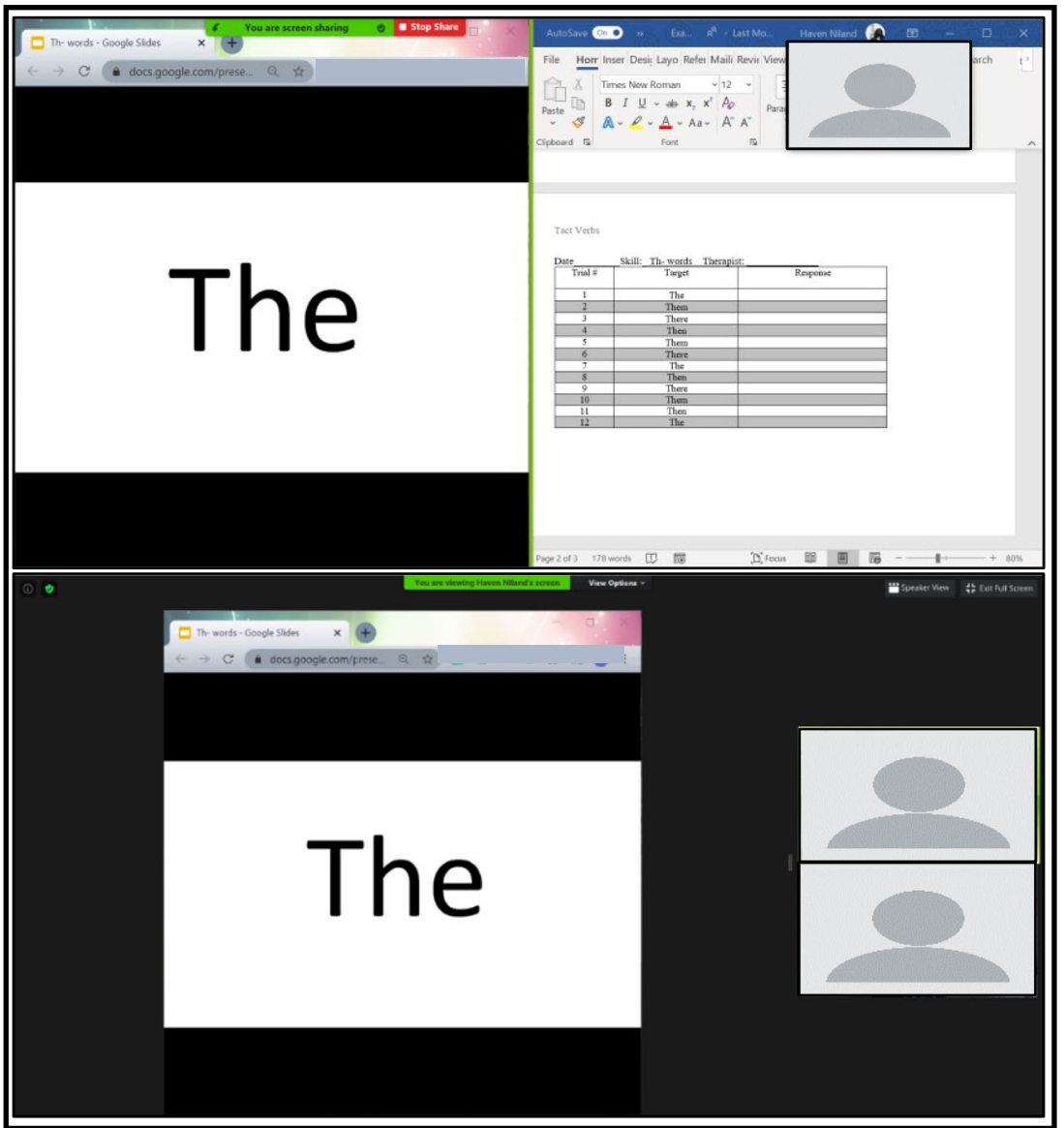

Fig. 6 Presenting the Slideshow Using Presenter View in Google The bottom panel shows the learner's view when the therapist shares the Slides: Therapist and Learner Views. Note: The top panel shows the slideshow as an individual window. therapist's screen as they share the slideshow and access a data sheet

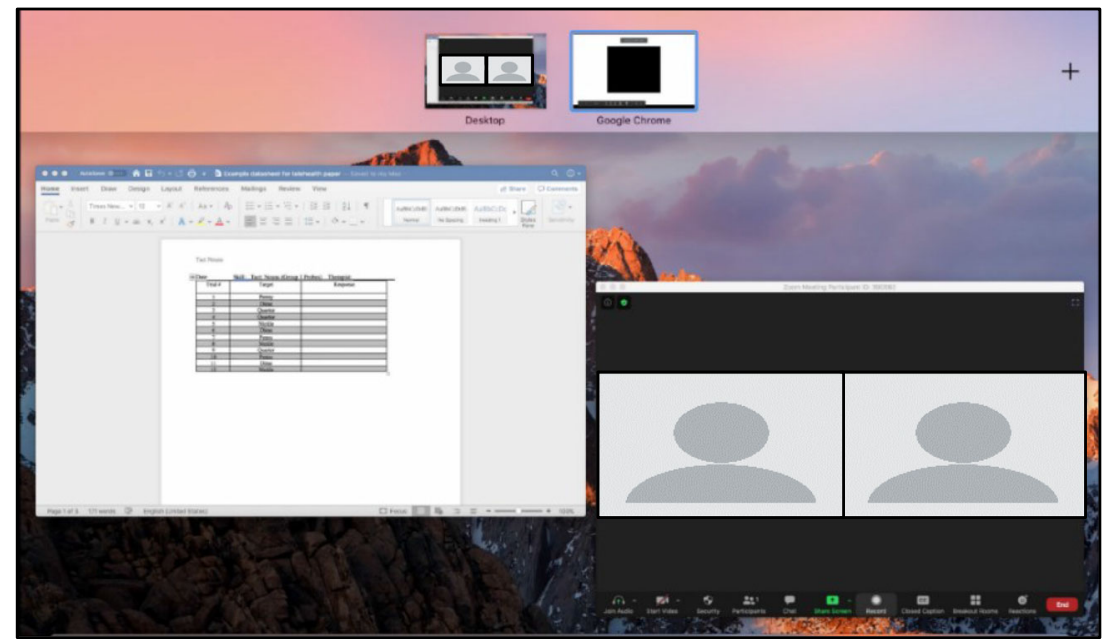

Fig. 7 Google Slides on a Separate Desktop on a Mac Computer 


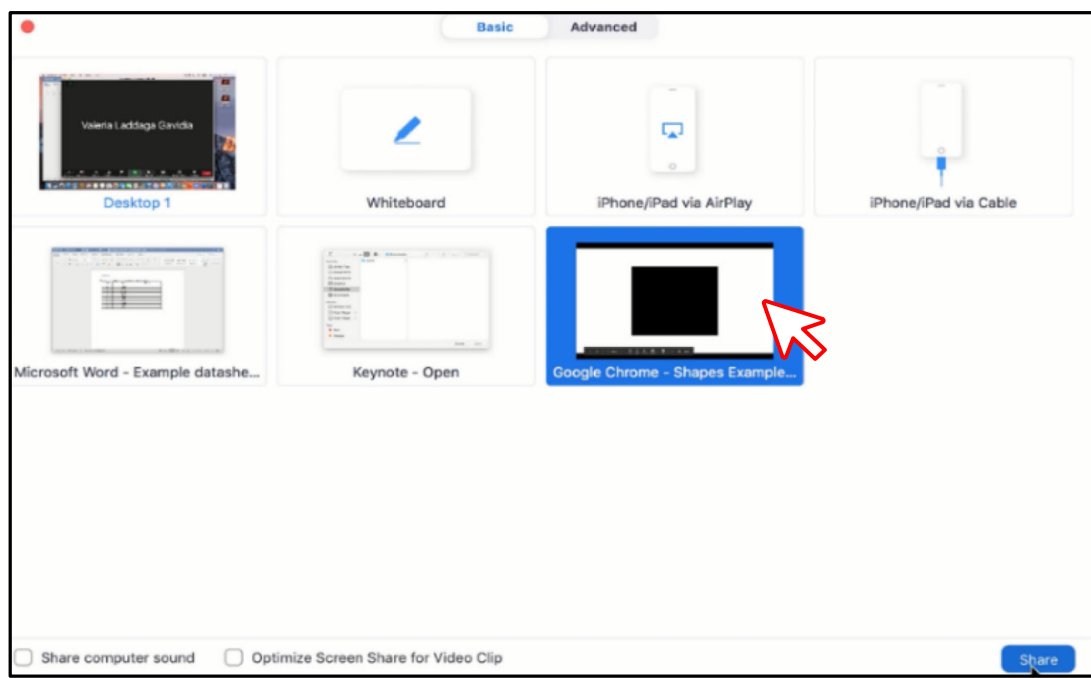

Fig. 8 Selecting a Secondary Desktop for Sharing Google Slides on a Mac

pause until the box is stationary again (Fig. 11, middle left panel).

\section{Antecedents}

\section{Reducing Distractions}

The use of virtual meeting rooms during telehealth services may introduce unique distractions that can challenge the learner's attending to instructional stimuli. In virtual meetings, videos of participants (i.e., the learner and the therapist) are streamed continuously and displayed on the screen along with instructional stimuli. As a result, a learner may shift their attention away from instructional stimuli and focus on the video of themselves or the therapist. In this event, the therapist may turn off the learner's self-view camera by either instructing the learner to turn it off themselves, soliciting caregiver assistance to turn it off, or using host privileges to turn it off remotely (see Host Privileges - Table 1). Similarly, if the learner attends to the view of the therapist in lieu of other instructional stimuli, the therapist may consider turning off their own camera if the view of the therapist is not required (see Settings and Controls - Turn Off Participant Camera Table 1). When either the therapist or the learner's camera is turned off, the Zoom platform automatically displays their name on a black screen. If this display negatively impacts the learner's attending response, the text box can be hidden by selecting the Zoom option to hide all nonvideo participants (see Settings and Controls - Hide Non-video Participants -

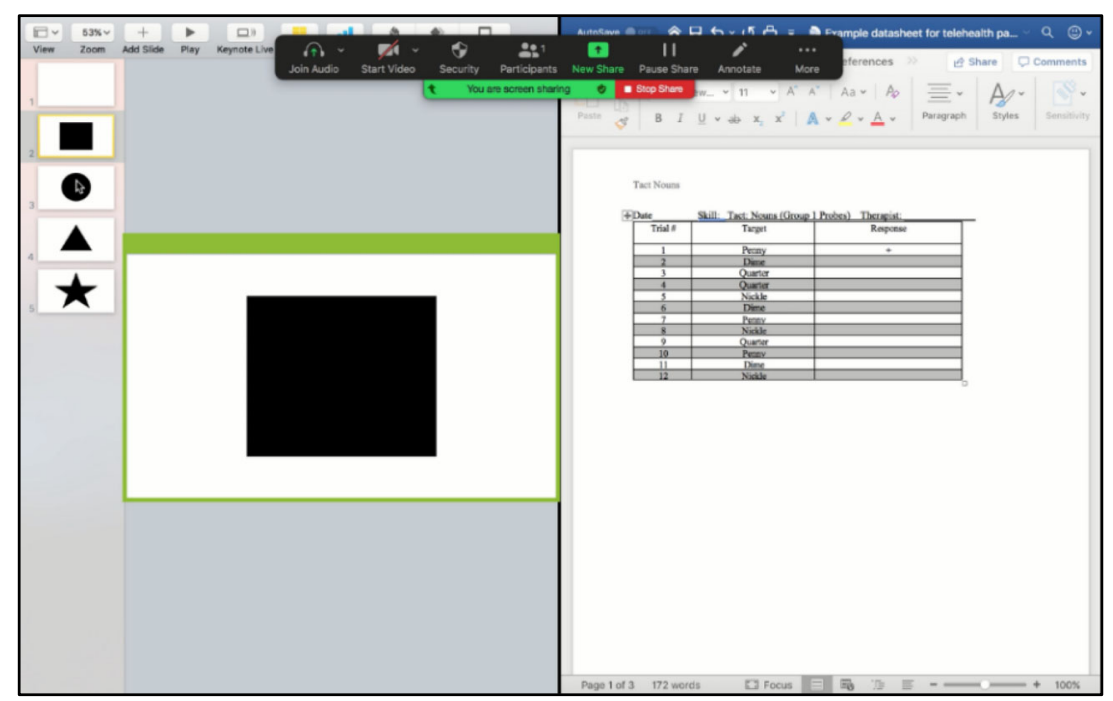

Fig. 9 Using Portion of Screen Share to Share Full-Screen Slides in Keynote 


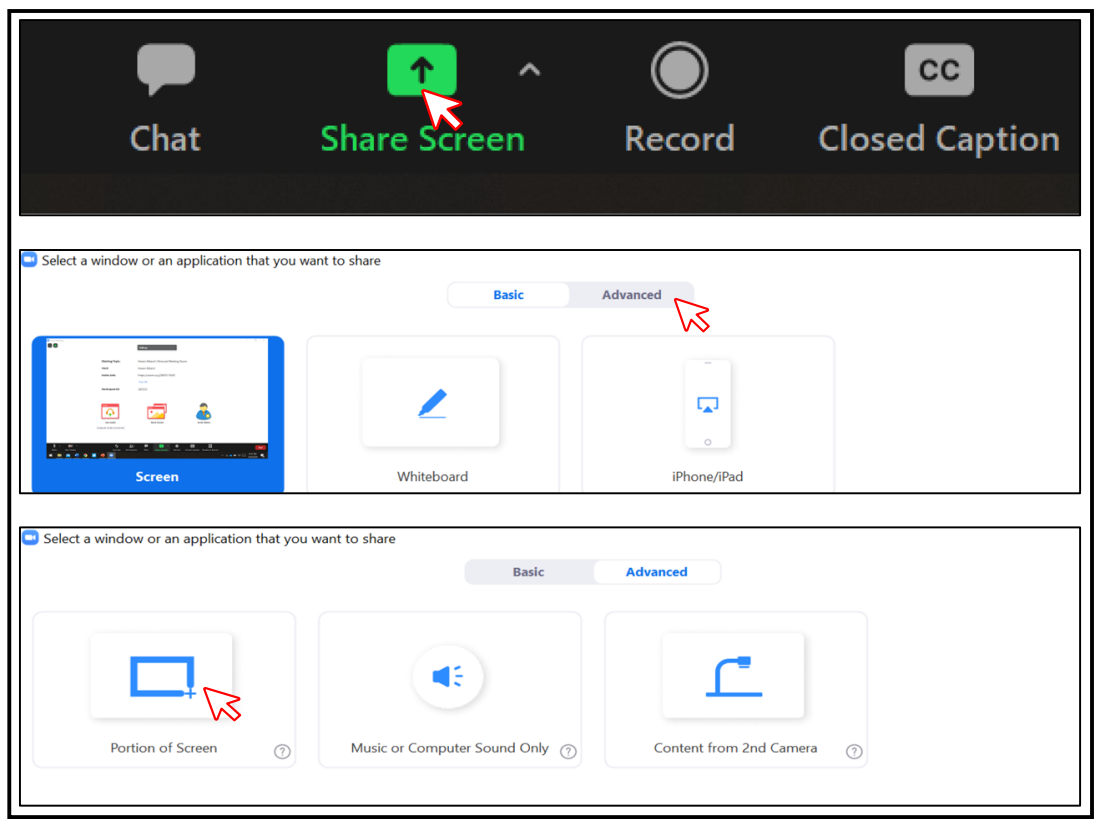

Fig. 10 Screen Share Feature on Zoom Toolbar (top panel), Advanced Screen Share Options (middle panel), and Portion of Screen Share (bottom panel)

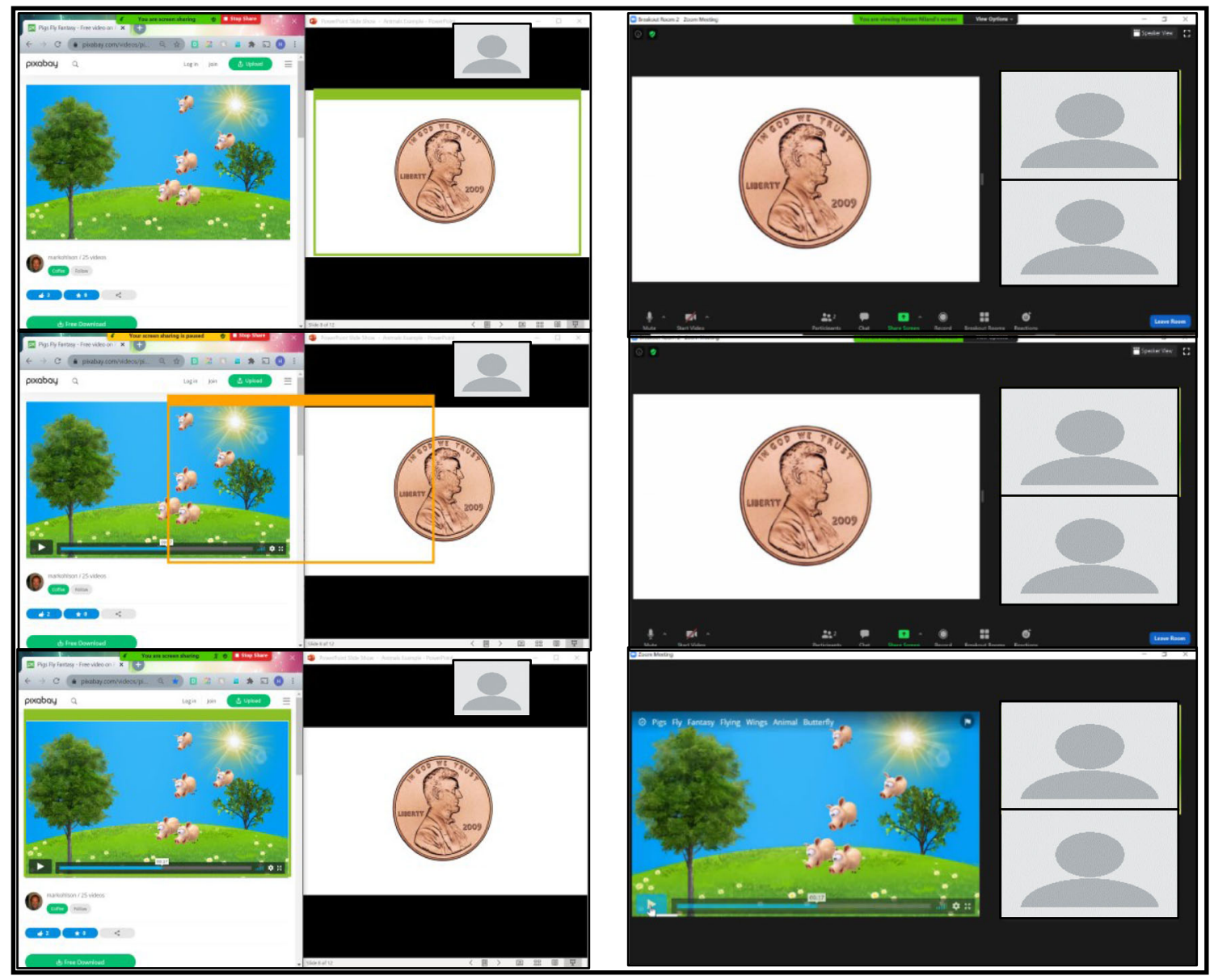

Fig. 11 Moving the Portion of the Screen Share Box. Note. Using Portion of Screen Share to show visual stimuli as instructional antecedents and reinforcers. The panel on the left shows, on the therapist's screen, from the top down, the process for changing which visual stimuli are shared in 
Table 1). Therapists may consider requesting increased caregiver assistance to arrange the learner's display and troubleshoot issues.

\section{Attending to the Screen}

In face-to-face and telehealth service models, learners need to attend to both the therapist and the instructional stimuli. Attending responses may include making eye contact with or orienting toward the therapist, but the observing repertoire in telehealth may be different from in-person services (Rodriguez, 2020). For example, attending behaviors in telehealth likely involve facing and directing one's eye gaze toward the screen rather than toward a tabletop or a person.

For learners who do not readily and reliably attend to the device used for telehealth, additional procedures (e.g., vocal or gestural prompts) may be required to establish this behavior. If vocal prompts do not occasion attending, therapists may consider incorporating Zoom features to promote attending to the computer screen or therapist. For example, the therapist can incorporate preferred images as virtual backgrounds (see Virtual Background - Table 1) or rotate videos of the therapist or the learner (see Rotate Camera - Table 1). However, these suggestions await empirical investigation.

With learners for whom prompting strategies do not occasion attending, therapists could shape attending to the screen. For example, Plavnick (2012) placed a highly preferred edible in front of a smartphone screen, and the researcher delivered the edible once the learner looked at the screen. The duration of attending was increased, and the reinforcement schedule was thinned across sessions. Contingent access to edibles would require a caregiver's assistance, but it is possible that electronic stimuli (e.g., movies, music) delivered on the device by the therapist could be used to increase attending.

In some cases, it may be beneficial to embed the requirement of a trial-initiation response into the instructional sequence to promote "ready behavior" from the learner. Trial-initiation responses require the learner to engage in an observable behavior before the therapist begins the learning trial with the presentation of instructional stimuli (Grow \& LeBlanc, 2013 [referred to as nonspecific observing responses]; Saunders \& Williams, 1998; Vedora, Barry, \& Ward-Horner, 2018). A trial-initiation response can be beneficial when the $\mathrm{S}^{\mathrm{D}}$ is removed from the environment before the learner has an opportunity to respond (i.e., a transient stimulus; e.g., nonrepeating auditory stimulus, sample stimulus in delayed match-to-sample). Eye contact with the therapist can be difficult to confirm via Zoom, so orientation toward the camera, saying "I'm ready," or another observable behavior (e.g., tacting a stimulus on the screen) may be used as a trial-initiation response. Trial-initiation responses could serve as a form of overt attending behavior, promote attending to instructional stimuli by making it less likely that the learner is engaging in incompatible behavior, and may suggest that a motivating operation is present for the learner.

\section{Attending to Visual and Auditory Stimuli}

Failure to attend to instructional stimuli can hinder skill acquisition (Dube \& McIlvane, 1999); therefore, a therapist should assess whether the learner is observing the instructional stimulus rather than an irrelevant or extraneous aspect of the screen. Ascertaining whether the learner is observing the relevant section of the screen may be a challenge in telehealth services, so the therapist may need to prompt the learner to attend to instructional stimuli even if the learner is attending to the device. If the therapist is presenting stimuli through their webcam, they could prompt the learner to attend by saying "look" while pointing to the instructional stimulus. This is analogous to using vocal and gestural prompts in an in-person teaching interaction (MacDuff, Krantz, \& McClannahan, 2001).

Although presenting stimuli through the webcam is an option, displaying visual stimuli using the Zoom Screen Share feature and presentation software is recommended (see the task analysis "Presenting Visual Stimuli Using Presentation Software"). Instead of using their finger to gesture to the $S^{D}$, a therapist could explore potential attending prompts in Zoom. For example, the Spotlight feature can change the mouse cursor to an arrow outline or red laser pointer that could function as a digital version of a gestural prompt (see Annotate - Spotlight Table 1). The Draw tool also offers several features to prompt attending (see Annotate - Draw - Table 1 and Fig. 12). For example, the Highlight tool may draw attention to items on the screen by surrounding them with color (see Annotate Highlight Stimuli - Table 1), and the Draw tool includes arrows, which can be made in various sizes and colors, that can be used to point to stimuli. The therapist could present visual stimuli on the screen and assess which supplemental stimuli function as attending prompts for the learner.

In addition to visual stimuli, the learner's attending responses to auditory stimuli may be evaluated in the virtual setting by presenting mastery-level auditory discrimination tasks. Previously acquired discriminated operants should be presented to rule out a skill deficit if the learner does not respond or responds incorrectly when the stimulus is presented (Rodriguez, 2020). The volume and sound quality of the speaker on the learner's device should be checked to reduce the likelihood of an incorrect response because the stimulus is too quiet or distorted. When presenting auditory stimuli of any kind, Zoom offers multiple tutorials that can walk a learner's caregiver through testing and adjusting the audio prior to a session (see Test and Adjust Audio - Table 1) .

The strategies described previously may be useful to prompt and promote attending from the learner within a virtual teaching interaction over Zoom; however, they may not be sufficient for some learners to observe or discriminate $\mathrm{S}^{\mathrm{D}}$ s. For these learners, 


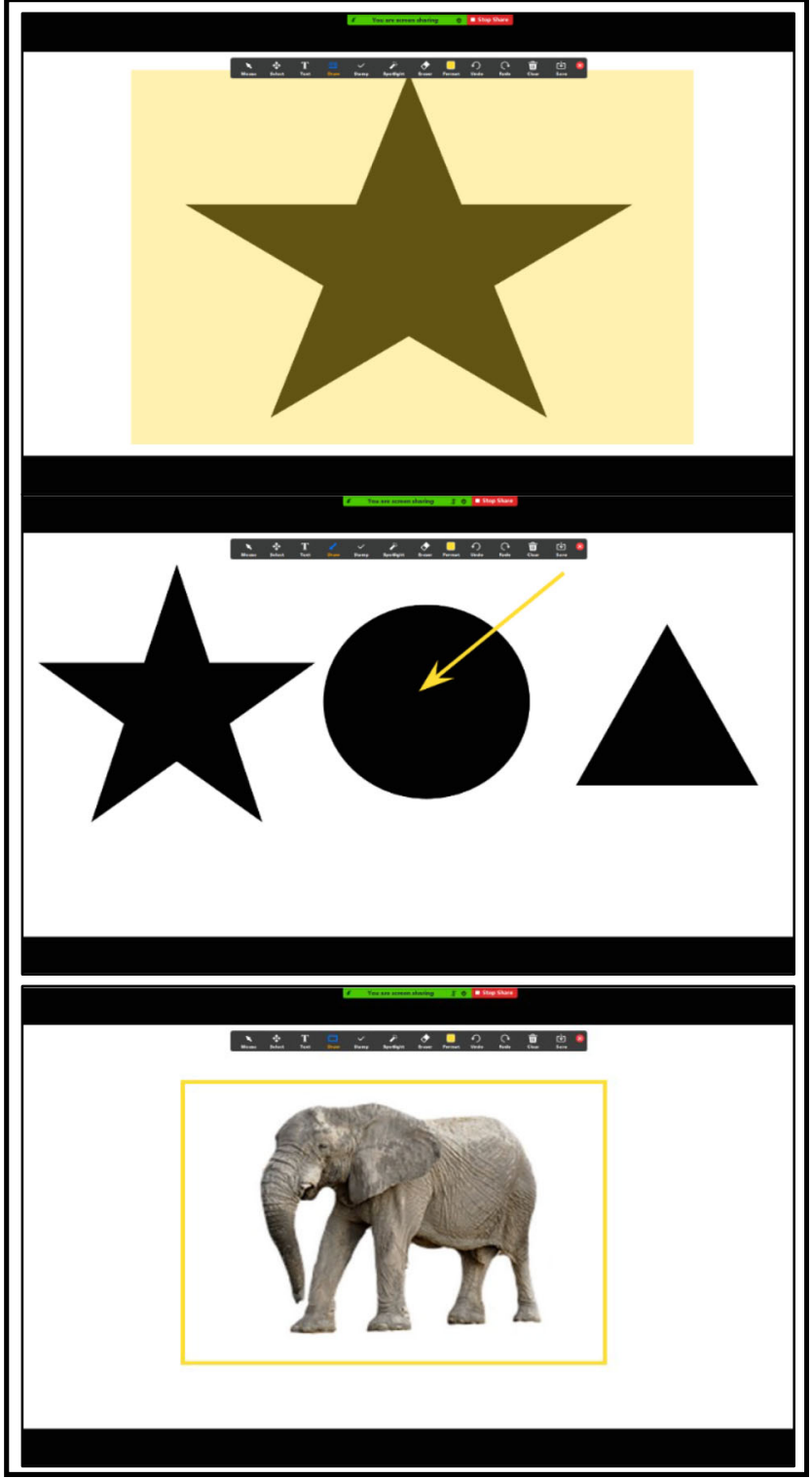

Fig. 12 Examples of Using Draw Tools for Capturing Attending on Shared Screen. Note. The top panel shows the star highlighted using the rectangle Highlight tool. The middle panel shows the arrow pointing toward the circle (the SD). The bottom panel shows a picture of an elephant outlined by a yellow rectangle

attending to specific stimuli in instructional trials may be necessary, so teaching trials could include an overt observing response, which is more specific than an attending or trial-initiation response (Dube \& McIlvane, 1999; Green, 2001; Grow \& LeBlanc, 2013; Saunders \& Williams, 1998, pp. 204, 213).

Observing responses require the learner to engage in differential behavior following the presentation of a stimulus (Kisamore, Karsten, \& Mann, 2016; Vedora, Barry, \& WardHorner, 2017). The learner may engage in the same observing response in the presence of every stimulus, which indicates that the learner has attended to a stimulus change in their environment. Rather than one observing response, the learner may be taught to engage in differential observing responses: topographically distinct responses in the presence of each $\mathrm{S}^{\mathrm{D}}$ (e.g., forming a fist in the presence of one stimulus and showing their open palm in the presence of another). Differential observing responses indicate that the learner has attended to a stimulus change and can "tell the difference" between stimuli. These may be suggested for learners who do not observe the critical features of a stimulus or have a history of stimulus overselectivity (Grow \& LeBlanc, 2013). The therapist can incorporate motor responses, tacts, or echoics as observing responses or differential observing responses without significant limitations (see the next section, "Learner's Response").

\section{Learner's Responses}

The response requirements for the learner are determined in relation to the instructional stimuli and goals of the program (Eikeseth, Smith, \& Klintwall, 2014). For example, following a model of clapping by a therapist, the learner might clap or say "Clapping" depending on additional vocal antecedents (e.g., "Copy me," "What am I doing?") and a history of differential reinforcement. Given the depth and breadth of skill domains that can be addressed in ABA (Lovaas, 1987), the goals constructed by a behavior analyst, the learner, and their family will include a wide range of responses. Similar behaviors to those addressed in a face-to-face service delivery model can be targeted via telehealth; however, some responses may be more easily adapted to the telehealth platform than others.

With the use of a webcam and speakers, it is likely that many topography-based responses (e.g., vocalizations, motor movements) included in the learner's treatment plan can be integrated with relative ease and few modifications. These behaviors may be observed and measured by the therapist in a telehealth service delivery model. The therapist's ability to observe and respond to these behaviors may be limited by interfering auditory stimuli in the learner's physical environment and the portability of the device if the execution of a behavior requires the learner to move around their environment (e.g., adaptive behavior chains).

Even with Screen Share features and a webcam, it can be difficult to observe selection-based responses. For example, if the therapist presents an array of animal pictures and provides the instruction "Point to the dog," the therapist cannot identify which picture the learner selected. Without direct observation of learner performance, the therapist cannot arrange for appropriate consequence delivery. To overcome these limitations, selection-based responses require support or adaptations through (a) a mediator, such as a caregiver, communicating to the therapist which stimulus was selected; (b) an additional camera, arranged in such a way that allows the therapist to see the child and the screen of their device; (c) a slideshow with embedded hyperlinks opened on the learner's device and 
shared with the therapist (see Mattson et al., 2020); or (d) the use of the Remote Access feature allowing the therapist to see the cursor as the child moves it (see Remote Access Table 1). The Remote Access option may include additional difficulties because there is often a lag between when the child moves the cursor and when the therapist sees the cursor move, even with strong internet connectivity for both parties. Delayed observation of selection-based responses can delay consequence delivery, which can interfere with the efficacy of the intervention (e.g., Carroll, Kodak, \& Adolf, 2016). We recommend that therapists consider potential challenges of including selection-based responses during intervention and identify the appropriate solution for the learner.

\section{Consequences}

\section{Prompts}

During the early stages of instruction, a learner is likely to err or not respond in the presence of a novel $S^{\mathrm{D}}$. Promptsantecedents that increase the likelihood that a learner will emit a correct response (Green, 2001) — can facilitate the acquisition of the target response. Ultimately, the goal is to transfer stimulus control of the target response from the prompt to the $\mathrm{S}^{\mathrm{D}}$, so prompt-fading techniques should be designed and implemented (e.g., Cengher, Budd, Farrell, \& Fienup, 2018; Markham, Giles, \& May, 2020a). Behavior analysts may arrange response prompts (i.e., the behavior of another person evokes the correct response) or stimulus prompts (i.e., modification of the $\mathrm{S}^{\mathrm{D}}$ evokes the correct response; Miltenberger, 2016).

Therapists should note that prompts that are effective for a learner in a face-to-face model may be impossible or fail to control behavior through the teleconferencing platform. For example, neither physical guidance (e.g., hand-over-hand prompting) nor graduated guidance can be provided through the telehealth platform without the assistance of a trained caregiver in the home. Therefore, a behavior analyst should identify which prompts reliably evoke correct responses and transfer behavior to the relevant $S^{D}$ when delivered via telehealth (Rodriguez, 2020; see Markham, Giles, \& May, 2020b, and Schnell et al., 2020, for prompt assessments). The therapist should work with a caregiver to identify the acceptability and feasibility of prompts that require caregiver facilitation (BACB, 2014, Section 4.06). Given the variety of prompting strategies available and that effective prompts and promptfading strategies vary across learners and skills, this tutorial will not prescribe specific prompts nor strategies. Instead, we describe several examples of how a therapist may use Zoom to provide evidence-based response and stimulus prompts.

Prompts can be programmed in presentation software to occur automatically (see Mattson et al., 2020, for a tutorial), and therapists may find this strategy beneficial when creating materials for use across multiple learners or when using the same prompting procedure across multiple programs for a learner. However, preprogramming prompts into presentation software can be a time-consuming activity, cumbersome for including prompt-fading strategies (e.g., prompt hierarchy, progressive prompt delay), and require multiple versions or frequent updates to accommodate fading steps.

Delivering response prompts via Zoom could solve the barriers listed previously and also permits the use of flexible prompt fading (Soluaga, Leaf, Taubman, McEachin, \& Leaf, 2008). Flexible prompt fading differs from other prompt-fading methods (e.g., prompt delay, least-to-most prompting) because the timing and type of prompt are determined by the therapist's clinical judgments rather than steps or decisions outlined in a protocol (Leaf, Cihon, Ferguson, Leaf, \& McEachin, 2019). To use flexible prompt fading, therapists are trained to follow guidelines to determine which prompts to provide when (e.g., past performance, a goal to keep the learner responding correctly; Leaf et al., 2016a, 2019). Studies on skill acquisition with children with ASD have shown that flexible prompt fading is likely to be as efficacious and sometimes more efficient than structured prompting arrangements (e.g., Leaf et al., 2016b, 2019; Soluaga et al., 2008). Implementing prompts with flexible prompt fading could be possible by using features built in to Zoom.

Several response prompts can be provided via Zoom. For vocal, visual, and model prompts, few additional features of Zoom are required. The therapist can deliver a vocal prompt after an increasing (i.e., progressive prompt delay) or constant (i.e., prompt delay; also referred to as time delay) response interval or provide partial- or full-vocal models. Similarly, visual prompts can be delivered by the therapist through the webcam or by using Screen Share to display visual stimuli that are embedded in a slideshow or featured on a webpage (see Share Screen Table 1 and the "Presenting Stimuli" section, previously). For example, if the learner is acquiring intraverbal fill-ins of animal sounds, the therapist may show a picture of a cow after delivering the $\mathrm{S}^{\mathrm{D}}$ "Moo says a ..." to strengthen the response "cow." To provide a model prompt, a therapist would show a learner how to engage or interact with instructional stimuli (e.g., Charlop, Lang, $\&$ Rispoli, 2018) in view of the webcam or with a video model embedded in a slideshow (Mattson et al., 2020; Niland, 2019). For example, when teaching listener discriminations of actions with an object, the therapist could model how to engage in the target responses "open book" and "turn pages." Learners who communicate with signs require special consideration regarding model prompts during telehealth services. If the learner can observe their own video, the therapist should request caregiver facilitation to turn on the Mirror feature (see Mirror Image Table 1) so that the learner's view of their sign is oriented correctly. If a therapist is using a 0 -s prompt delay with a visual or model prompt, we recommend using the Portion of Screen Share feature (see Portion of Screen Share - Table 1 and the "Portion of Screen Share" section) to provide prompts quickly. 
A textual prompt is a written or typed word that evokes the target response. For example, if the learner is acquiring tacts, a therapist may type the word "cow" after presenting a picture of a cow to strengthen the response "cow" (Vedora, Meunier, \& Mackay, 2009). Textual prompts can be added to any Screen Share by using Annotate (see Annotate - Text Prompt - Table 1 and the "Inserting and Altering Textual Stimuli" task analysis). Using the Annotate feature, the therapist may type the name of the stimulus on the screen and adjust the size and color of the text before or after typing. If using script fading with textual prompts (see Akers, Pyle, Higbee, Pyle, \& Gerencser, 2016, for a review), the therapist can easily modify the text to meet the fading requirements with Annotate (see Annotate - Text Prompt - Table 1 and the "Inserting and Altering Textual Stimuli" task analysis).

In addition to response prompts, stimulus prompts can be included in telehealth intervention. Mattson et al. (2020, p. 48) provides several examples of stimulus prompts (e.g., the stimulus can grow larger, slide toward the bottom of the screen, or shake) that can be integrated into Google Slides, and stimulus prompts can be created within Zoom, too. An example of a stimulus prompt includes teaching textual responses using the Annotate tool on the Whiteboard or in a slideshow. The therapist can type the word "red" in red font (see Annotate - Table 1 and Fig. 13) or draw a red circle next below the word.

\section{Inserting and Altering Textual Stimuli}

1. While sharing the screen with the visual stimuli, click "Text" in the Screen Share toolbar (Fig. 14, left panel).

2. Click the desired location for the text (Fig. 14, middle panel).

a. Type the desired text (Fig. 14, right panel).

3. After inserting text using the Text feature, click "Select" in the toolbar (Fig. 15, top left panel).

4. With the Select tool, double-click anywhere on the desired text. The cursor and text outline box will reappear (Fig. 15, top right panel).

6. Once the text is highlighted, click "Format" in the toolbar and select the desired changes, such as color and size (Fig. 15 , bottom right panel).

\section{Error Correction}

Sometimes called remedial trials, error correction makes use of repeated practice opportunities and prompting strategies to transfer control to the $\mathrm{S}^{\mathrm{D}}$. Error-correction procedures are implemented following an incorrect response and increase the probability that the learner will emit a correct response under similar conditions in the future (Cariveau,

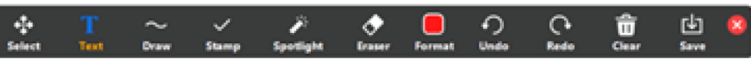

\section{RED}

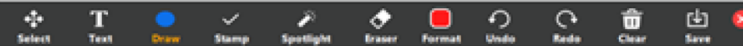

La Cruz Montilla, Gonzalez, \& Ball, 2019). Errorcorrection procedures may vary in components across instructional programs, but some common elements include (a) presentation of the correct response, (b) differential reinforcement of the correct response, and (c) use of a negative reinforcement contingency after errors (Cariveau et al., 2019 , p. 574). The behavior-analytic literature includes numerous examples of error-correction procedures, and comparative evaluations have yet to identify the most effective and efficient error-correction procedure across learners (e.g., Kodak et al., 2016; McGhan \& Lerman, 2013). Learners may acquire skills with multiple formats of error correction, but they may prefer one error-correction procedure (Kodak et al., 2016). It is possible to incorporate a variety of error-correction strategies in Zoom. The "Remove and Re-Present Error Correction" task analyses provide two methods for incorporating the procedure to re-present until correct, but the steps in each task analysis can be adapted for the error-correction procedure that is clinically indicated for the learner (see Cariveau et al., 2019, for a review of error-correction procedures). 


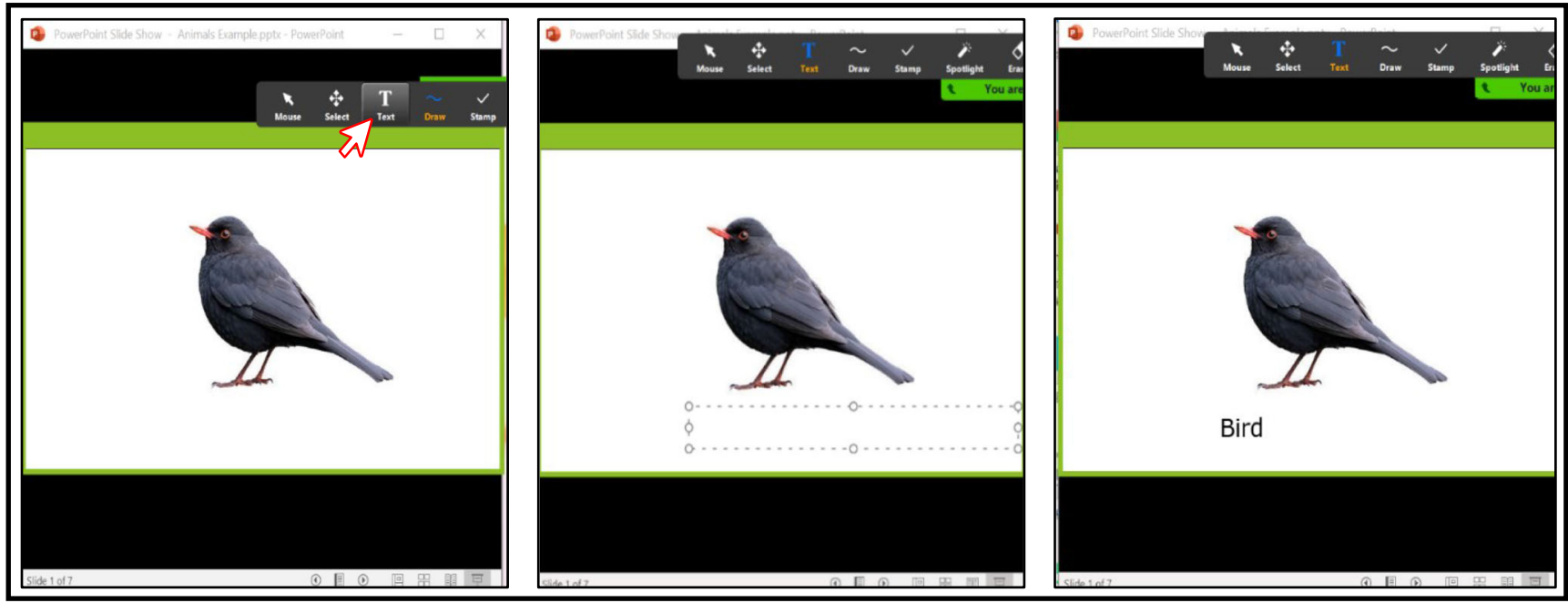

Fig. 14 Place a Textual Prompt Over a Shared Screen

The procedure to re-present until correct involves (a) the provision of a model of the correct response, (b) the requirement that the learner echo or imitate the model, (c) the brief removal of the $\mathrm{S}^{\mathrm{D}}$, (d) the re-presentation of the $\mathrm{S}^{\mathrm{D}}$, (e) an opportunity for the learner to emit an independent response, and (f) the repetition of this sequence until either the learner engages in a correct independent response or a maximum number of trials is reached (e.g., 10). For example, if a learner says "triangle" in the presence of a square, the therapist would (a) say "square," (b) require the learner to echo "square," (c) remove or cover up the drawing of the square briefly, and (d) re-present the drawing of the square with an opportunity for an independent response from the learner.

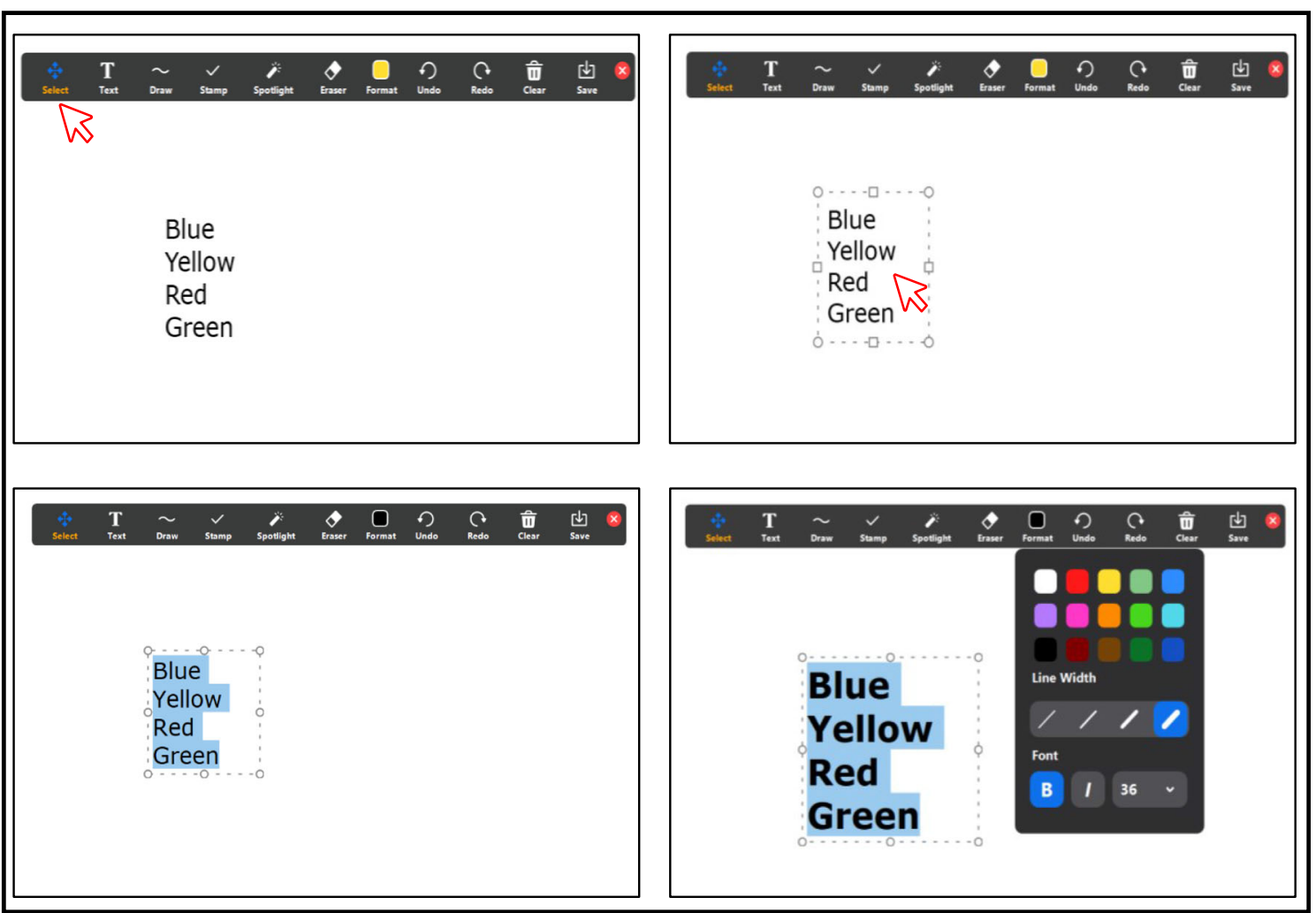

Fig. 15 Changing the Color of Text 
Programs targeting intraverbal responses may not require the use of any of the special features of Zoom to implement an error-correction strategy like re-present until correct. However, programs that involve visual $\mathrm{S}^{\mathrm{D}} \mathrm{S}$ require special attention because the visual stimulus must be removed and re-presented for each independent opportunity. Visual stimuli can be easily removed and re-presented using Zoom Screen Share by either toggling between slides in a slideshow (see Share Screen - Table 1 and the "Remove and Re-Present Error Correction: Embedding Blank Slides in a Slideshow" task analysis) or covering visual stimuli in a slideshow with Annotate (see Annotate - Draw Box - Table 1 and the "Remove and Re-Present Error Correction: Using Annotate Draw" task analysis). Both methods permit multiple representations without the need to add hyperlinks or preprogrammed transitions, allowing the therapist to adapt quickly based on the learner's response.

\section{Remove and Re-Present Error Correction: Embedding Blank Slides in a Slideshow}

1. Open the teaching slideshow in the presentation software.

2. Create trial slides (those slides containing visual discriminative stimuli $[\mathrm{SDs}]$ ) by adding new slides to the slideshow.

a. For PowerPoint, click "New Slide" in the toolbar (Fig. 16, left panel).

b. For Google Slides and Keynote, click "+" in the toolbar (Fig. 16, middle and right panels).

3. Embed your instructional SD s into the slides. This example shows shape stimuli within a PowerPoint presentation (Fig. 17, top panel).

4. Insert blank slides in between trial slides using Steps 2a or 2b. Fig. 17, bottom panel uses PowerPoint.

5. Display the slideshow as a presentation (see the "Presenting Visual Stimuli Using Presentation Software" section).

6. Toggle between trial slides and blank slides using the forward and backward arrows on the keyboard to present and remove visual stimuli.

\section{Remove and Re-Present Error Correction: Using Annotate Draw}

1. Open and share the window on your computer containing the visual instructional stimuli (see Screen Share in Table 1).

2. Click "Annotate" in the Screen Share toolbar (Fig. 18).

3. Click "Draw" to draw a shape over the visual stimulus. This example shows a solid rectangle being selected to match the shape of the $S^{\mathrm{D}}$ (Fig. 19).

4. Use the cursor to draw the shape so that it covers the visual stimulus. In this example, the shape is drawn in yellow for tutorial purposes; however, the color can be changed to blend in with the background (Fig. 20, top panel).

5. Click "Select" to select the shape and move it to cover and uncover the $S^{\mathrm{D}}$ (Fig. 20, bottom panel).

\section{Identifying Preferred Stimuli}

Stimulus preference assessments (SPAs) were developed to identify preferred stimuli that may function as reinforcers (DeLeon \& Iwata, 1996; Fisher et al., 1992; Pace, Ivancic, Edwards, Iwata, \& Page, 1985). There are different types of SPAs, and a behavior analyst determines which SPA to conduct based on several factors: the learner's preference for and engagement with different types of stimuli (e.g., social interactions, edible items), choice-making repertoire (e.g., select from an array, scan an array), and undesirable behavior in the context of preferred items (e.g., problem behavior following removal, selecting from one position in an array; see Karsten, Carr, \& Lepper, 2011, for a decision-making guide). Choice-based SPAs that require the learner to choose one stimulus over another tend to identify preferred stimuli more accurately than single-item SPAs (Piazza, Fisher, Hagopian, Bowman, \& Toole, 1996); therefore, we will discuss choicebased SPAs in this tutorial.

The first step in a choice-based SPA is to identify a variety of preferred items by interviewing individuals familiar with the learner (e.g., RAISD; Fisher et al., 1996) or considering

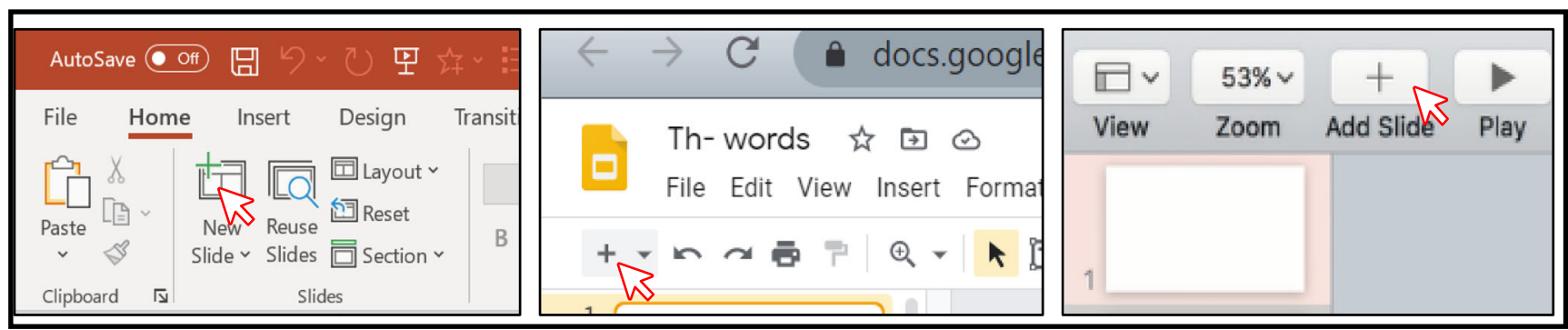

Fig. 16 Inserting a New Slide in PowerPoint (left panel), Google Slides (middle panel), and Keynote (right panel) 


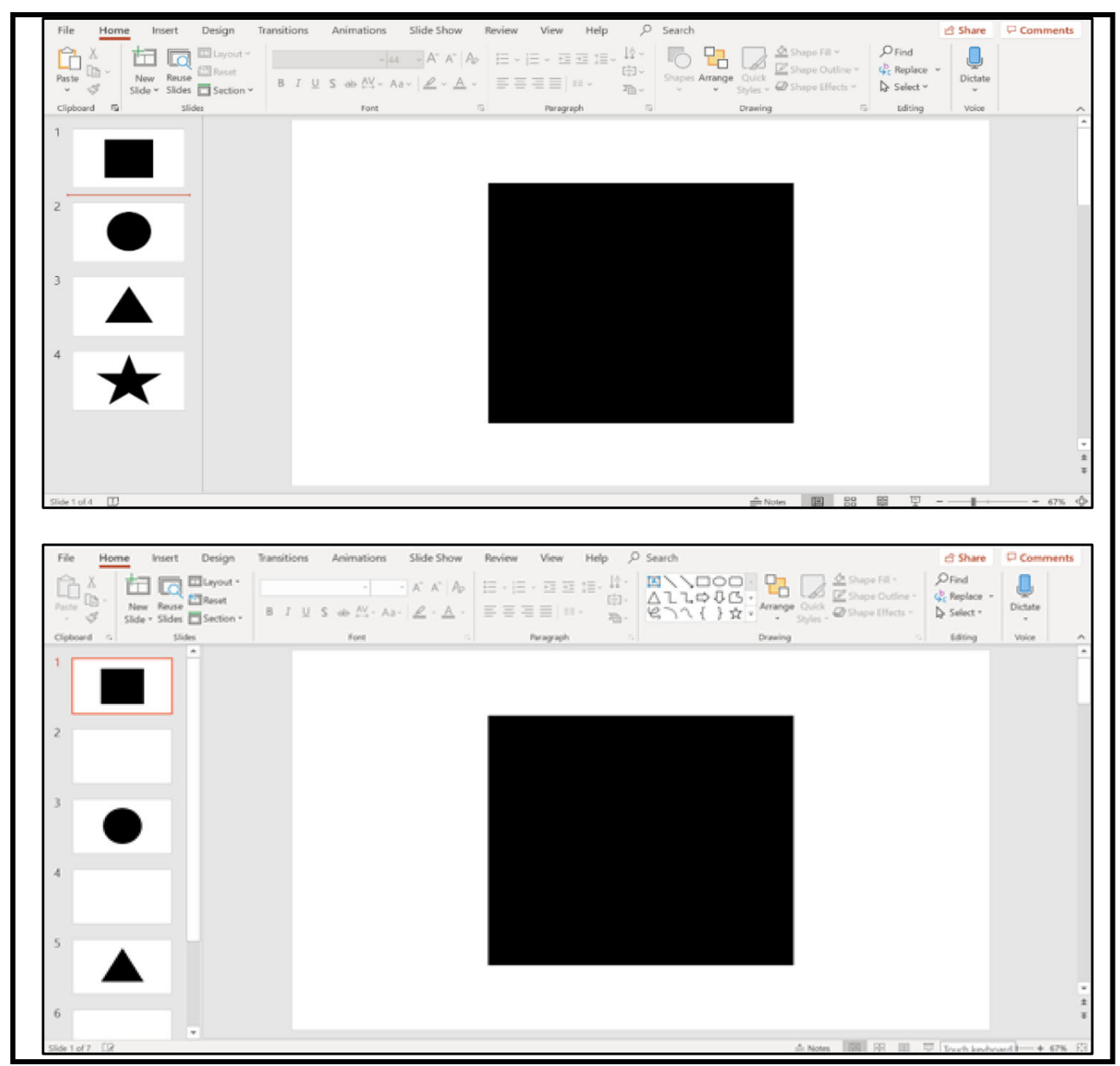

Fig. 17 A Slideshow With Instructional $\mathrm{S}^{\mathrm{D}} \mathrm{S}$ (top panel) and Blank Slides in Between Trials (bottom panel)

the learner's prior engagement with items. The therapist then arranges the items, allows the learner to select one item, and provides access to the chosen item for a brief period. This process is repeated to provide the learner with an opportunity to select each item. The order or frequency of selection determines whether an item is considered high or low preference. Items selected early or more frequently are considered high

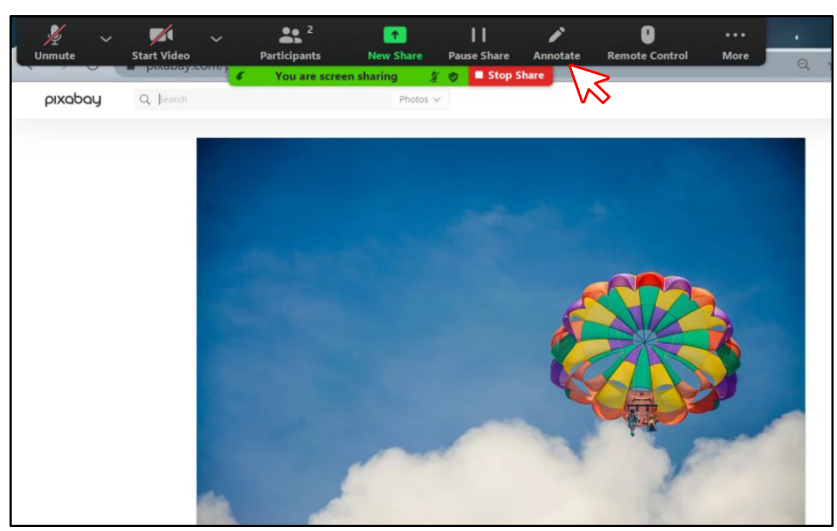

Fig. 18 Using Annotate preference, and items selected later or less frequently are considered low preference. Previous research suggests that highpreference items are more effective reinforcers than lowpreference items (Roane, Vollmer, Ringdahl, \& Marcus, 1998) or arbitrarily selected items (i.e., items not included in the SPA; Vollmer, Marcus, \& LeBlanc, 1994).

Although SPAs were originally developed and evaluated in a face-to-face context, subsequent research on SPA procedural variations suggests that they can be adapted for telehealth services. An important consideration is the type of stimuli included in the SPA and how those options are displayed to the learner. Previous research suggests that SPAs with pictorial (Groskreutz \& Graff, 2009) and video (Brodhead, AlDubayan, Mates, Abel, \& Brouwers, 2015) depictions of tangible stimuli obtain similar preference hierarchies to SPAs with those tangible stimuli. Therapists can include tangible stimuli, such as edibles and toys, and display picture or video representations of those items using Portion of Screen Share (see Portion of Screen Share - Table 1 and the "Portion of Screen Share" task analysis). If using tangible items, caregiver assistance would likely be required. Therapists can also include nontangible stimuli, such as video content (Curiel \& Poling, 


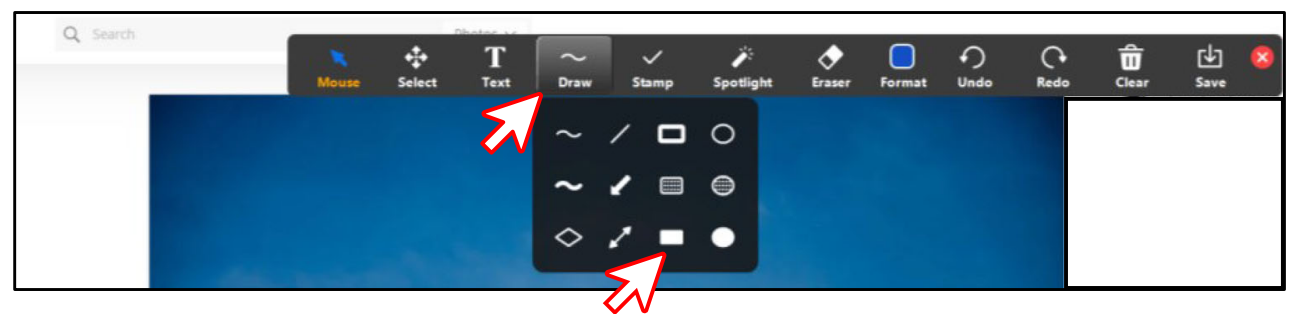

Fig. 19 Using Draw to Create Shapes

2019; see Fig. 23) and nonphysical social interactions (Morris \& Vollmer, 2019). There may also be unique features of Zoom that broaden the availability of stimuli that may function as reinforcers. For instance, a learner may prefer when the therapist provides a virtual reaction (e.g., thumbs-up), includes a virtual background when social interactions are provided, or rotates their video to an upside-down orientation (see Virtual Reactions, Virtual Background, and Rotate Camera - Table 1).
Nontangible stimuli are particularly advantageous for telehealth because they do not require caregiver assistance to deliver.

To conduct an SPA using Zoom, we suggest using the Portion of Screen Share feature accompanied by presentation software. Relative to alternative Zoom options (e.g., Whiteboard, Annotate), this method allows a therapist to use pictures or videos of stimuli, quickly remove the selected stimulus after a trial, and rearrange the stimulus positions between

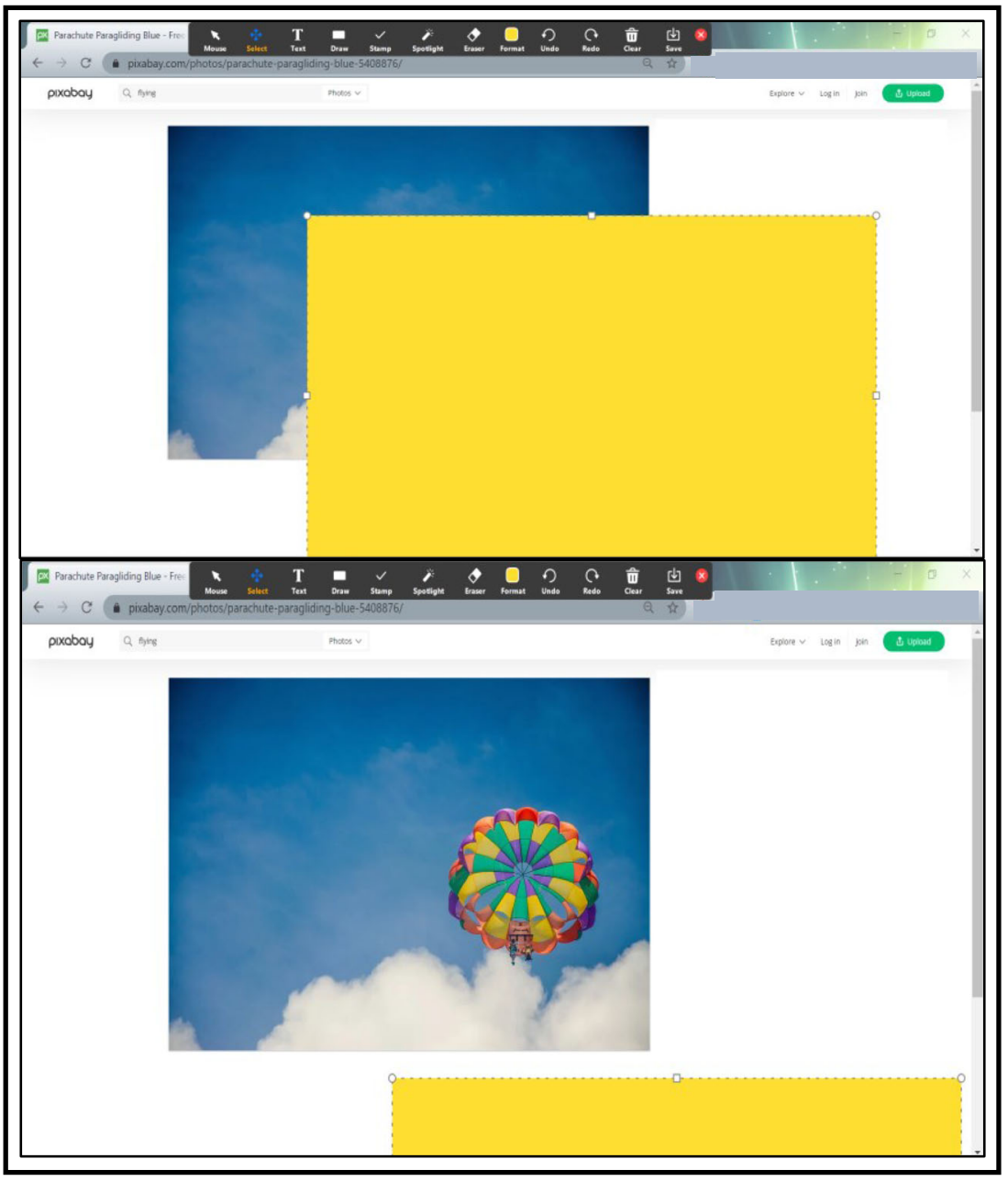

Fig. 20 Drawing Shapes Over an $\mathrm{S}^{\mathrm{D}}$ (top panel) and Using Select Tool to Move Shapes (bottom panel) 
trials. For an illustration, see the task analysis "Preparing and Conducting an MSWO." We illustrated the multiple stimulus without replacement (MSWO) preference assessment because it is commonly implemented (Graff \& Karsten, 2012).

\section{Preparing and Conducting a Multiple-Stimulus Without- Replacement (MSWO) Stimulus Preference Assessment (SPA)}

1. Prepare the array of pictorial representations of stimuli by capturing screenshots of the video content. The example shown in Fig. 21 uses a Microsoft PowerPoint slide to display the array; however, Microsoft Word documents, Google Slides, Google Docs, and Adobe PDFs are also compatible options.

2. Determine a preferred method for delivering access to the stimulus upon each selection and prepare the array accordingly.

a. Option 1: Embed a hyperlink within each picture to its corresponding webpage. In this example, links are embedded using Microsoft PowerPoint; however, these steps are identical in Microsoft Word, Google Slides, and Google Docs. The steps for using Adobe PDFs differ slightly (see https://helpx.adobe.com/ acrobat/using/links-attachmentspdfs.html).

i. Click the image (Fig. 22).

ii. Click the Insert tab in the toolbar (Fig. 23, top panel).

iii. Click "Link" in the toolbar (Fig. 23, middle panel). iv. Enter the URL for the online video in the Address field (Fig. 23, bottom panel).

v. Click "OK" (Fig. 23, bottom panel).

vi. Repeat Steps i-v for all stimuli in the array (Figs. 22 and 23 top, middle, and bottom panels).

Note. Embedding the video in the slide is not recommended. The content should play on a separate application from that of the MSWO slide, such as a web browser, so that the therapist can modify the slide to rearrange the array after each selection without interrupting the learner's access.

b. Option 2: Load all video content prior to the session to avoid delays due to buffering or loading. The example shown in Fig. 24 includes multiple browser tabs using Pixaby.com.

\section{Conducting the MSWO}

3. Enable the Portion of Screen Share (see "Portion of Screen Share") feature to display the prepared MSWO array (Fig. 25). Do not select presentation mode.

a. If you selected Option 1, the remaining portion of the computer screen can be blank (Fig. 26). The electronic data sheet in Fig. 26 is adapted from PDFfiller https://www.pdffiller.com/.

b. If you selected Option 2, have the preloaded video content displayed on the remaining portion of your computer screen (Fig. 27).

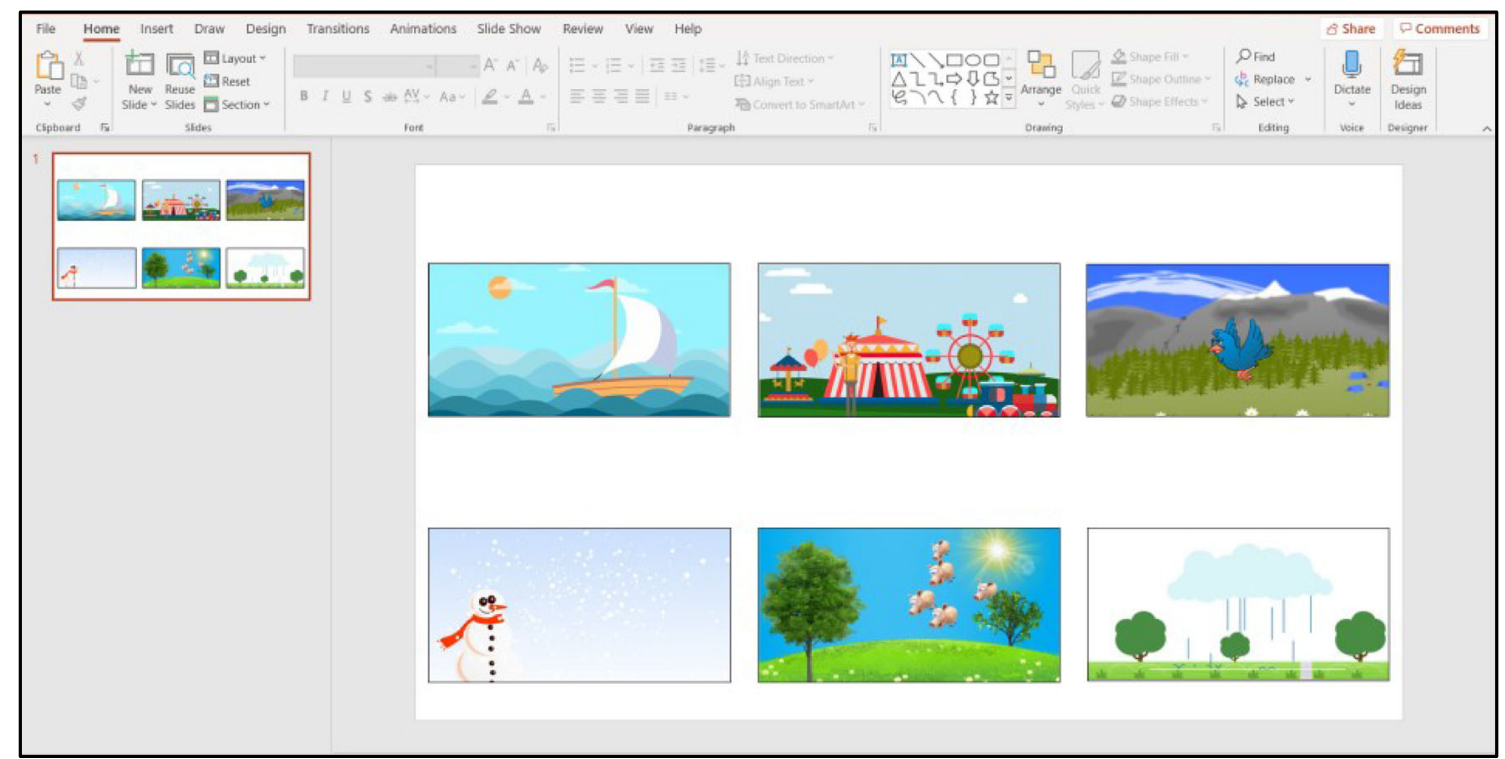

Fig. 21 Array of Pictorial Representations of Stimuli. Note. When determining the number of stimuli to include in the array, consider that the image size will decrease as more stimuli are added 


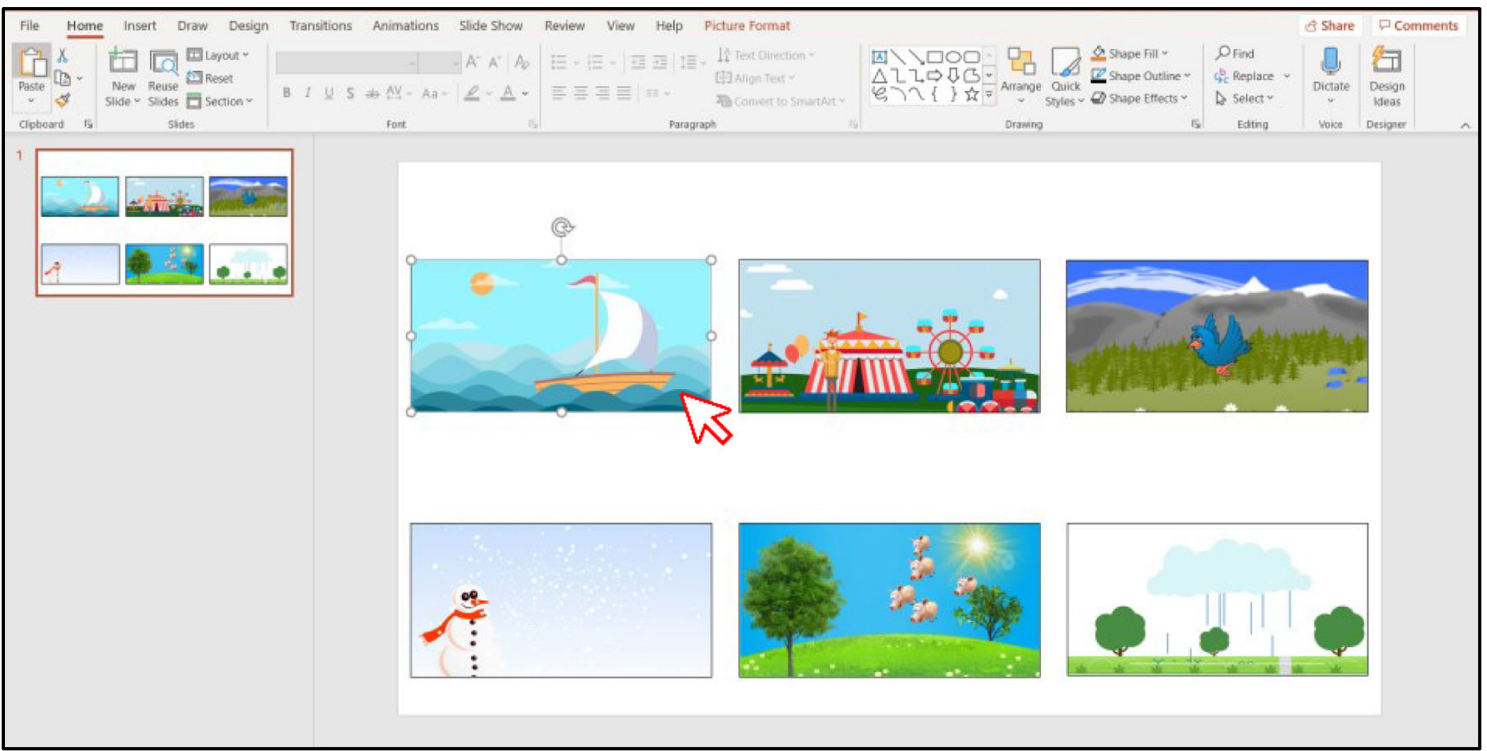

Fig. 22 Clicking on the Image

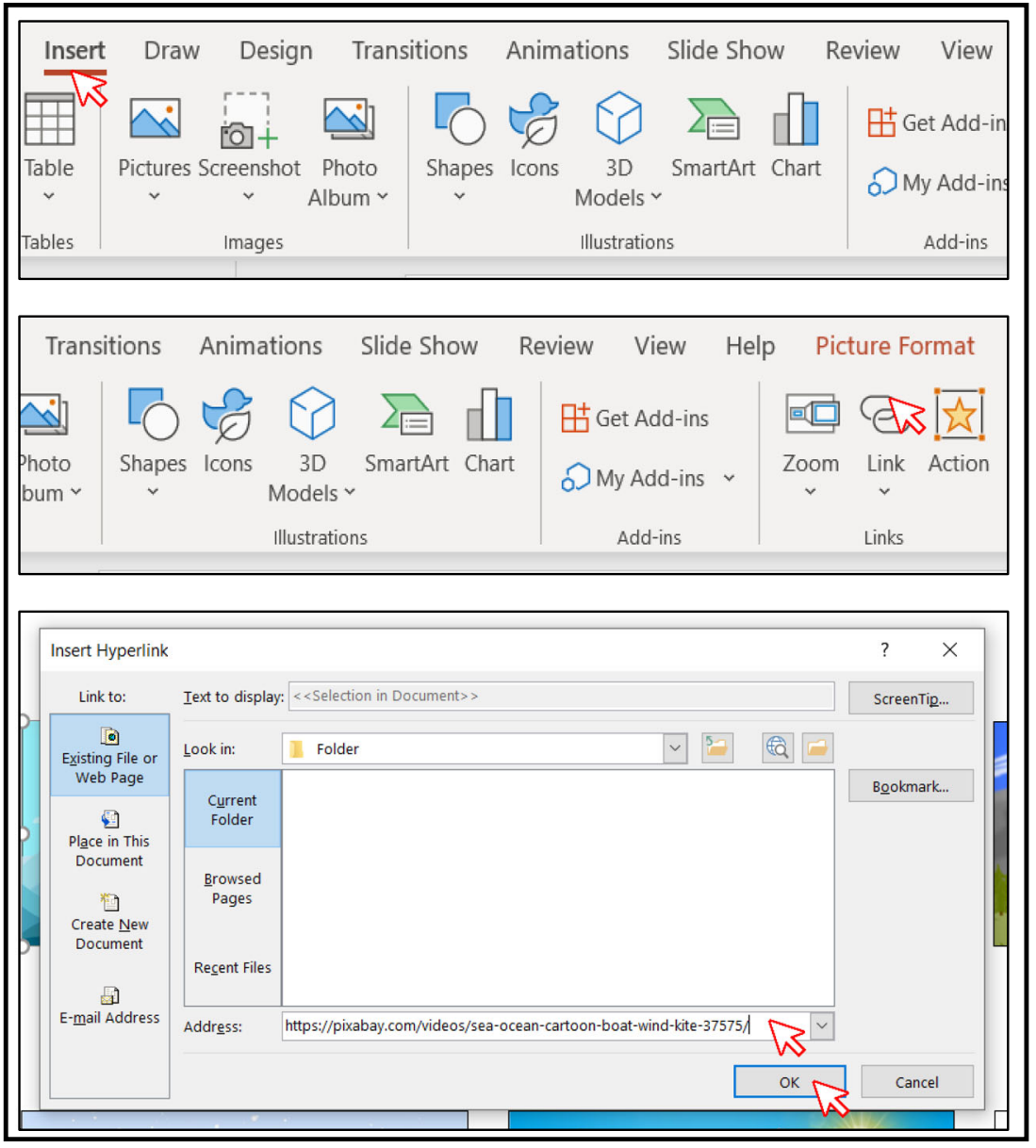

Fig. 23 Clicking on the Insert Tab (top panel), Clicking on the Link Tab (middle panel), Entering the URL in the Address Field and Clicking "OK" (bottom panel) 


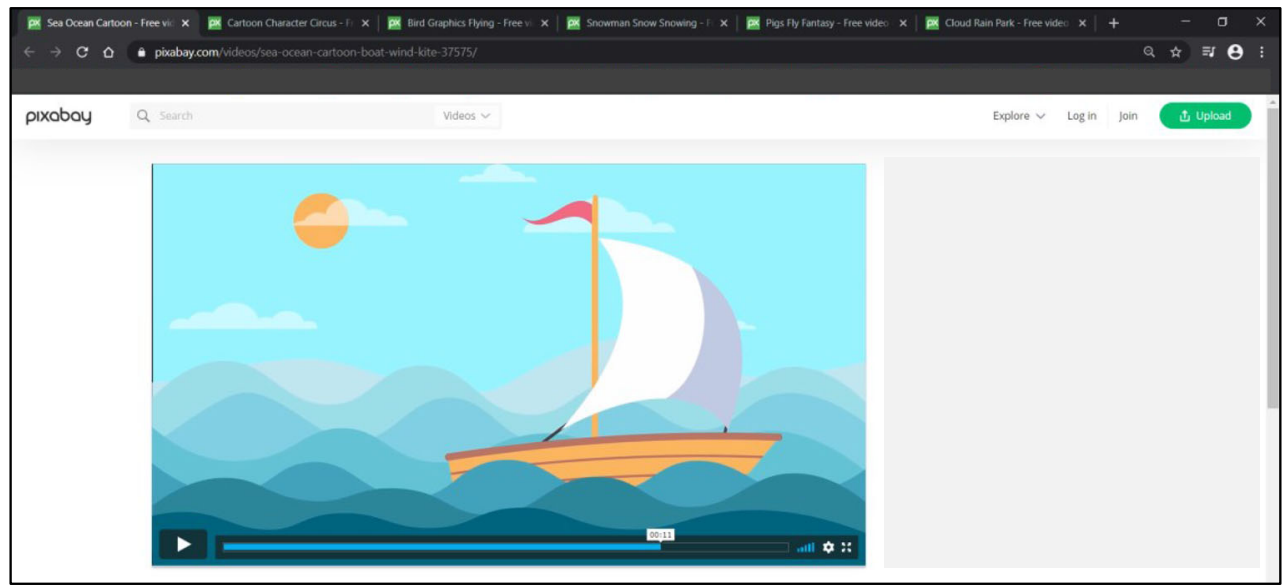

Fig. 24 All Video Content Loaded on the Web Browser

4. Instruct the learner to select a stimulus (e.g., "Pick one video.").

5. The learner should make a selection. In this example, the learner selected the "Snowman." The therapist should use topography-based responses or arrange the learner's environment or SPA preparation to observe a selection-based response (see "Learner's Response" section).

a. If you selected Option 1, click the image. The embedded link will open the web browser (Fig. 28). b. If you selected Option 2, click the corresponding web browser tab (Fig. 29).

6. Move the Portion of Screen Share box to the video and press play (Fig. 30).

7. While the learner accesses the selected video content:

a. Collect data on the learner's selection (Fig. 31, top panel).

b. Delete the pictorial representation of that stimulus from the array (Fig. 31, middle panel).

c. Rearrange the remaining stimuli in the array (Fig. 31, bottom panel).

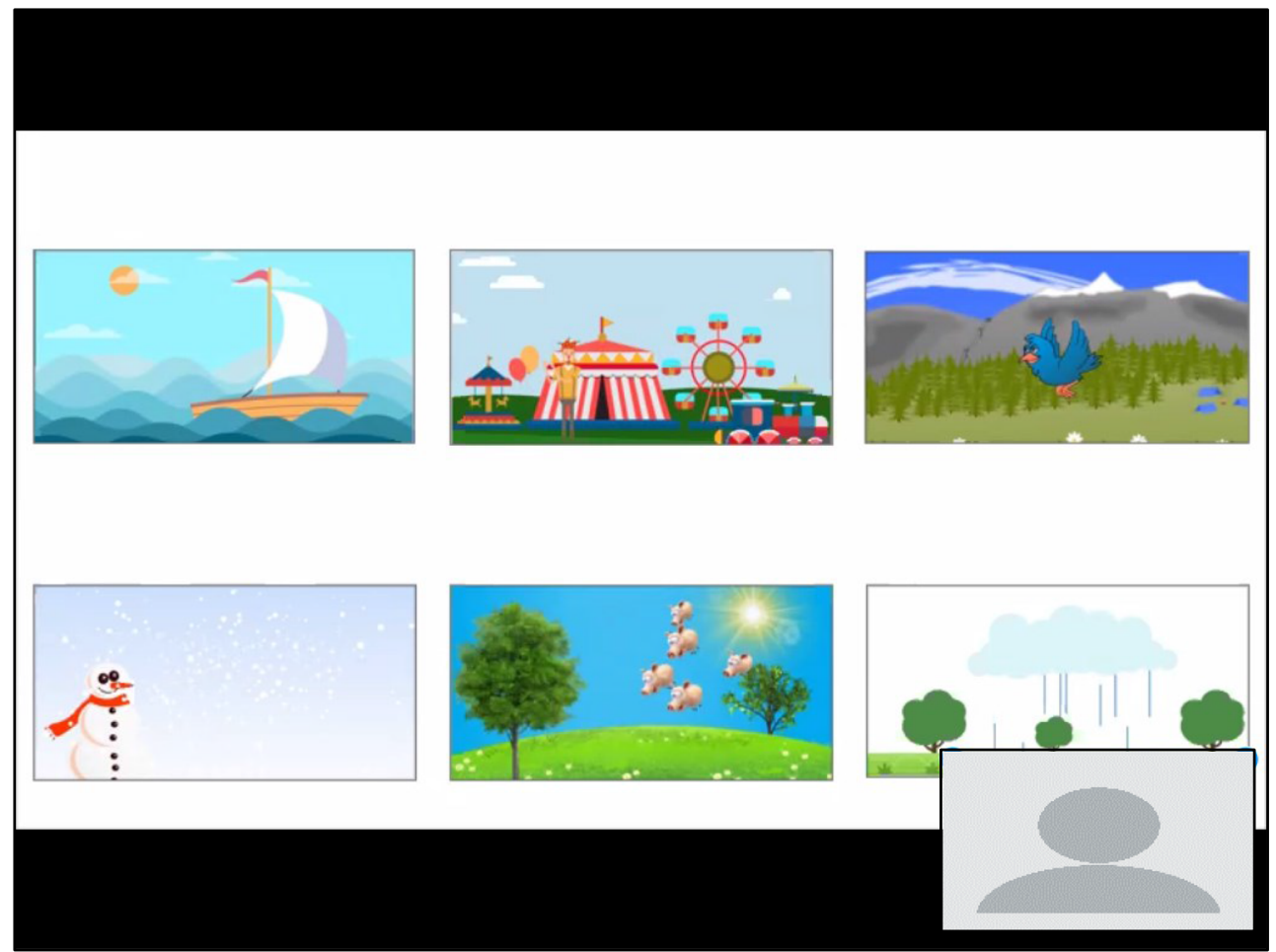

Fig. 25 Learner View of MSWO Screen 


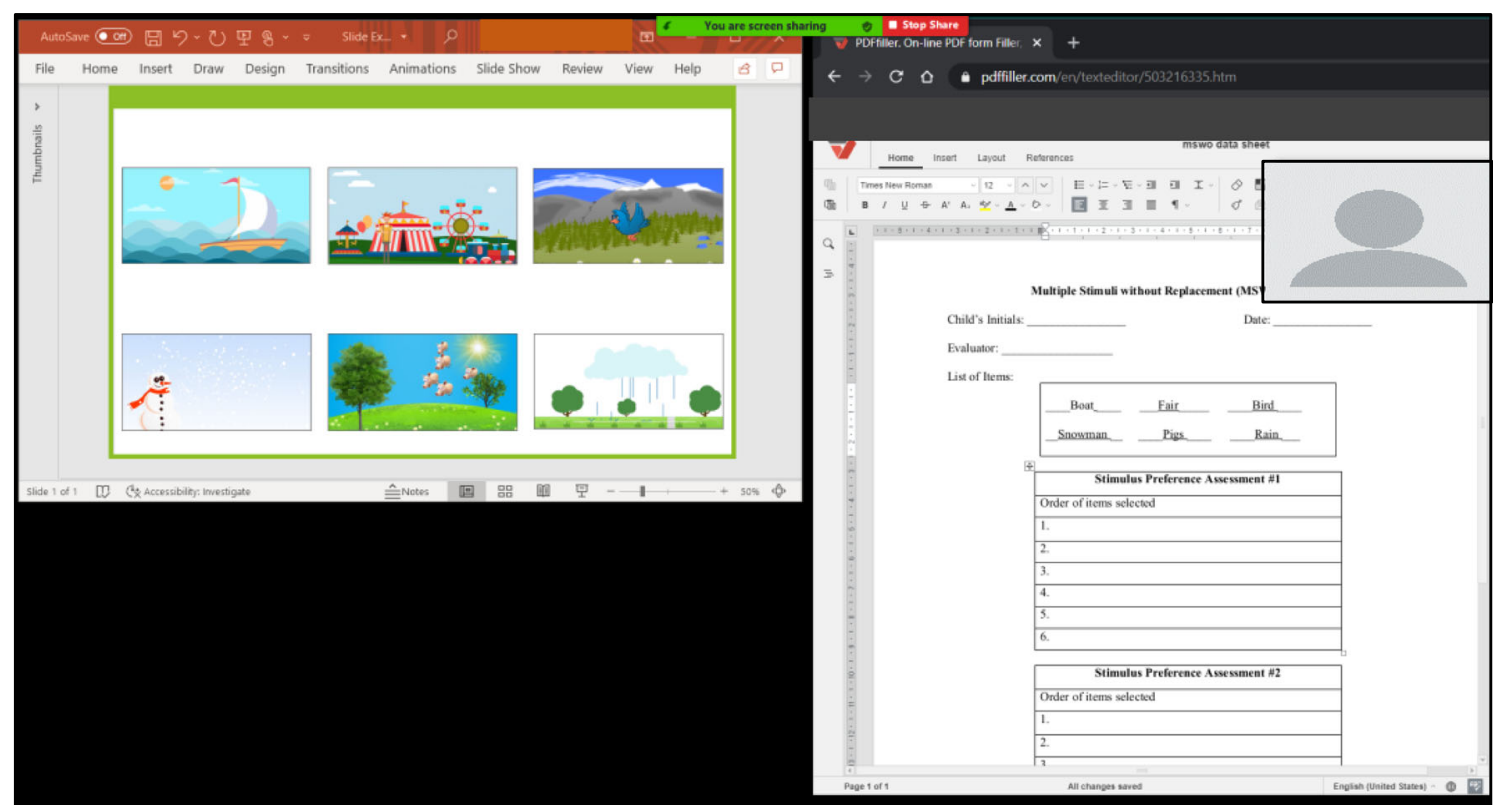

Fig. 26 Therapist View of MSWO Screen Display for Option 1: Stimuli and Data Sheet

8. At the end of the reinforcement period, move the portion of your screen shared with the learner back to the MSWO array.

9. Repeat Steps 4-8 until all stimuli from the array have been selected (Fig. 32).

\section{Reinforcer Delivery}

Highly preferred stimuli identified in an SPA are more likely to function as reinforcers than other stimuli (Roane et al., 1998; Vollmer et al., 1994), thereby increasing the probability and

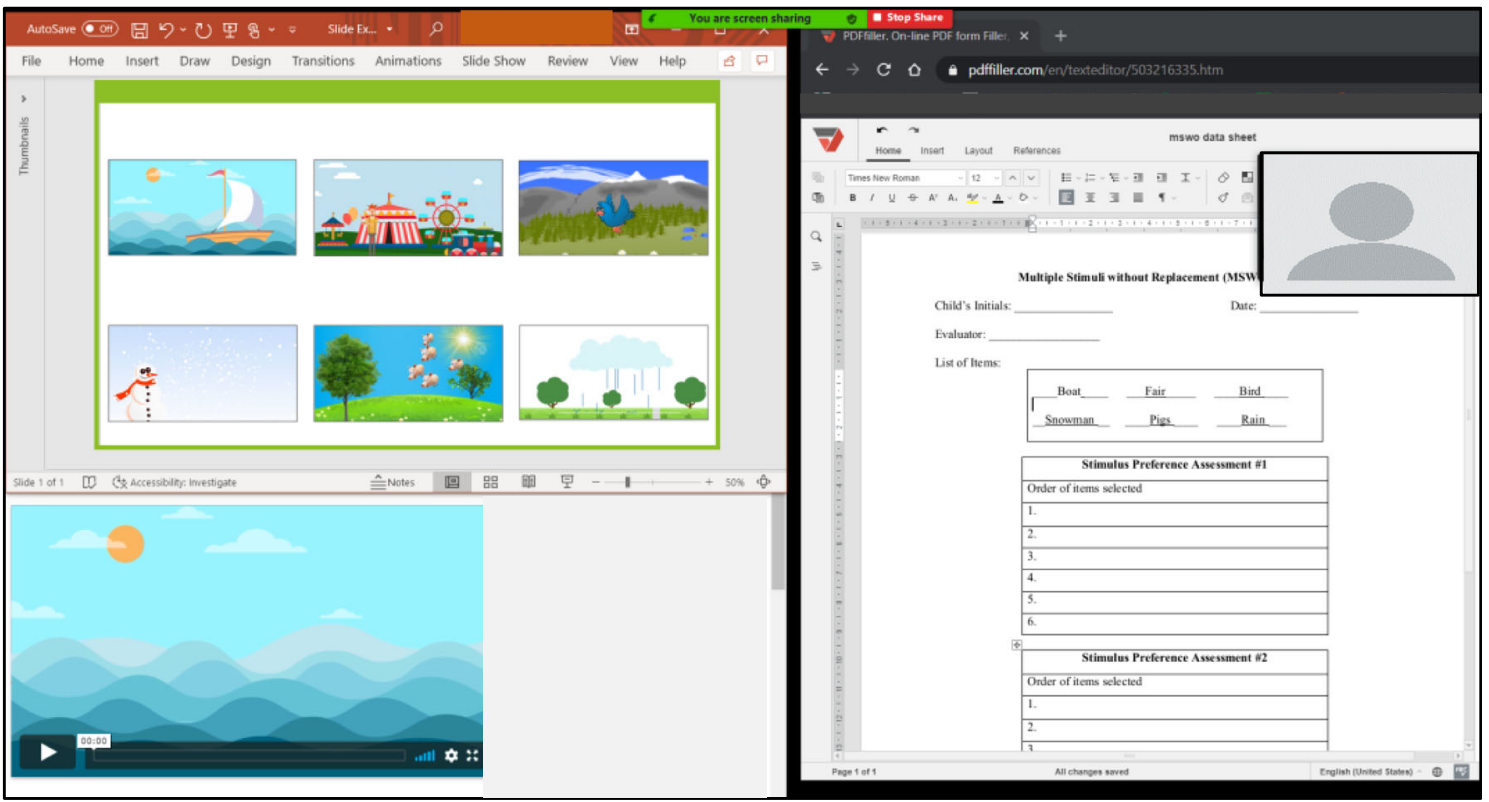

Fig. 27 Therapist View of MSWO Screen Display for Option 2: Stimuli, Data Sheet, and Preloaded Video Content 


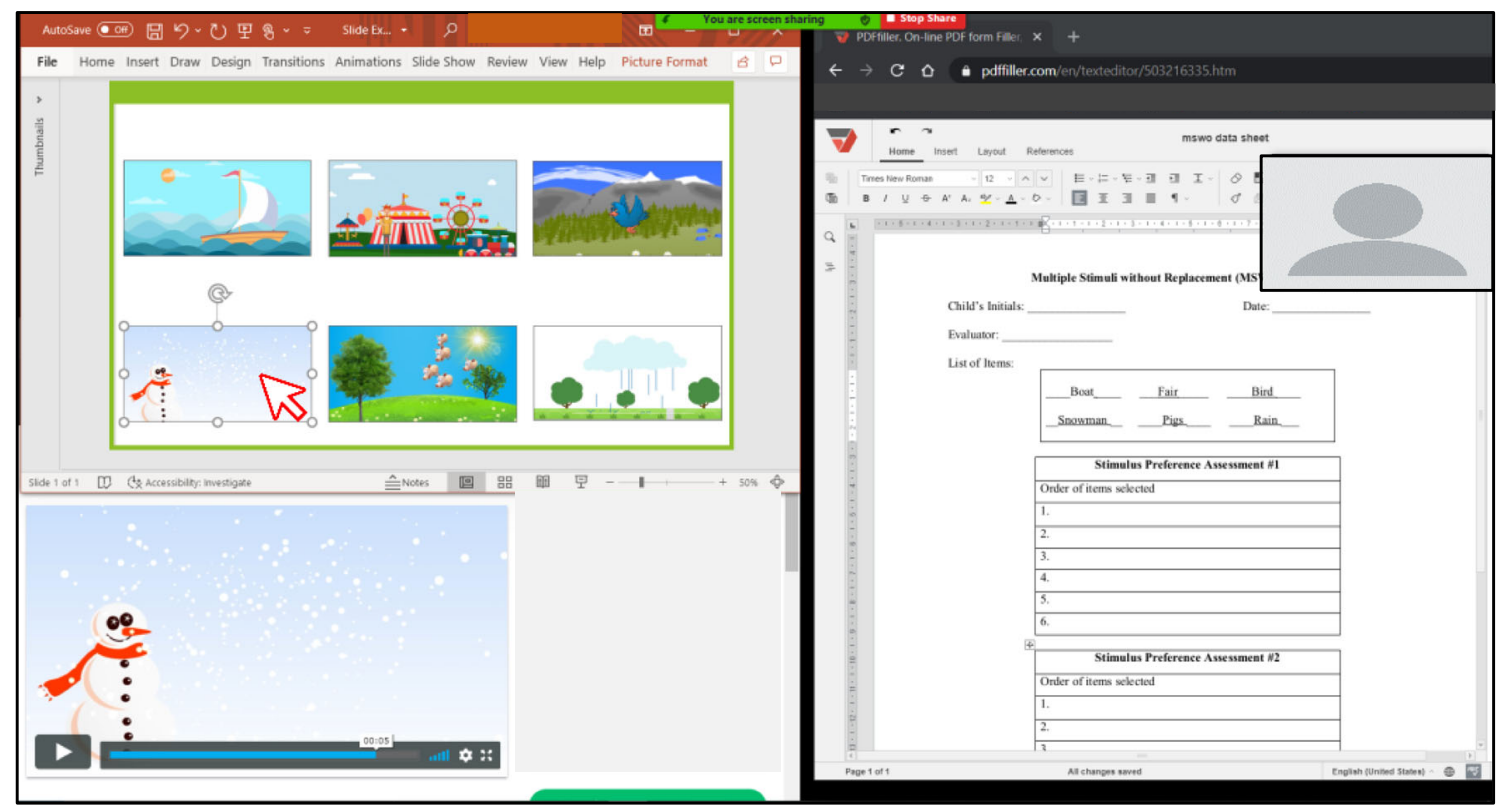

Fig. 28 Clicking on the Selected Image and the Corresponding Video Content Displayed

maintenance of the target response they follow. In addition to preference, several factors can influence the effectiveness of reinforcers, including quality, magnitude (e.g., quantity, intensity, duration of access), immediacy, and distribution. When other parameters are held constant, high-quality (Hoch, McComas, Johnson, Faranda, \& Guenther, 2002) and high-magnitude reinforcers (Trosclair-Lasserre, Lerman, Call, Addison, \& Kodak, 2008) increase responding.
Similar considerations regarding the quality and magnitude of reinforcers are likely required across interventions delivered in person or via telehealth; therefore, these topics will not be covered in the current tutorial (see Johnson, Vladescu, Kodak, \& Sidener, 2017, for an assessment). We will focus on the parameters that we believe require special consideration or modification for service delivery via telehealth: immediacy and distribution.

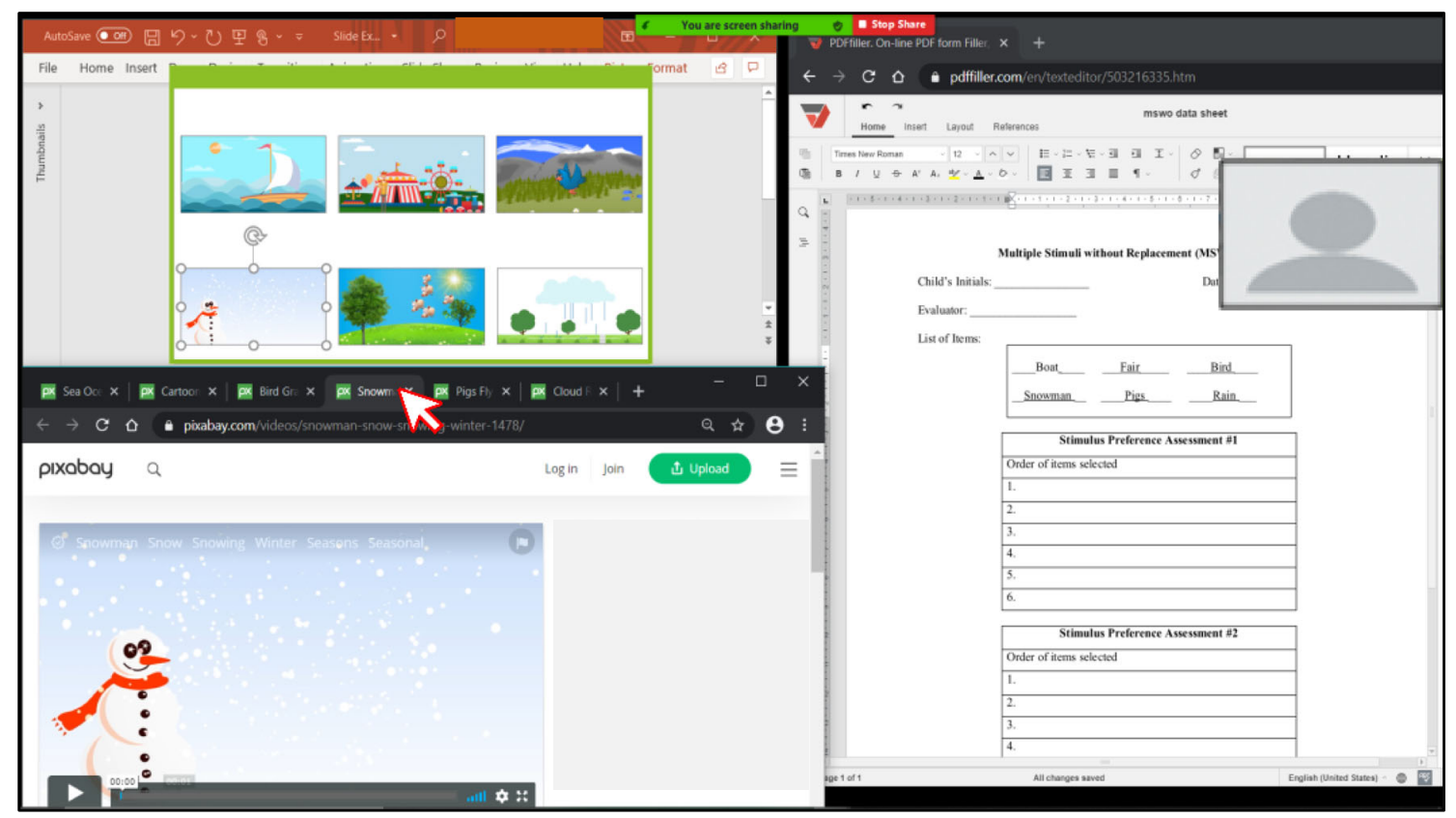

Fig. 29 Clicking the Corresponding Tab on the Web Browser 


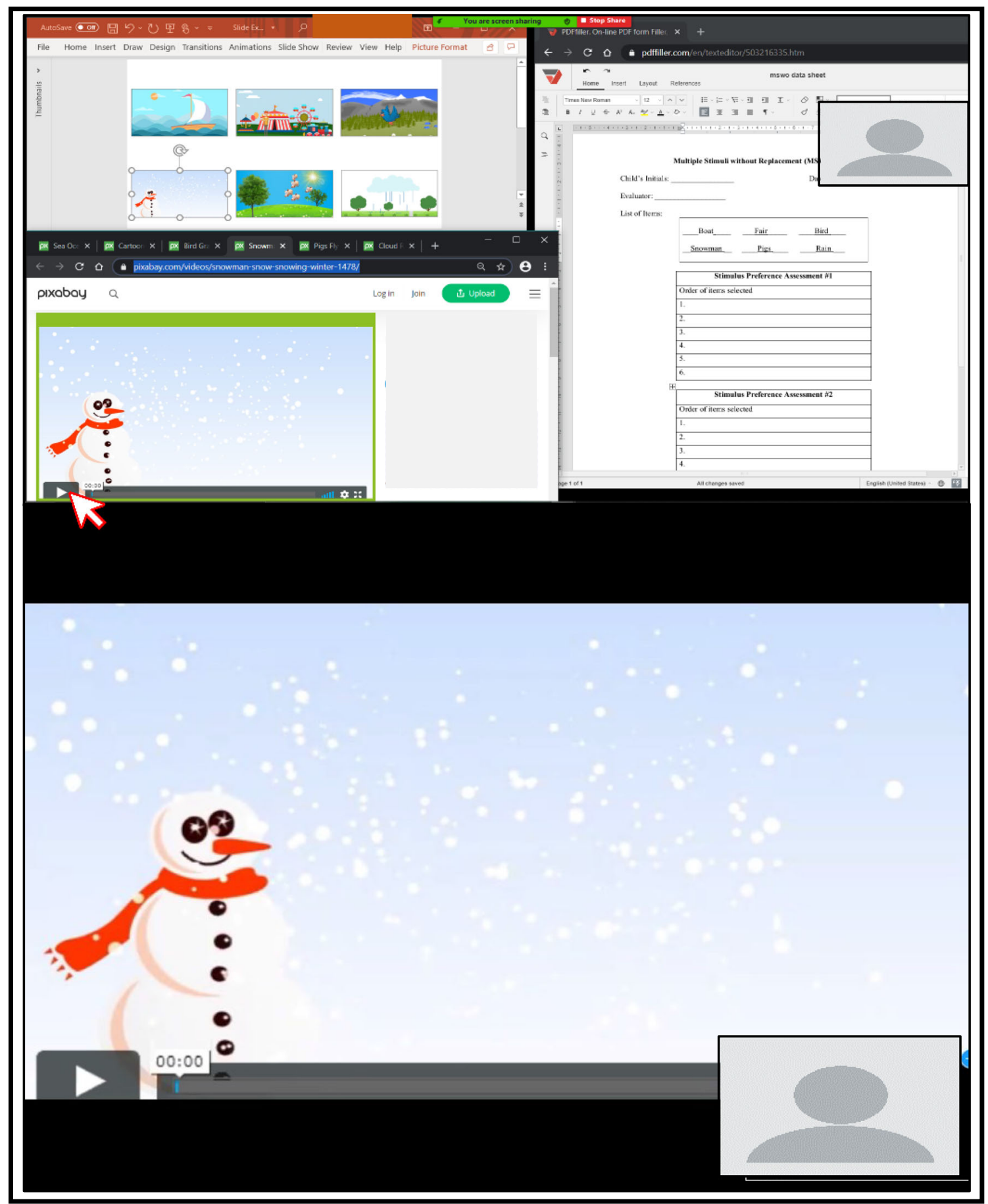

Fig. 30 Moving the Portion of Screen Share Box. Note. The top panel shows the therapist's view after moving the Portion of Screen Share box to the selected video content. The bottom panel shows the learner's view after moving the Portion of the Screen box to the selected video content

Immediacy of Reinforcer Delivery To increase the future frequency of a target response, it is important that reinforcers immediately follow the emission of the response (Michael, 2004). Carroll et al. (2016) compared the acquisition of novel tacts for children with ASD when the reinforcer was delivered immediately or delayed by $10 \mathrm{~s}$. Compared to responding in the immediate condition, responding in the 10-s delay condition was less likely to reach the mastery criterion or required additional training sessions; these data support the importance of temporal contiguity between the target response and reinforcer delivery. To maintain temporal contiguity in Zoom, we recommend using the Portion of Screen Share feature (see Portion of Screen Share - Table 1 and the "Portion of Screen Share" task analysis) because it allows the therapist to 


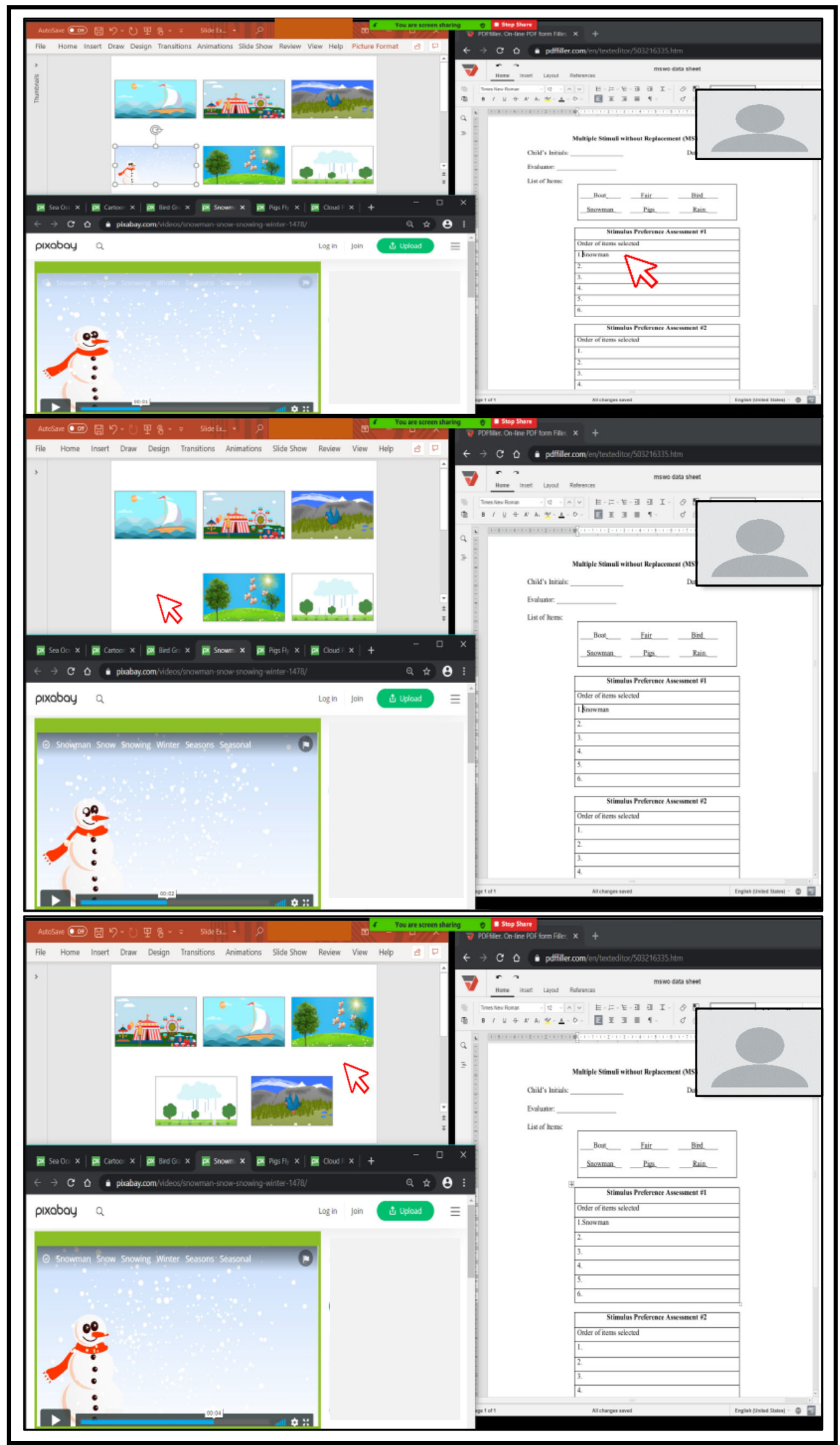

Fig. 31 Collecting Data on the Learner's Selection (top panel), Deleting the Pictoral Representation of the Selected Stimulus From the Array (middle panel), and Rearranging the Remaining Stimuli in the Array (bottom panel) 


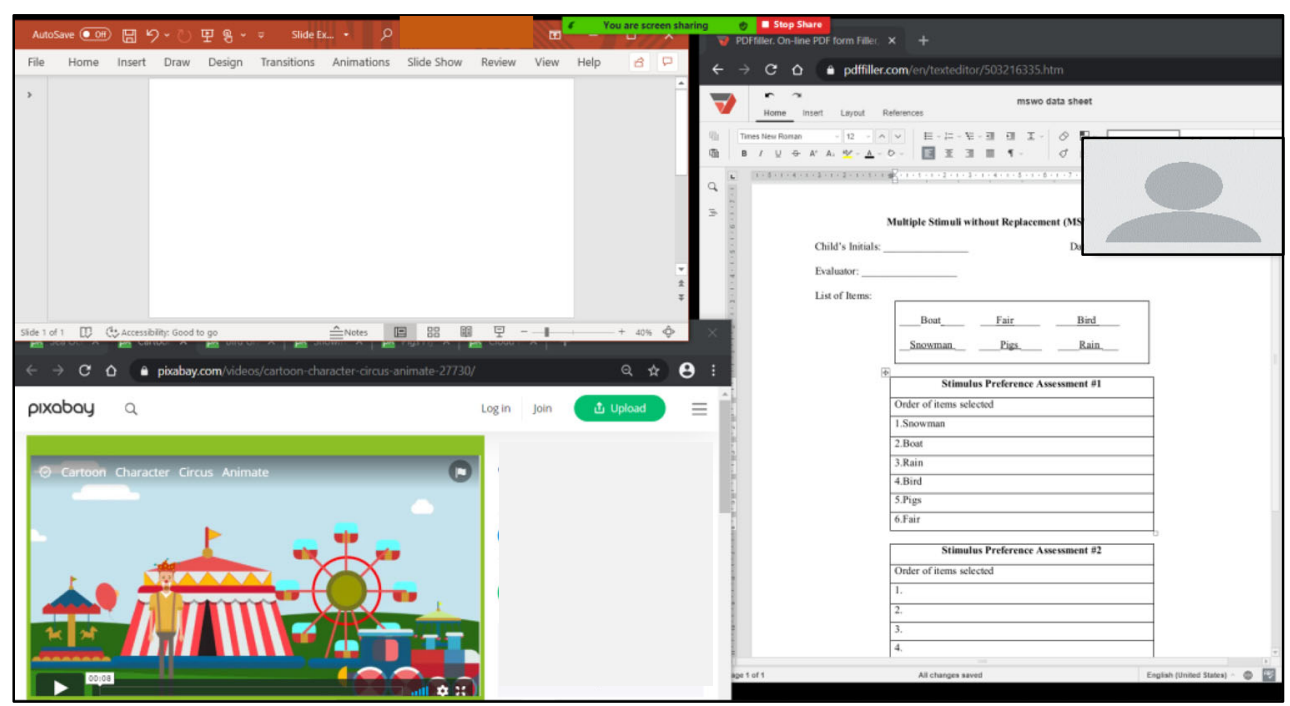

Fig. 32 Completed MSWO Display

transition quickly between instructional stimuli and reinforcers without an intermediary step.

Distribution of Reinforcers Although the immediacy of consequence delivery influences performance, it may be advantageous to delay delivery of a terminal consequence when the learner prefers uninterrupted access to a reinforcer. For example, a learner may prefer to watch longer segments of a video after engaging in multiple target responses (i.e., accumulated reinforcement) rather than watching shorter segments of the video following each target response (i.e., distributed reinforcement). In a study that compared accumulated and distributed reinforcement arrangements with individuals diagnosed with an intellectual disability, DeLeon et al. (2014) found that performance was similar under both conditions for most participants, and all participants preferred the accumulated arrangement when the consequence was activity based (e.g., videos, games). Therapists should consider whether learners prefer to access activity-based stimuli for longer durations and arrange for accumulated access (see the next section, "Token Economies"). This consideration may be increasingly meaning-

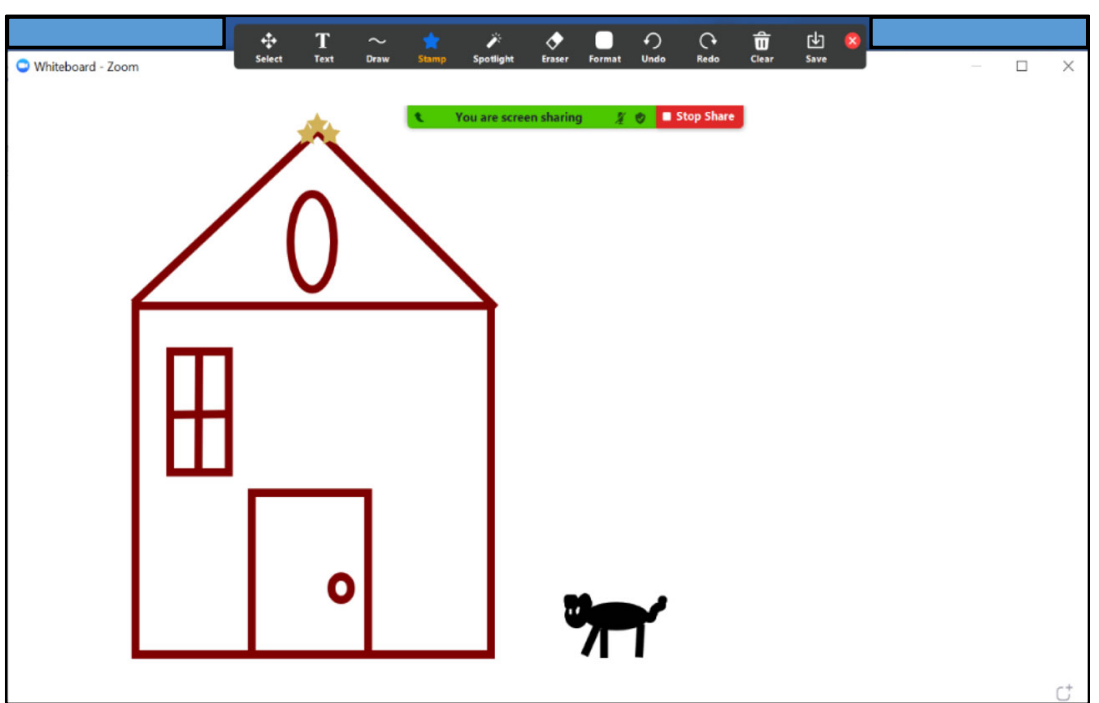

Fig. 33 Using the Whiteboard as a Reinforcer. Note. The therapist and learner would share the same view. Both the therapist and learner can draw together if permission to annotate is configured in the Advanced Settings 
ful because digital, activity-based stimuli lend themselves well to telehealth-delivered interventions, and this category of reinforcers may be utilized more often as a result.

A therapist can use Screen Share (see Share Screen - Table 1) to provide access to activity-based stimuli (e.g., videos, online games, drawing on the Whiteboard [see Whiteboard - Table 1 and Fig. 33], and drawing with Annotate [see Annotate - Table 1 and Fig. 34]) so that the learner can access the content for the predetermined access period. However, activity-based stimuli may be restricted depending on the strength of the internet connection for either party, as well as the type of device the learner uses. For learners who prefer to control the content (e.g., repeatedly rewinding a video), the therapist can enable Remote Access (see Remote Access -Table 1). Remote Access can be slow and may require a caregiver's assistance, which can increase the delay to the reinforcer and impact efficacy.

\section{Token Economies}

A token economy is a reinforcement system in which generalized conditioned reinforcers (i.e., tokens) are presented following target behaviors, accumulated across target behaviors, and exchanged for access to preferred items or activities. Token economies have been used to produce behavior change across many different environments, target behaviors, and populations of human and nonhuman organisms (Hackenberg, 2018), including consumers with ASD participating in ABA interventions (Matson \& Boisjoli, 2009).

Incorporating token economies in ABA interventions can be beneficial for several reasons. Tokens can be less timeconsuming and effortful to deliver than other tangible reinforcers, and tokens are accumulated and exchanged after several responses instead of following each response (Tarbox, Ghezzi, \& Wilson, 2006). Delivering tokens can permit quick and consistent reinforcement, and tokens may bridge the temporal gap between the learner's behavior and delayed backup reinforcers (Kazdin \& Bootzin, 1972; Kelleher, 1966). In addition, tokens as generalized conditioned reinforcers tend to be less sensitive to fluctuating motivating operations than backup reinforcers (Russell, Ingvarsson, \& Haggar, 2017).

When integrating a token economy in telehealth services, a behavior analyst has several options to consider, whether they are attempting to transfer or adapt a learner's preexisting token economy or establishing a new one. For consumers with a history of therapist-managed token economies, one lowtechnology option is for the therapist to hold a physical token board in view of the webcam and deliver tokens following target responses. For a virtual token board, therapists may incorporate an existing application-based virtual token board (e.g., ClassDojo; Robacker, Rivera, \& Warren, 2016), or therapists can develop one in Zoom using a number of features (e.g., Whiteboard, Screen Share with presentation software). Of all the options, we recommend using Zoom with Annotate (see Annotate - Table 1) and Portion of Screen Share (see Portion of Screen Share - Table 1). The "Incorporating a Token Economy Using Annotate and Portion of Screen Share" task analysis shows how to create a token board that is continuously visible to the learner and continuously visible and accessible to the therapist. With continuous visibility, the therapist can reinforce the learner's on-task behaviors (e.g., attending) without interrupting the presentation of other stimuli or switching between screens. With continuous access, a therapist can provide the token immediately following the response, which is beneficial for acquisition (see the "Immediacy of Reinforcer Delivery" section, previously).

The target responses that will be strengthened in a token economy are based on the learner's goals, and many target behaviors can be addressed in a telehealth service delivery model (see the "Learner's Response" section, previously). Regardless

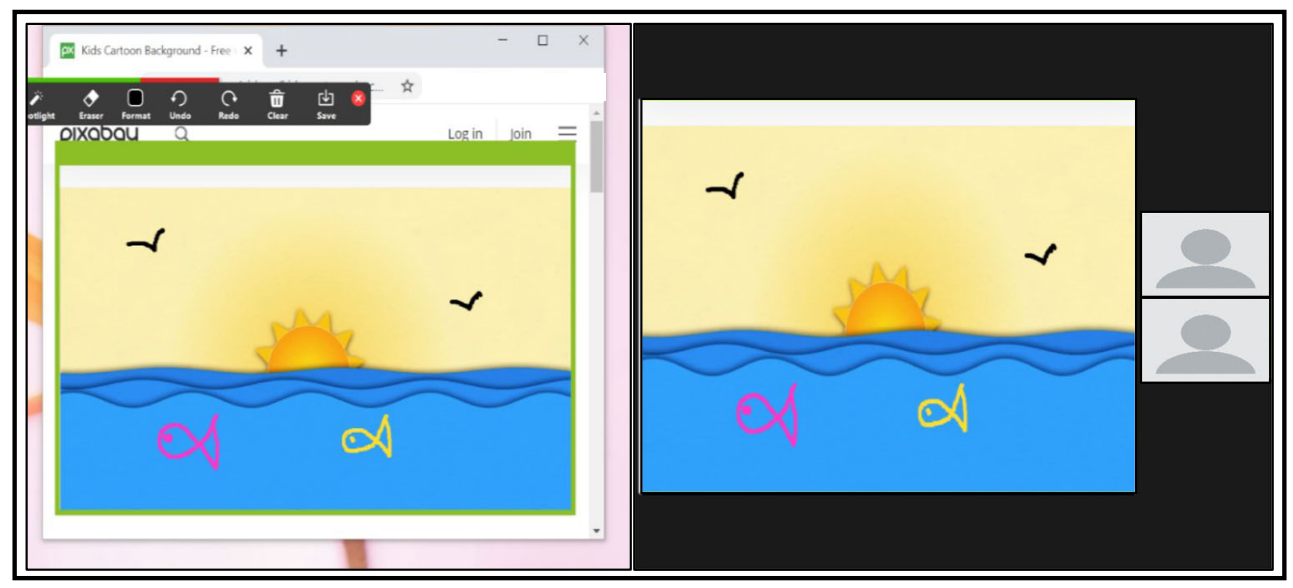

Fig. 34 Using Annotate on a Shared Screen as a Reinforcer. Note. The left panel is the therapist view, and the right panel is the learner view 
of whether a token economy is presented in face-to-face or remote service delivery, the development of a token economy requires the behavior analyst to consider the (a) target responses, (b) type of tokens (e.g., physical objects, such as coins; nonphysical objects, such as tallies), (c) token-production schedule, (d) token-exchange schedule, (e) opportunity to exchange tokens, and (f) backup reinforcers (Hackenberg, 2009; Miltenberger, 2016). All these aspects should be considered in telehealth services to maintain treatment integrity (Rodriguez, 2020).

Although the form of the token is less important than its reinforcing function, some research suggests that interestbased tokens (i.e., images of preferred items; e.g., jigsaw puzzle pieces) enhance the reinforcing efficacy of tokens (Carnett et al., 2014). To use interest-based tokens, a therapist must use Portion of Screen Share and a slideshow to deliver images as tokens, which means this token board will not be continuously visible nor available. If interest-based tokens are not clinically indicated, the therapist can create virtual stimuli with the Stamp or Draw tools in Annotate (see Annotate - Stamp and Annotate - Draw - Table 1, Figs. 35 and 37). No matter which stimuli are used as tokens, a therapist needs to condition tokens as generalized conditioned reinforcers, and conditioning protocols (e.g., Dozier, Iwata, Thomason-Sassi, Worsdell, \& Wilson, 2012; Holth, Vandbakk, Finstad, Grønnerud, \& Sørensen, 2009; Leon, Borrero, \& DeLeon, 2016, Supporting Information) could be adapted for telehealth delivery. If the learner has an existing token economy that can be adapted for a virtual teaching environment, the therapist should verify that the tokens function as conditioned reinforcers before working on additional skills in telehealth (Rodriguez, 2020).

After selecting tokens, the behavior analyst should determine the token-production schedule: when target responses will produce a token. As in direct service delivery in a faceto-face format, therapists can provide tokens depending on the reinforcement schedule (e.g., variable ratio, fixed interval) appropriate for the learner or program. Portion of Screen Share allows the therapist to use a timer on their screen without showing it on the learner's screen, which could be beneficial for time- and interval-based schedules (see Fig. 35). If the token-production schedule changes based on the learner's response (i.e., differential reinforcement; e.g., Campanaro, Vladescu, Kodak, DeBar, \& Nippes, 2020), this is eased by creating a token board with Annotate because it is continuously visible and available (see Fig. 35, bottom panel).

The behavior analyst must identify the token-exchange schedule: the number of tokens required for an exchange. The token-exchange schedule can be based on a fixed or flexible earning requirement (Cihon et al., 2019). In fixed earning requirements, the therapist determines the criteria for the exchange prior to a teaching session. In flexible earning requirements, the therapist determines the criteria for the exchange during a teaching session based on the learner's responding. A therapist can use the Annotate and Portion of Screen Share features to draw a shape to create a virtual token board. A fixed earning requirement uses placeholders or markers within the token board to denote the number of responses (see Fig. 37), whereas a flexible earning requirement does not use placeholders or markers within the token board (see Fig. 38). Once the learner's performance meets the criterion for the exchange in both fixed and flexible earning arrangements, the learner can emit an exchange response (see Leon et al., 2016, Supporting Information). In face-to-face interventions, a learner may hand the token board to the therapist as an exchange response, but this is not possible in telehealth. As an alternative, the therapist may teach the learner to emit a specific motor or vocal response following a full token board (fixed-earning requirement; see Fig. 37) or after the therapist provides the $S^{\mathrm{D}}$ (flexible-earning requirement). After the learner engages in the exchange response, the therapist can remove the tokens with the Erase tool (see Fig. 41).

Token-exchange responses will result in access to the backup reinforcer immediately, following accumulation, or after a delay (Miltenberger, 2016). The contingent delivery of highly preferred stimuli as backup reinforcers is crucial to the conditioned reinforcing effectiveness of tokens (Fiske, Isenhower, Bamond, \& Lauderdale-Littin, 2020), and backup reinforcers should be identified with an SPA (see the "Identifying Preferred Stimuli" section, previously) when possible. Therapists may also consider incorporating a variety of backup reinforcers to increase the effectiveness and social validity of a token economy (Hine et al., 2018). Although virtual reinforcers (e.g., images, videos, songs) may be the easiest to integrate with Zoom (see the "Presenting Stimuli" section, previously, and Figure 42), a therapist is not limited to virtual stimuli as backup reinforcers. Therapists may also use items and activities in the learner's environment depending on the availability of the items and caregiver assistance. A token economy may be particularly advantageous if access to the backup reinforcers requires a prolonged duration to either obtain or consume the reinforcer or if the reinforcers require caregiver facilitation.

\section{Incorporating a Token Economy Using Annotate and Portion of Screen Share}

1. Open the program(s) you will use to present instructional stimuli and online reinforcers, if applicable. In this example, a slideshow is used to present $\mathrm{S}^{\mathrm{D}} \mathrm{S}$ and an online video is used as a reinforcer.

a. We recommend opening all necessary programs side by side to allow you to quickly switch between programs.

2. Use the Portion of Screen Share (see "Portion of Screen Share") feature to create a screen-sharing box that surrounds your instructional stimuli. 


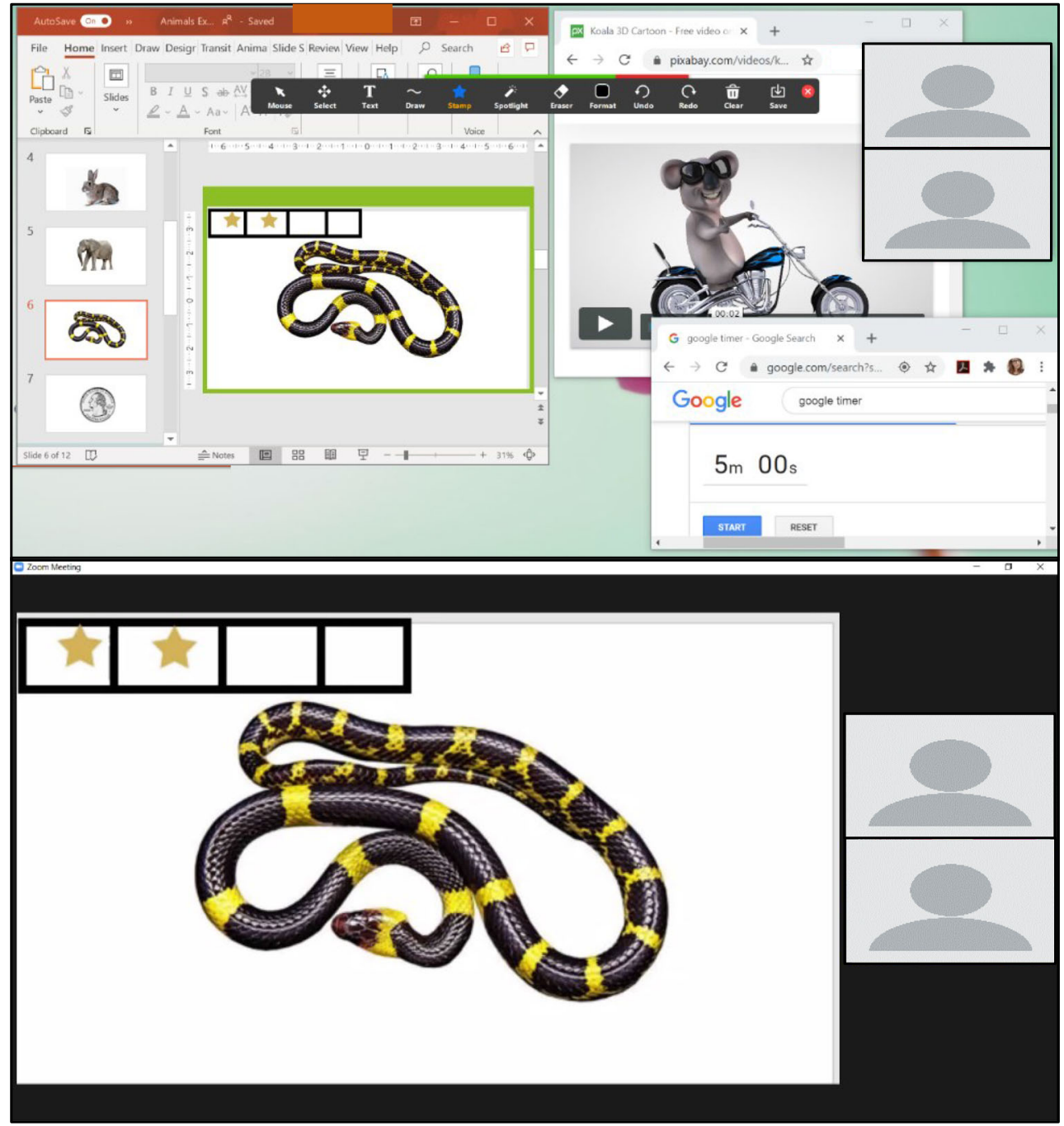

Fig. 35 Therapist's (top panel) and Learner's (bottom panel) Views of a Timer and a Token Economy. Note. Portion of Screen Share is used to show the learner the discriminative stimulus and token board without showing them the timer

3. Move your cursor to the top of the screen to reveal the Screen Share toolbar. Click "Annotate" (Fig. 36).

4. Create a token board using lines and shapes from the Draw tool. Draw the token board on a blank slide before presenting the first target stimulus.

a. Figure 37 shows a token board using a fixed earning requirement with four boxes in the top-left corner of the Portion of Screen Share box. b. Figure 38 shows a token board using a flexible earning requirement with one box in the top-left corner of the Portion of Screen Share box.

5. Present your first visual target stimulus in the Portion of Screen Share box (Fig. 39). This example shows the therapist selecting the next slide in the slideshow.

a. If you are presenting stimuli from a website, move the Portion of Screen Share box to surround that stimulus; the token board will move with the box.

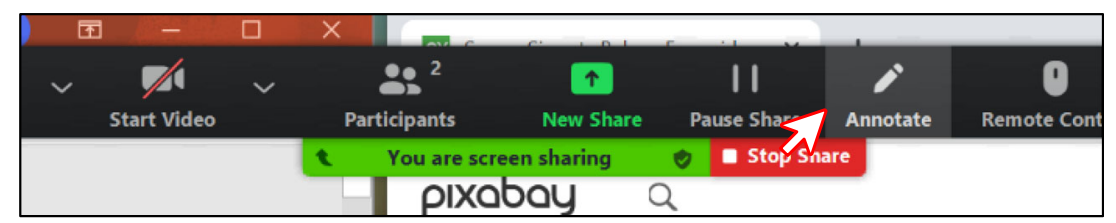

Fig. 36 Screen Share Toolbar 


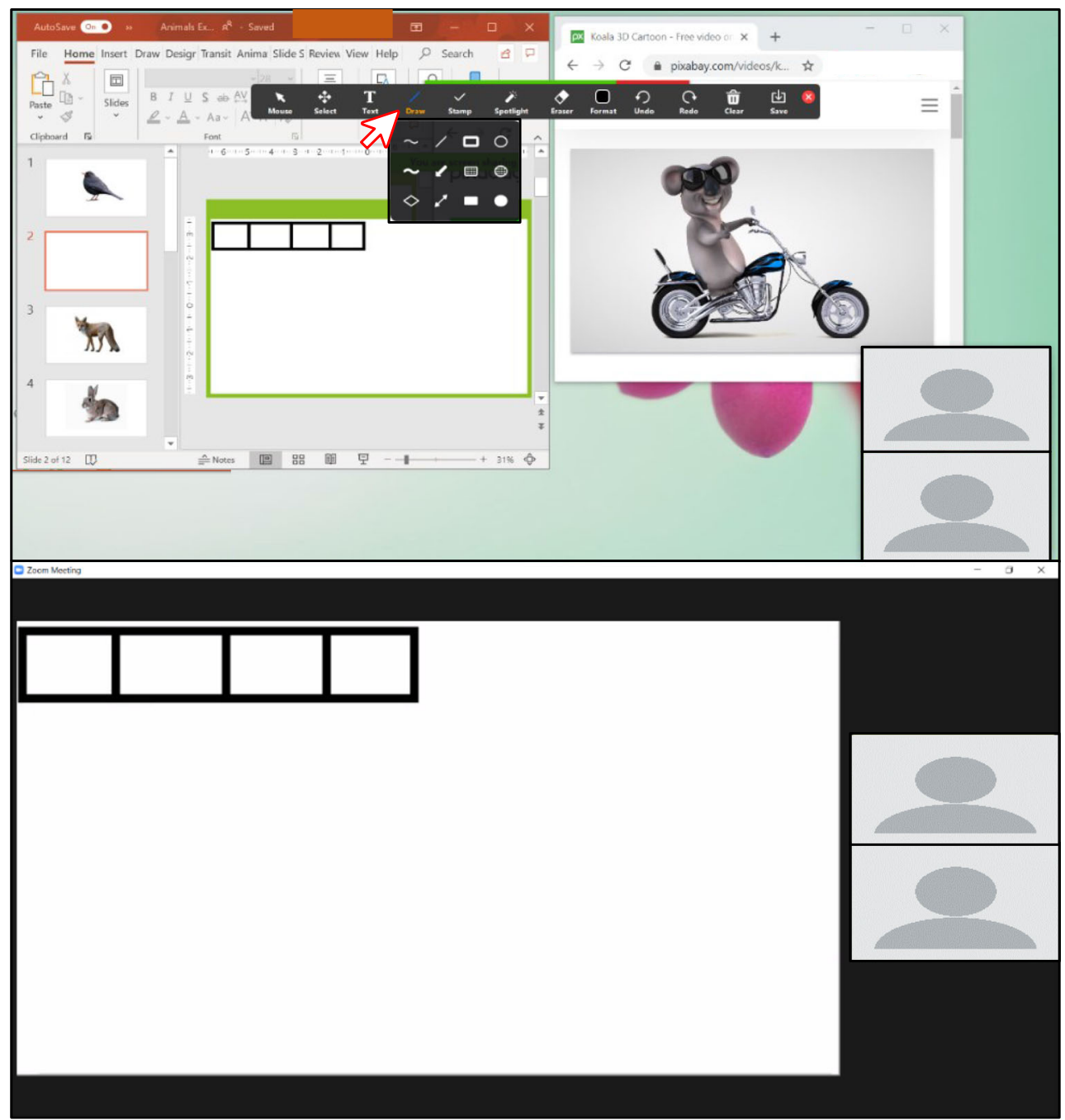

Fig. 37 Empty Token Board Using a Fixed Earning Requirement Drawn in the Portion of Screen Share Box. Note. The top panel shows the therapist's view, and the bottom panel shows the learner's view

6. To add a token on the token board:

a. Use the Draw tool in the Annotate toolbar (refer to Step 4).

b. Use the Stamp tool (Fig. 40) in the Annotate toolbar.

i. Click "Stamp."

ii. Select the preferred stamp shape.

iii. Click the desired location on the board to place the stamp (token).

iv. Repeat as needed.

7. Repeat Steps 5 and 6 until the fixed or flexible earning requirement is met.

8. To remove the tokens once the requirement is met, click "Eraser" in the Annotate toolbar and click each token to erase it (Fig. 41).

9. To deliver a digital reinforcer after the exchange, move the Portion of Screen Share box to share the reinforcer (Fig. 42).

\section{Discussion}

In response to COVID-19, behavior analysts are quickly adopting a telehealth service delivery model to maintain access to behavioral intervention for consumers while limiting face-toface interactions. Unfortunately, behavior analysts have little guidance for delivering ABA interventions directly to a learner via telehealth because previous research has concentrated on applications that train caregivers to implement assessment and intervention procedures (Ferguson et al., 2019). To address this gap in support, we created a tutorial on how to utilize Zoom, a popular teleconferencing platform, to create an analogue of the direct services provided in a face-to-face format. Although we focused on the Zoom platform, this tutorial could be useful for other teleconferencing platforms with similar features. In direct service provision of comprehensive interventions, the behavior analyst employs the three-term contingency as the framework 


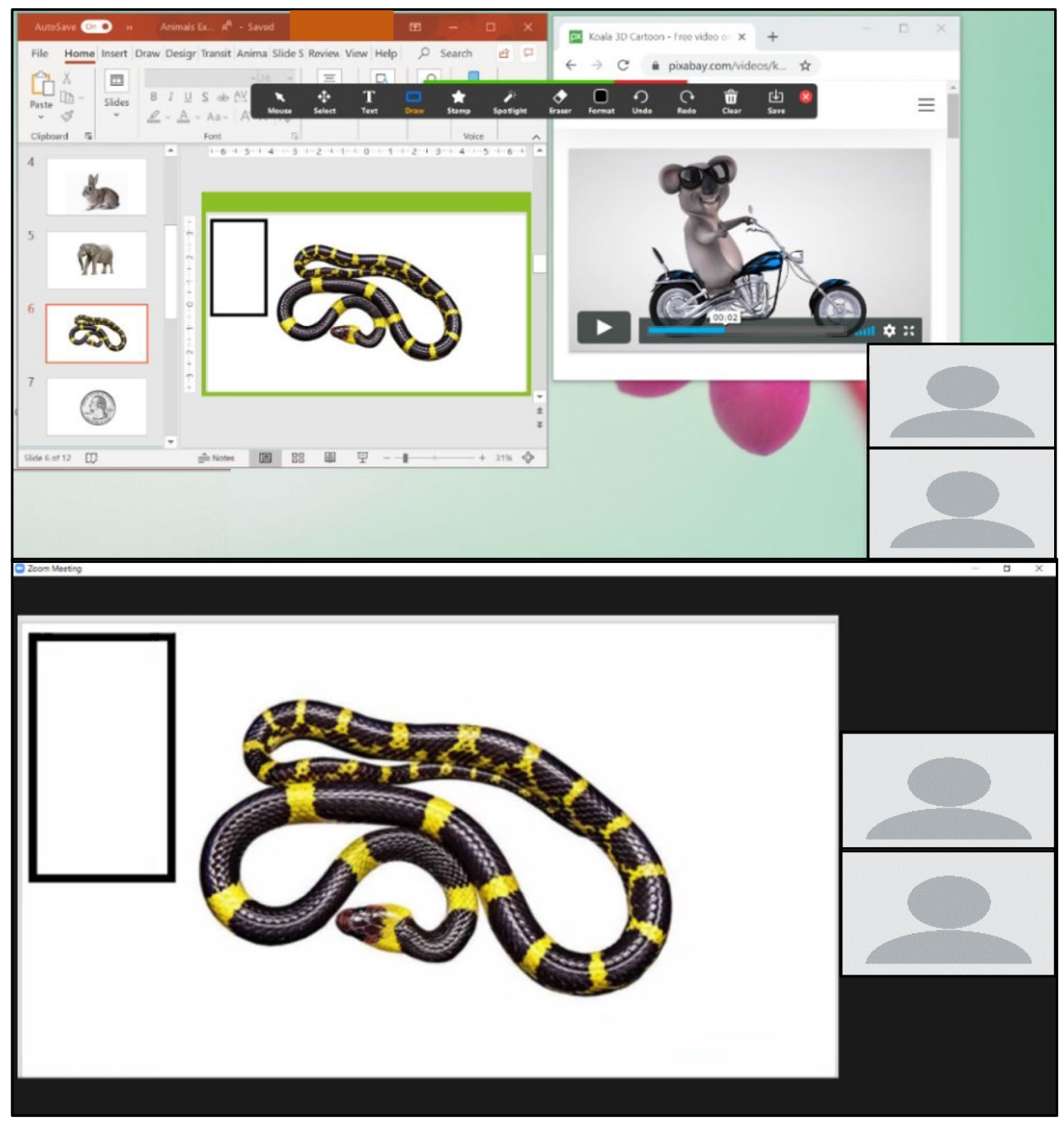

Fig. 38 Empty Token Board Using a Flexible Earning Requirement Drawn in the Portion of Screen Share Box. Note. The top panel shows the therapist's view, and the bottom panel shows the learner's view

to combine several research-supported operant procedures (e.g., prompt fading and reinforcement) to create an individualized, comprehensive behavior-change program (Ivy \& Schreck, 2016). Therefore, we used the three-term contingency, as it relates to instructional arrangements, as a general framework to create and deliver learning opportunities via telehealth. For each unit in the three-term contingency, we provided recommendations, task analyses, and references to Zoom walk-throughs to help a behavior analyst adapt evidencebased strategies to telehealth. Behavior analysts may also find the tutorial useful as a clinical-decision guide, coupled with other resources (Blanco et al., 2020; CASP, 2020b; Colombo et al., 2020; Cox et al., 2020; LeBlanc et al., 2020; Rodriguez, 2020), to determine the feasibility of direct service delivery via telehealth.

In this tutorial, we provided suggestions on how to utilize features within Zoom to create a virtual learning environment and reduce technological barriers to telehealth services. Despite access to built-in features in a teleconferencing platform, remaining limitations create barriers to direct intervention services provided via telehealth to learners with ASD. We recognize that there are multiple barriers, both technological and nontechnological, that a therapist may encounter during telehealth service provision that we have not addressed in this tutorial. We recommend reviewing resources that have identified common limitations and potential solutions for telehealth more generally (Dorsey \& Topol, 2016) and behavior-analytic interventions specifically (Lerman et al., 2020). Many of these considerations are applicable to providing direct intervention services via telehealth.

A barrier that we did not address in this tutorial is existing disparities in access to health care. Prior to the pandemic, Black and Latinx children with ASD were less likely to access intervention services than White children with ASD (Gourdine \& 


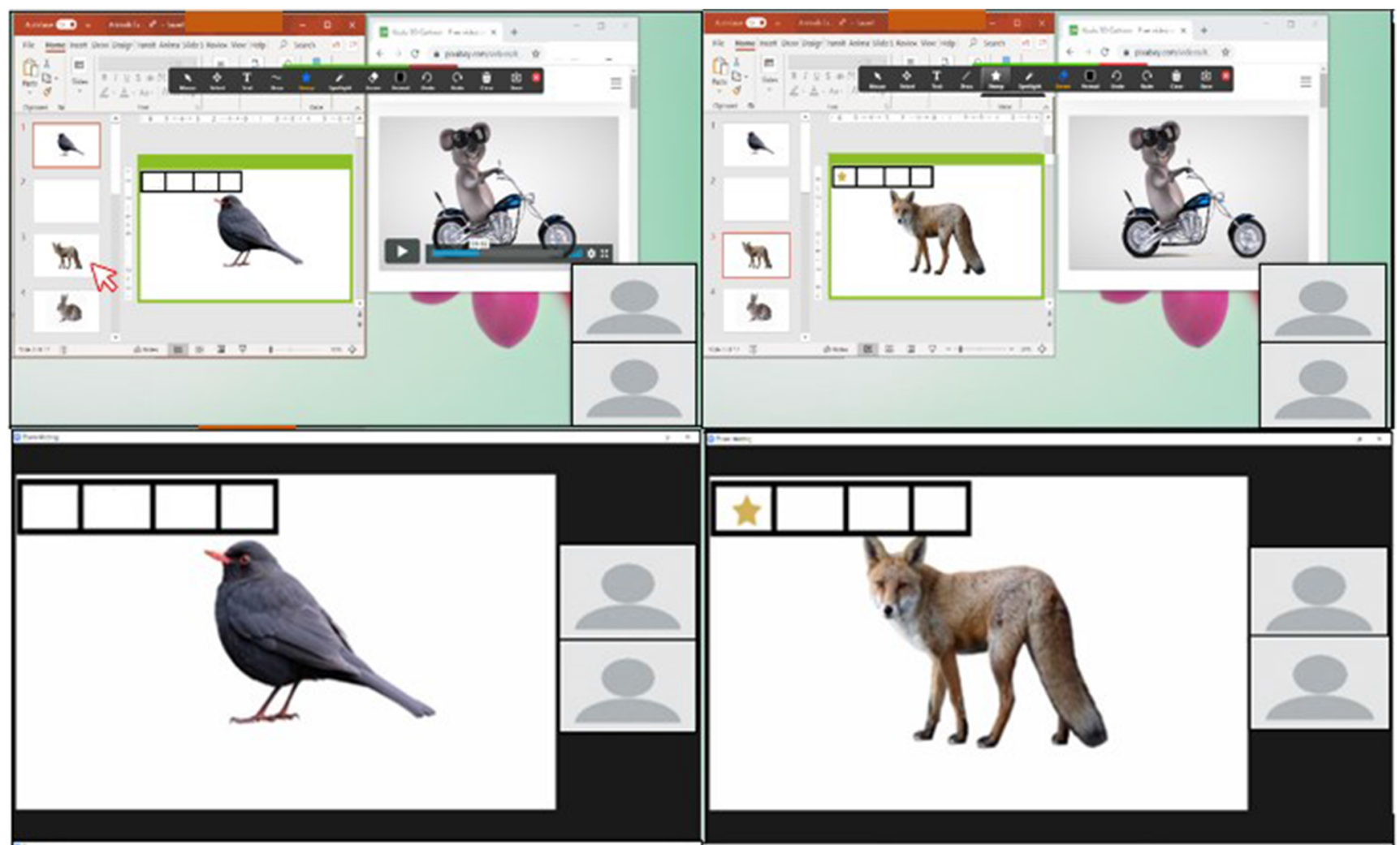

Fig. 39 Presenting the Target Stimulus. Note. Therapist and learner views of presenting a trial and selecting the next trial in a slideshow (left panel). Therapist and learner views of presenting the selected trial (right panel)

Algood, 2014; Liptak et al., 2008; Sell, Giarelli, Blum, Hanlon, \& Levy, 2012; K. A. Smith, Gehricke, Iadarola, Wolfe, \& Kuhlthau, 2020). The COVID-19 pandemic has exacerbated existing disparities, exemplified by the increased number of confirmed cases and deaths of people of color (Kirby, 2020; Yancy, 2020). Social inequities related to income, housing, and occupation may partially account for increased incidence (CDC, 2020a; Pareek et al., 2020), and many of the same societal factors can also inhibit families' capacities to participate in telehealth services. For example, families with lower socioeconomic status have less access to technology requirements, such as broadband internet access at home (Pew Research Center, 2019). People of color are more likely to be employed as essential workers in many industries, and caregivers who work as essential workers will have on-site work requirements that could reduce their availability to assist with telehealth sessions (McNicholas \& Poydock, 2020).

Behavior analysts should be aware of the many factors that contribute to inequitable access to health care, and they may find suggestions from telemedicine providers helpful (Nouri, Khoong, Lyles, \& Karliner, 2020) to address these disparities. Providers should consider implementing compassionate and culturally responsive practice parameters (LeBlanc et al., 2020; Miller, Re Cruz, \& Ala'i-Rosales, 2019), such as the potential need to anticipate and accommodate the rescheduling of sessions for families managing multiple stressors under strained conditions (Alegría, Alvarez, Ishikawa, DiMarzio, \& McPeck, 2016). We also encourage research that addresses culturally responsive telehealth adaptations that do not further exacerbate health disparities for racial-ethnic minority populations (Webb Hooper, Nápoles, \& Pérez-Stable, 2020).

The COVID-19 pandemic has dramatically transformed the landscape of health care provision for service providers, including behavior analysts. There is currently a large adoption of telehealth service models in response to COVID-19 without available evidence to guide practitioner behavior. Although the effectiveness of the strategies presented in this tutorial has not been evaluated in telehealth service delivery, the strategies are drawn from an existing evidence base in behavior analysis, which behavior analysts may find helpful as they traverse the telehealth landscape. Even when a behavior analyst adapts evidence-based strategies for telehealth service delivery, intervention success for each learner cannot be guaranteed. Behavior analysts evaluate intervention success by measuring progress per learner on a continuous basis (Anderson \& Romanczyk, 1999); we emphasize the importance of a formative assessment approach given the lack of research on direct service provision within telehealth and our ethical obligation to provide effective treatment (BACB, 


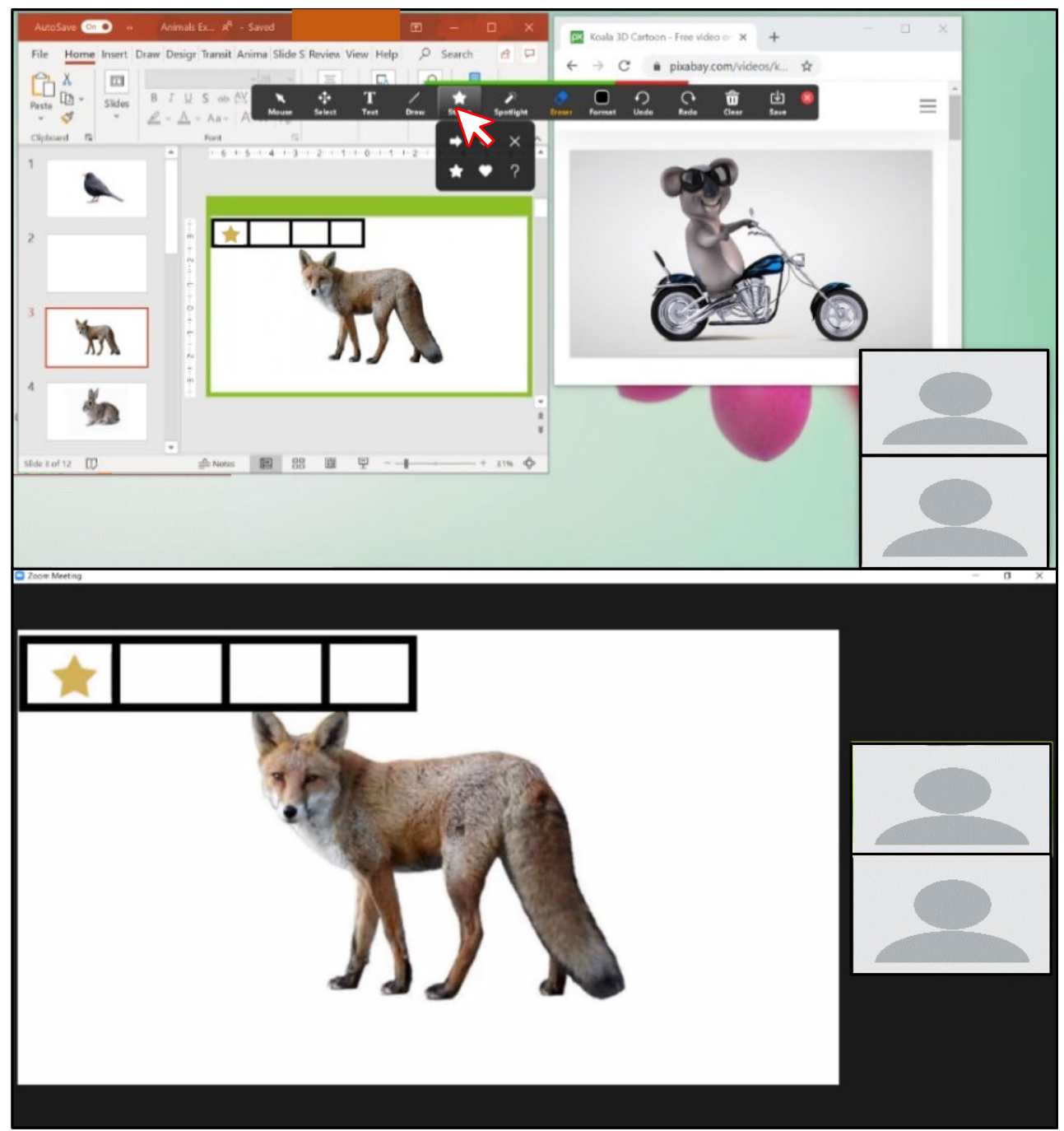

Fig. 40 Therapist View (Top Panel) and Learner View (Bottom Panel) of a Star Token

2014, Section 2.09a). In addition to the ongoing analysis of the learner's response to intervention, frequent reassessment of the learner's skills that indicate treatment appropriateness is likely necessary. For example, a learner may develop incompatible responses (e.g., accessing electronic content that is not germane to the instructional session) that were not present in the original assessment. In contrast, the learner may acquire novel readiness skills (e.g., attending to stimuli on an electronic display) over periods of social distancing that generalize to telehealth delivery. With a heightened focus on ongoing assessment, behavior analysts may optimize the direct provision of ABA services via telehealth using the learner's response to intervention as their evidence base.
The shift to telehealth models was due to a pandemic, but it may provide added value to the profession in the long run, as telehealth has produced favorable outcomes of intervention service provision in other fields. For example, O'Neil et al. (2014) found that patients receiving telehealth reported a greater improvement in depression symptoms than participants receiving face-to-face psychotherapeutic interventions and pharmacotherapy. Similar advantages may be available to consumers of direct behavior-analytic interventions via telehealth. We encourage intervention research that evaluates which intervention strategies, including those described in the present tutorial, are effective and for whom.

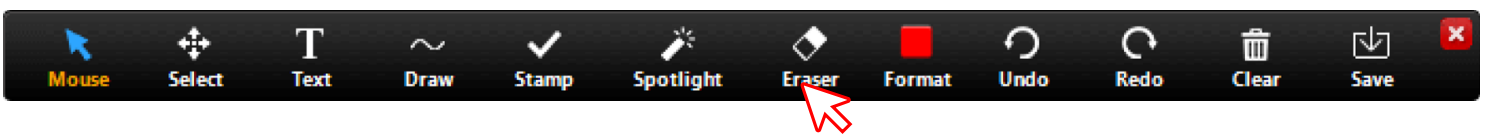

Fig. 41 Selecting the Annotate Eraser Tool 


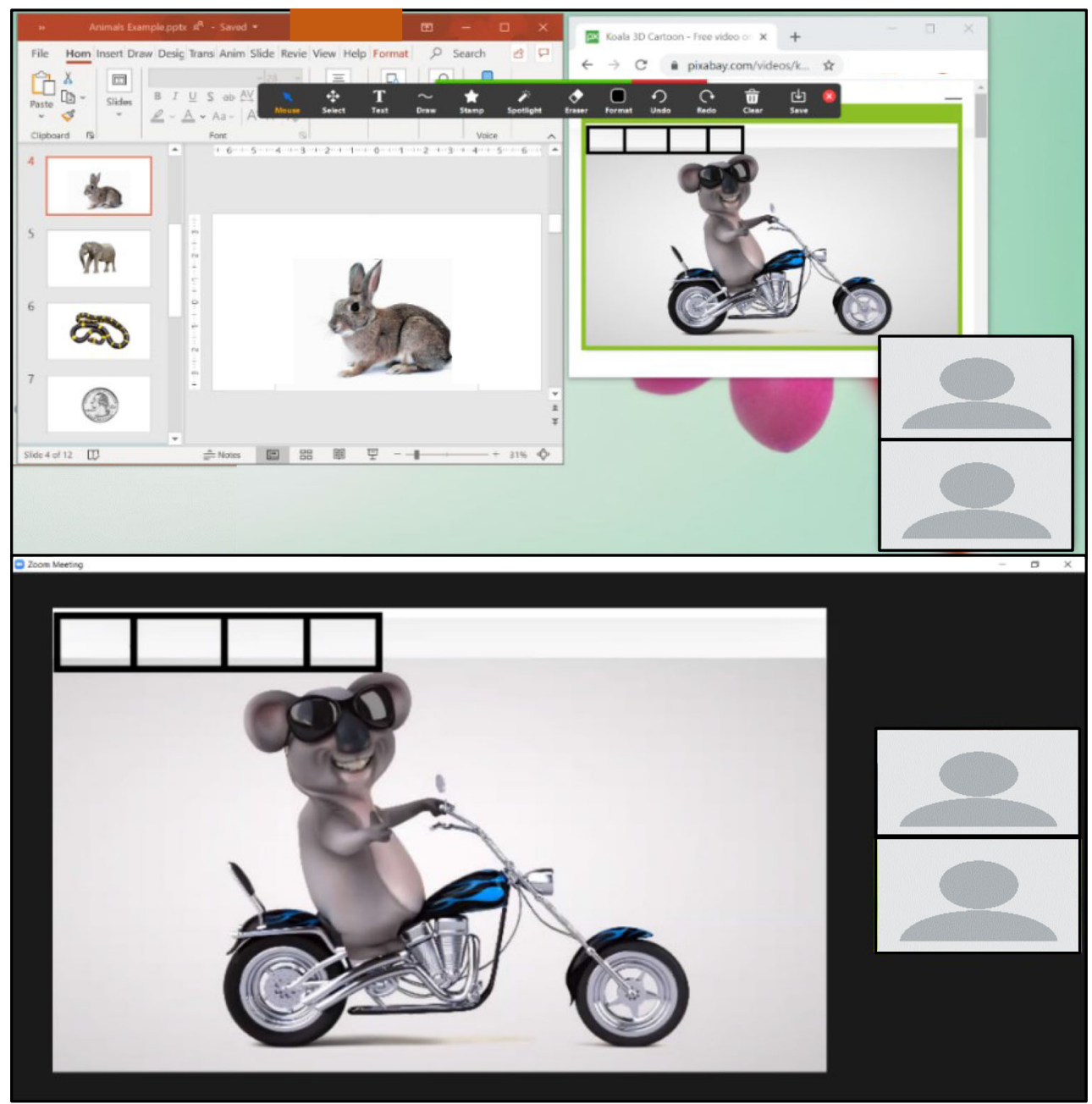

Fig. 42 Therapist (Top Panel) and Learner (Bottom Panel) Views of Sharing Video Reinforcement and Empty Token Board Using Portion of Screen Share

Acknowledgement The authors thank the UNT Kristin Farmer Autism Center for their support.

Data of Availability Data sharing is not applicable to this article as no data sets were generated or analyzed during the current study. Task analyses created by the authors are included in the article.

\section{Declarations}

Ethical Approval The article does not include any human or nonhuman research performed by the authors.

Conflicts of Interest Authors' contributions Samantha Bergmann conceptualized the tutorial, and all authors contributed to the design. Material preparation was performed by Gabriel Armshaw, Marla Baltazar, Haven Niland, and Elizabeth Sansing. The first draft of the manuscript was written by Samantha Bergmann, Haven Niland, Elizabeth Sansing, and Karen Toussaint. The manuscript was reviewed and edited by Samantha Bergmann and Karen Toussaint. All authors commented on previous versions of the manuscript. All authors read and approved the final manuscript.
Competing Interest The UNT Kristin Farmer Autism Center provides financial support to the authors for professional development and education. The authors have no relationship with Zoom.

Supplementary Information The online version contains supplementary material available at https://doi.org/10.1007/s40617-020-00529-5.

\section{References}

Akers, J. S., Pyle, N., Higbee, T. S., Pyle, D., \& Gerencser, K. R. (2016). A synthesis of script fading effects with individuals with autism spectrum disorder: A 20-year review. Review Journal of Autism and Developmental Disorders, 3(1), 1-17. https://doi.org/10.1007/ s40489-015-0062-9.

Alegría, M., Alvarez, K., Ishikawa, R. Z., DiMarzio, K., \& McPeck, S. (2016). Removing obstacles to eliminating racial and ethnic disparities in behavioral health care. Health Affairs, 35(6), 991-999. https://doi.org/10.1377/hlthaff.2016.0029. 
Anderson, S. R., \& Romanczyk, R. G. (1999). Early intervention for young children with autism: Continuum-based behavioral models. Journal of the Association for Persons With Severe Handicaps, 24(3), 162-173. https://doi.org/10.2511/rpsd.24.3.162.

Archibald, M. M., Ambagtsheeer, R. C., Casey, M. G., \& Lawless, M. (2019). Using Zoom videoconferencing for qualitative data collection: Perceptions and experiences of researchers and participants. International Journal of Qualitative Methods, 18(1), 1-8. https:// doi.org/10.1177/1609406919874596.

Association of Professional Behavior Analysts. (2020). Guidelines for practicing applied behavior analysis during the COVID-19 pandemic. https://cdn.ymaws.com/www.apbahome.net/resource/ collection/1FDDBDD2-5CAF-4B2A-AB3F-DAE5E72111BF/ APBA_Guidelines_-_Practicing_During_COVID-19_Pandemic 040920.pdf

Behavior Analyst Certification Board. (2014). Professional and ethical compliance code for behavior analysts. http://www.bacb.com/wpcontent/uploads/BACB-Compliance-Code-english 190318.pdf

Behavior Analyst Certification Board. (2020). Ethics guidance for ABA providers during Covid-19 pandemic. https://www.bacb.com/ ethics-guidance-for-aba-providers-during-covid-19-pandemic-2/

Blanco, S., Meisels, M., Blair, B., \& Leonard, L. (2020). What are some strategies for implementation of evidence-based telehealth practice in the time of COVID-19? Science in Autism Treatment, 17(4).

Brodhead, M. T., Al-Dubayan, M. N., Mates, M., Abel, E. A., \& Brouwers, L. (2015). An evaluation of a brief video-based multiple-stimulus without replacement preference assessment. Behavior Analysis in Practice, 9(2), 160-164. https://doi.org/10.1007/ s40617-015-0081-0.

Campanaro, A. M., Vladescu, J. C., Kodak, T., DeBar, R. M., \& Nippes, K. C. (2020). Comparing skill acquisition under varying onsets of differential reinforcement: A preliminary analysis. Journal of Applied Behavior Analysis, 53(2), 690-706. https://doi.org/10. 1002/jaba.615.

Cariveau, T., La Cruz Montilla, A., Gonzalez, E., \& Ball, S. (2019). A review of error correction procedures during instruction for children with developmental disabilities. Journal of Applied Behavior Analysis, 52(2), 574-579. https://doi.org/10.1002/jaba.524.

Carnett, A., Raulston, T., Lang, R., Tostanoski, A., Lee, A., Sigafoos, J., \& Machalicek, W. (2014). Effects of a perseverative interest-based token economy on challenging and on-task behavior in a child with autism. Journal of Behavioral Education, 23(3), 368-377. https:// doi.org/10.1007/s10864-014-9195-7.

Carroll, R. A., Kodak, T., \& Adolf, K. J. (2016). Effect of delayed reinforcement on skills acquisition during discrete-trial instruction: Implications for treatment-integrity errors in academic settings. Journal of Applied Behavior Analysis, 49(1), 176-181. https://doi. org/10.1002/jaba.268.

Cengher, M., Budd, A., Farrell, N., \& Fienup, D. M. (2018). A review of prompt-fading procedures: Implications for effective and efficient skill acquisition. Journal of Developmental and Physical Disabilities, 30(2), 155-173. https://doi.org/10.1007/s10882-0179575-8.

Centers for Disease Control and Prevention. (2020a). Coronavirus (COVID-19): Health equity considerations and racial and ethnic minority groups. Retrieved August 8, 2020, from https://www.cdc. gov/coronavirus/2019-ncov/community/health-equity/raceethnicity.html?CDC AA refVal=https $\% 3 \mathrm{~A} \% 2 \mathrm{~F} \% 2 \mathrm{Fwww} . c d c$. gov $\% 2 \mathrm{~F}$ coronavirus $\% 2 \mathrm{~F} 2019$-ncov $\% 2$ Fneed-extra-precautions $\%$ 2Fracial-ethnic-minorities.html

Centers for Disease Control and Prevention. (2020b). Coronavirus (COVID-19): How to protect yourself and others. Retrieved April 2020, from https://www.cdc.gov/coronavirus/2019-ncov/preventgetting-sick/prevention.html?CDC_AA_refVal=https $\% 3 \mathrm{~A} \% 2 \mathrm{~F} \%$ $2 \mathrm{Fwww}$.cdc.gov $\% 2 \mathrm{~F}$ coronavirus $\% 2 \mathrm{~F} 2019$-ncov$\% 2 \mathrm{Fprepare} \%$ 2Fprevention.html
Charlop, M. H., Lang, R., \& Rispoli, M. (2018). All children can play: Prompting and modeling procedures to teach play to children with autism spectrum disorder. In H. M. Charlop, R. Lang, \& M. Rispoli (Eds.), Play and social skills for children with autism spectrum disorder (pp. 33-52). Springer. https://doi.org/10.1007/978-3-31972500-0 3.

Cihon, J. H., Ferguson, J. L., Milne, C. M., Leaf, J. B., McEachin, J., \& Leaf, R. (2019). A preliminary evaluation of a token system with a flexible earning requirement. Behavior Analysis in Practice, 12(3), 548-556. https://doi.org/10.1007/s40617-018-00316-3.

Colombo, R. A., Wallace, M., \& Taylor, R. (2020). An essential service decision model for applied behavior analytic providers during crisis. Behavior Analysis in Practice, 13(2), 306-311. https://doi.org/10. 1007/s40617-020-00432-z.

Council of Autism Service Providers. (n.d.). Coronavirus-State-bystate-resources. https://casproviders.org/coronavirus-resources/ state-by-state-covid-resources/

Council of Autism Service Providers. (2020a). Applied behavior analysis treatment of autism spectrum disorder: Practice guidelines for healthcare funders and managers (2nd ed.). https://casproviders. org/wp-content/uploads/2020/03/ABA-ASD-Practice-Guidelines. pdf

Council of Autism Service Providers. (2020b). Practice parameters for telehealth-implementation of applied behavior analysis: Continuity of care during COVID-19 pandemic. https://casproviders.org/wpcontent/uploads/2020/03/PracticeParametersTelehealthABA 040320.pdf

Cox, D. J., Plavnick, J. B., \& Brodhead, M. T. (2020). A proposed process for risk mitigation during the COVID-19 pandemic. Behavior Analysis in Practice, 13(2), 299-305. https://doi.org/10.1007/ s40617-020-00430-1.

Cummings, C., \& Saunders, K. J. (2019). Using PowerPoint 2016 to create individualized matching to sample sessions. Behavior Analysis in Practice, 12(2), 483-490. https://doi.org/10.1007/ s40617-018-0223-2.

Curiel, H., \& Poling, A. (2019). Web-based stimulus preference assessment and reinforcer assessment for videos. Journal of Applied Behavior Analysis, 52(3), 796-803. https://doi.org/10.1002/jaba. 593.

DeLeon, I. G., Chase, J. A., Frank-Crawford, M. A., Carreau-Webster, A. B., Triggs, M. M., Bullock, C. E., \& Jennett, H. K. (2014). Distributed and accumulated reinforcement arrangements: Evaluations of efficacy and preference. Journal of Applied Behavior Analysis, 47(2), 293-313. https://doi.org/10.1002/jaba. 116.

DeLeon, I. G., \& Iwata, B. A. (1996). Evaluation of a multiple-stimulus presentation format for assessing reinforcer preferences. Journal of Applied Behavior Analysis, 29(4), 519-533. https://doi.org/10.1901/ jaba.1996.29-519.

Dorsey, E. R., \& Topol, E. J. (2016). State of telehealth. New England Journal of Medicine, 375(2), 154-161. https://doi.org/10.1056/ NEJMra1601705.

Dozier, C. L., Iwata, B. A., Thomason-Sassi, J., Worsdell, A. S., \& Wilson, D. M. (2012). A comparison of two pairing procedures to establish praise as a reinforcer. Journal of Applied Behavior Analysis, 45(4), 721-735. https://doi.org/10.1901/jaba.2012.45721.

Dube, W. V., \& McIlvane, W. J. (1999). Reduction of stimulus overselectivity with nonverbal differential observing responses. Journal of Applied Behavior Analysis, 32(1), 25-33. https://doi. org/10.1901/jaba.1999.32-25.

Eikeseth, S., Smith, D., \& Klintwall, L. (2014). Discrete trial teaching and discrimination training. In J. Tarbox, D. Dixon, P. Sturmey, \& J. Matson (Eds.), Handbook of early intervention for autism spectrum disorders (pp. 229-253). Springer. https://doi.org/10.1007/978-14939-0401-3_12. 
Ferguson, J., Craig, E. A., \& Dounavi, K. (2019). Telehealth as a model for providing behaviour analytic interventions to individuals with autism spectrum disorder: A systematic review. Journal of Autism and Development Disorders, 49(2), 582-616. https://doi.org/10. 1007/s10803-018-3724-5.

Fisher, W. W., Piazza, C. C., Bowman, L. G., \& Amari, A. (1996). Integrating caregiver report with a systematic choice assessment. American Journal on Mental Retardation, 101(1), 15-25 https:// www.kennedykrieger.org/sites/default/files/library/documents/ patient-care/centers-and-programs/down-syndrome-clinic-andresearch-center/reinforcer-assessment.pdf.

Fisher, W., Piazza, C. C., Bowman, L. G., Hagopian, L. P., Owens, J. C., \& Slevin, I. (1992). A comparison of two approaches for identifying reinforcers for persons with severe and profound disabilities. Journal of Applied Behavior Analysis, 25(2), 491-498. https://doi. org/10.1901/jaba.1992.25-491.

Fiske, K. E., Isenhower, R. W., Bamond, M. J., \& Lauderdale-Littin, S. (2020). An analysis of the value of token reinforcement using a multiple-schedule assessment. Journal of Applied Behavior Analysis, 53(1), 563-571. https://doi.org/10.1002/jaba.613.

Gourdine, R. M., \& Algood, C. L. (2014). Autism in the African American population. In V. Patel, V. Preedy, \& C. Martin (Eds.), Comprehensive guide to autism (pp. 2455-2467). Springer. https:// doi.org/10.1007/978-1-4614-4788-7_155.

Graff, R. B., \& Karsten, A. M. (2012). Assessing preferences of individuals with developmental disabilities: A survey of current practices. Behavior Analysis in Practice, 5(2), 37-48. https://doi.org/10.1007/ BF03391822.

Green, G. (2001). Behavior analytic instruction for learners with autism: Advances in stimulus control technology. Focus on Autism and Other Developmental Disabilities, 16(2), 72-85. https://doi.org/10. 1177/108835760101600203.

Groskreutz, M., \& Graff, R. (2009). Evaluating pictorial preference assessment: The effect of differential outcomes on preference assessment results. Research in Autism Spectrum Disorders, 3(1), 113128. https://doi.org/10.1016/j.rasd.2008.04.007.

Grow, L., \& LeBlanc, L. (2013). Teaching receptive language skills: Recommendations for instructors. Behavior Analysis in Practice, 6(1), 56-75. https://doi.org/10.1007/BF03391791.

Hackenberg, T. D. (2009). Token reinforcement: A review and analysis. Journal of the Experimental Analysis of Behavior, 91(2), 257-286. https://doi.org/10.1901/jeab.2009.91-257.

Hackenberg, T. D. (2018). Token reinforcement: Translational research and application. Journal of Applied Behavior Analysis, 51(2), 393432. https://doi.org/10.1002/jaba.439.

Hine, J. F., Ardoin, S. P., \& Call, N. A. (2018) Token economies: Using basic experimental research to guide practical applications. Journal of Contemporary Psychotherapy, 48(3), 145-154. https://doi.org/ 10.1007/s10879-017-9376-5.

Hoch, H., McComas, J. J., Johnson, L., Faranda, N., \& Guenther, S. L. (2002). The effects of magnitude and quality of reinforcement on choice responding during play activities. Journal of Applied Behavior Analysis, 35(2), 171-181. https://doi.org/10.1901/jaba. 2002.35-171.

Holth, P., Vandbakk, M., Finstad, J., Grønnerud, E. M., \& Sørensen, J. M. A. (2009). An operant analysis of joint attention and the establishment of conditioned social reinforcers. European Journal of Behavior Analysis, 10(2), 143-158. https://doi.org/10.1080/ 15021149.2009 .11434315

Ivy, J. W., \& Schreck, K. A. (2016). The efficacy of ABA for individuals with autism across the lifespan. Current Developmental Disorders Report, 3(1), 57-66. https://doi.org/10.1007/s40474-016-0070-1.

Johnson, K. A., Vladescu, J. C., Kodak, T., \& Sidener, T. M. (2017). An assessment of differential reinforcement procedures for learners with autism spectrum disorder. Journal of Applied Behavior Analysis, 50(2), 290-303. https://doi.org/10.1002/jaba.372.
Karsten, A. M., Carr, J. E., \& Lepper, T. L. (2011). Description of a practitioner model for identifying preferred stimuli with individuals with autism spectrum disorders. Behavior Modification, 35(4), 347369. https://doi.org/10.1177/0145445511405184.

Kazdin, A. E., \& Bootzin, R. R. (1972). The token economy: An evaluative review. Journal of Applied Behavior Analysis, 5(3), 343-372. https://doi.org/10.1901/jaba.1972.5-343.

Kelleher, R. T. (1966). Chaining and conditioned reinforcement. In W. K. Honig (Ed.), Operant behavior: Areas of research and application (pp. 160-212) Appleton-Century-Crofts.

Kirby, T. (2020). Evidence mounts on the disproportionate effect of COVID-19 on ethnic minorities. Lancet Respiratory Medicine, 8(6), 547-548. https://doi.org/10.1016/S2213-2600(20)30228-9.

Kisamore, A., Karsten, A. M., \& Mann, C. C. (2016). Teaching multiply controlled intraverbals to children and adolescents with autism spectrum disorders. Journal of Applied Behavior Analysis, 49(4), 826847. https://doi.org/10.1002/jaba.344.

Kodak, T., Campbell, V., Bergmann, S., LeBlanc, B., Kurtz-Nelson, E., Cariveau, T., Haq, S., Zemantic, P., \& Mahon, J. (2016). Examination of efficacious, efficient, and socially valid errorcorrection procedures to teach sight words and prepositions to children with autism spectrum disorder. Journal of Applied Behavior Analysis, 49(3), 532-547. https://doi.org/10.1002/jaba.310.

Leaf, J. B., Cihon, J. H., Ferguson, J. L., Leaf, R., \& McEachin, J. (2019). Comparing no-no prompt to flexible prompt fading to teach expressive labels to individuals diagnosed with autism spectrum disorder. Education and Training in Autism and Developmental Disabilities, 54(3), 274-287 http://www.daddcec.com/uploads/2/5/2/0/2520220/ etadd_september_54_3_2019.pdf\#page $=65$.

Leaf, J. B., Cihon, J. H., Leaf, R., McEachin, J., \& Taubman, M. (2016a). A progressive approach to discrete trial teaching: Some current guidelines. International Electronic Journal of Elementary Education, 9(2), 361-372 https://www.iejee.com/index.php/IEJEE/ article/view/163.

Leaf, J. B., Leaf, J. A., Alcalay, A., Kassardjian, A., Tsuji, K., Dale, S., Ravid, D., Taubman, M., McEachin, J., \& Leaf, R. (2016b). Comparison of most-to-least prompting to flexible prompt fading for children with autism spectrum disorder. Exceptionality, 24(2), 109-122. https://doi.org/10.1080/09362835.2015.1064419.

LeBlanc, L. A., Lazo-Pearson, J. F., Pollard, J. S., \& Unumb, L. S. (2020). The role of compassion and ethics in decision making regarding access to applied behavior analysis services during the COVID-19 crisis: A response to Cox, Plavnick, and Brodhead. Behavior Analysis in Practice, 13, 604-608. https://doi.org/10. 1007/s40617-020-00446-7.

Leon, Y., Borrero, J. C., \& DeLeon, I. G. (2016). Parametric analysis of delayed primary and conditioned reinforcers. Journal of Applied Behavior Analysis, 49(3), 639-655. https://doi.org/10.1002/jaba. 311.

Lerman, D. C., O’Brien, M. J., Neely, L., Call, N. A., Tsami, L., Schieltz, K. M., Berg, W. K., Graber, J., Huang, P., Kopelman, T., \& CooperBrown, L. J. (2020). Remote coaching of caregivers via telehealth: Challenges and potential solutions. Journal of Behavioral Education, 29(2), 195-221. https://doi.org/10.1007/s10864-02009378-2.

Liptak, G. S., Benzoni, L. B., Mruzek, D. W., Nolan, K. W., Thingvoll, M. A., Wade, C. M., \& Fryer, G. E. (2008). Disparities in diagnosis and access to health services for children with autism: Data from the National Survey of Children's Health. Journal of Developmental and Behavioral Pediatrics, 29(3), 152-160. https://doi.org/10. 1097/DBP.0b013e318165c7a0.

Lovaas, O. I. (1987). Behavioral treatment and normal educational and intellectual functioning in young autistic children. Journal of Consulting and Clinical Psychology, 55(1), 3-9. https://doi.org/10. 1037/0022-006X.55.1.3. 
MacDuff, G. S., Krantz, P. J., \& McClannahan, L. E. (2001). Prompts and prompt-fading strategies for people with autism. In C. Maurice, G. Green, \& R. M. Foxx (Eds.), Making a difference: Behavioral intervention for autism (pp. 37-50) Pro-Ed. https://dddc.rutgers.edu/ pdf/prompting.pdf.

Markham, V., Giles, A., \& May, R. (2020a). Evaluating efficacy and preference for prompt type during discrete-trial teaching. Behavior Modification, 44(1), 49-69. https://doi.org/10.1177/ 0145445518792245.

Markham, V., Giles, A., \& May, R. (2020b). A systematic evaluation of prompt fading methods during conditional discrimination training. European Journal of Behavior Analysis, 21(2), 255-270. https://doi. org/10.1080/15021149.2020.1719335.

Matson, J. L., \& Boisjoli, J. A. (2009). The token economy for children with intellectual disability and/or autism: A review. Research in Developmental Disabilities, 30(2), 240-248. https://doi.org/10. 1016/j.ridd.2008.04.001.

Mattson, S. L., Higbee, T. S., Aguilar, J., Nichols, B., Campbell, V. E., Nix, L. D., Reiner, K. S., Peck, S., \& Lewis, K. (2020). Creating and sharing digital instructional activities: A practical tutorial. Behavior Analysis in Practice, 13, 772-798. https://doi.org/10.31234/osf.io/ 9gwpj.

McGhan, A. C., \& Lerman, D. C. (2013). An assessment of errorcorrection procedures for learners with autism. Journal of Applied Behavior Analysis, 46(3), 626-639. https://doi.org/10.1002/jaba.65.

McNicholas, C., \& Poydock, M. (2020). Who are essential workers? A comprehensive look at their wages, demographics, and unionization rates. Economic Policy Institute. https://www.epi.org/blog/who-areessential-workers-a-comprehensive-look-at-their-wagesdemographics-and-unionization-rates/

Michael, J. L. (2004). Concepts and principles of behavior analysis. Association for Behavior Analysis International: Western Michigan University https://scholarworks.wmich.edu/books/353.

Miller, K. L., Re Cruz, A., \& Ala'i-Rosales, S. (2019). Inherent tensions and possibilities: Behavior analysis and cultural responsiveness. Behavior and Social Issues, 28(1), 16-36. https://doi.org/10.1007/ s42822-019-00010-1.

Miltenberger, R. G. (2016). Behavior modification: Principles and procedures (6th ed.) Cengage Learning.

Morris, S. L., \& Vollmer, T. R. (2019). Assessing preference for types of social interaction. Journal of Applied Behavior Analysis, 52(4), 1064-1075. https://doi.org/10.1002/jaba.597.

Neely, L., Rispoli, M., Gerow, S., \& Hong, E. R. (2016). Preparing interventionists via telepractice in incidental teaching for children with autism. Journal of Behavior Education, 25(4), 393-416. https://doi.org/10.1007/s10864-016-9250-7.

Niland, H. (2019). Embedding online videos as video reinforcers into slide shows [Video]. YouTube. https://www.youtube.com/watch? $\mathrm{v}=\mathrm{amTF} \_4 \mathrm{Bi} 6 \mathrm{vA} \&$ feature=youtu.be

Nouri, S., Khoong, E. C., Lyles, C. R., \& Karliner, L. (2020). Addressing equity in telemedicine for chronic disease management during the COVID-19 pandemic. NEJM Catalyst Innovations in Care Delivery. https://catalyst.nejm.org/doi/pdf/10.1056/CAT.20.0123

Office for Civil Rights. (2020). Notification of enforcement discretion for telehealth remote communications during the COVID-19 nationwide public health emergency. U.S. Department of Health and Human Services. https://www.hhs.gov/hipaa/for-professionals/ special-topics/emergency-preparedness/notification-enforcementdiscretion-telehealth/index.html

O’Neil, A., Taylor, B., Sanderson, K., Cyril, S., Chan, B., Hawkes, A. L., Hare, D. L., Jelinek, M., Venugopal, K., Atherton, J. J., Amerena, J., Grigg, L., Walters, D. L., Oldenburg, B., \& MoodCare Investigator Team. (2014). Efficacy and feasibility of a tele-health intervention for acute coronary syndrome patients with depression: Results of the "MoodCare" randomized controlled trial. Annals of Behavioral
Medicine, 48(2), 163-174. https://doi.org/10.1007/s12160-0149592-0.

Pace, G. M., Ivancic, M. T., Edwards, G. L., Iwata, B. A., \& Page, T. J. (1985). Assessment of stimulus preference and reinforcer value with profoundly retarded individuals. Journal of Applied Behavior Analysis, 18(3), 249-255. https://doi.org/10.1901/jaba.1985.18249.

Pareek, M., Bangash, M. N., Pareek, N., Pan, D., Sze, S., Minhas, J. S., Hanif, W., \& Khunti, K. (2020). Ethnicity and COVID-19: An urgent public health research priority. Lancet, 395(10234), 14211422. https://doi.org/10.1016/S0140-6736(20)30922-3.

Pew Research Center. (2019). Internet/broadband fact sheet. https:// www.pewresearch.org/internet/fact-sheet/internet-broadband/

Piazza, C. C., Fisher, W. W., Hagopian, L. P., Bowman, L. G., \& Toole, L. (1996). Using a choice assessment to predict reinforcer effectiveness. Journal of Applied Behavior Analysis, 29(1), 1-9. https://doi. org/10.1901/jaba.1996.29-1.

Plavnick, J. B. (2012). A practical strategy for teaching a child with autism to attend to and imitate a portable video model. Research and Practice for Persons With Severe Disabilities, 37(4), 263-270. https://doi.org/10.2511/027494813805327250.

Quintero, N., \& McIntyre, L. L. (2010). Sibling adjustment and maternal well-being: An examination of families with and without a child with an autism spectrum disorder. Focus on Autism and Other Developmental Disabilities, 25(1), 37-46. https://doi.org/10.1177/ 1088357609350367

Roane, H. S., Vollmer, T. R., Ringdahl, J. E., \& Marcus, B. A. (1998). Evaluation of a brief stimulus preference assessment. Journal of Applied Behavior Analysis, 31(4), 605-620. https://doi.org/10. 1901/jaba.1998.31-605.

Robacker, C. M., Rivera, C. J., \& Warren, S. H. (2016). A token economy made easy through ClassDojo. Intervention in School and Clinic, 52(1), 39-43. https://doi.org/10.1177/1053451216630279.

Rodriguez, K. A. (2020). Maintaining treatment integrity in the face of crisis: A treatment selection model for transitioning direct ABA services to telehealth. Behavior Analysis in Practice. Advance online publication. https://doi.org/10.1007/s40617-020-00429-8.

Russell, D., Ingvarsson, E. T., \& Haggar, J. L. (2017). Using progressive ratio schedules to evaluate tokens as generalized conditioned reinforcers. Journal of Applied Behavior Analysis, 51(1), 40-52. https:// doi.org/10.1002/jaba.424.

Saunders, K. J., \& Williams, D. (1998). Stimulus-control procedures. In K. A. Lattal \& M. Perone (Eds.), Handbook of research methods in human operant behavior (1st ed., pp. 193-228). Springer. https:// doi.org/10.1007/978-1-4899-1947-2.

Schnell, L. K., Vladescu, J. C., Kisamore, A. N., DeBar, R. M., Kahng, S., \& Marano, K. (2020). Assessment to identify learner-specific prompt and prompt-fading procedures for children with autism spectrum disorder. Journal of Applied Behavior Analysis, 53(2), 11111129. https://doi.org/10.1002/jaba.623.

Sell, N. K., Giarelli, E., Blum, N., Hanlon, A. L., \& Levy, S. E. (2012). A comparison of autism spectrum disorder DSM-IV criteria and associated features among African American and White children in Philadelphia County. Disability and Health Journal, 5(1), 9-17. https://doi.org/10.1016/j.dhjo.2011.08.002.

Smith, K. A., Gehricke, J., Iadarola, S., Wolfe, A., \& Kuhlthau, K. A. (2020). Disparities in service use among children with autism: A systematic review. Pediatrics, 145(Supplement 1), S35-S46. https://doi.org/10.1542/peds.2019-1895G

Smith, T. (2001). Discrete trial training in the treatment of autism. Focus on Autism and Other Developmental Disabilities, 16(2), 86-92. https://doi.org/10.1177/108835760101600204.

Smith, T. (2012). Evolution of research on interventions for individuals with autism spectrum disorder: Implications for behavior analysts. The Behavior Analyst, 35(1), 101-113. https://doi.org/10.1007/ BF03392269. 
Soluaga, D., Leaf, J. B., Taubman, M., McEachin, J., \& Leaf, R. (2008). A comparison of flexible prompt fading and constant time delay for five children with autism. Research in Autism Spectrum Disorder, 2(4), 753-765. https://doi.org/10.1016/j.rasd.2008.03.005.

Tarbox, R. S. F., Ghezzi, P. M., \& Wilson, G. (2006). The effects of token reinforcement on attending in a young child with autism. Behavioral Interventions, 21(3), 155-164. https://doi.org/10.1002/bin.213.

Telehealth in ABA. (2015). Discussion [Facebook group]. Facebook. Retrieved May 2020, from: https://www.facebook.com/groups/ 668891769907036

Tomlinson, S. R. L., Gore, N., \& McGill, P. (2018). Training individuals to implement applied behavior analytic procedures via telehealth: A systematic review of the literature. Journal of Behavior Education, 27(1), 172-222. https://doi.org/10.1007/s10864-018-9292-0.

Trosclair-Lasserre, N. M., Lerman, D. C., Call, N. A., Addison, L. R., \& Kodak, T. (2008). Reinforcement magnitude: An evaluation of preference and reinforcer efficacy. Journal of Applied Behavior Analysis, 41(2), 203-220. https://doi.org/10.1901/jaba.2008.41203.

Vedora, J., Barry, T., \& Ward-Horner, J. C. (2017). An evaluation of differential observing responses during receptive label training. Behavior Analysis in Practice, 10(3), 290-295. https://doi.org/10. 1007/s40617-017-0188-6.

Vedora, J., Barry, T., \& Ward-Horner, J. C. (2018). Sample first versus comparison first stimulus presentations: Preliminary findings for two individuals with autism. Behavior Analysis in Practice, 12(2), 423-429. https://doi.org/10.1007/s40617-018-00299-1.

Vedora, J., Meunier, L., \& Mackay, H. (2009). Teaching intraverbal behavior to children with autism: A comparison of textual and echoic prompts. The Analysis of Verbal Behavior, 25(1), 79-86. https:// doi.org/10.1007/BF03393072.

Vismara, L. A., McCormick, C., Young, G. S., Nadhan, A., \& Monlux, K. (2013). Preliminary findings of a telehealth approach to parent training in autism. Journal of Autism and Developmental Disorders, 43(5), 2953-2969. https://doi.org/10.1007/s10803-013-1841-8.

Vollmer, T. R., Marcus, B. A., \& LeBlanc, L. (1994). Treatment of selfinjury and hand mouthing following inconclusive functional analyses. Journal of Applied Behavior Analysis, 27(2), 331-344. https:// doi.org/10.1901/jaba.1994.27-331.

Wacker, D. P., Lee, J. F., Padilla Dalmau, Y. C., Todd, K. G., Lindgren, S. D., Kuhle, J., Pelzel, K. E., Dyson, S., Schieltz, K. M., \& Waldron, D. B. (2013a). Conducting functional analyses of problem behavior via telehealth. Journal of Applied Behavior Analysis, 46(1), 31-46. https://doi.org/10.1002/jaba.29.

Wacker, D. P., Lee, J. F., Padilla Dalmau, Y. C., Todd, K. G., Lindgren, S. D., Kuhle, J., Pelzel, K. E., Dyson, S., Schieltz, K. M., \& Waldron, D. B. (2013b). Conducting functional communication training via telehealth to reduce the problem behavior of young children with autism. Journal of Developmental and Physical Disabilities, 25(1), 35-48. https://doi.org/10.1007/s10882-0129314-0.

Webb Hooper, M., Nápoles, A. M., \& Pérez-Stable, E. J. (2020). COVID-19 and racial/ethnic disparities. JAMA, 323(24), 24662467. https://doi.org/10.1001/jama.2020.8598.

World Health Organization. (2020). Coronavirus disease (COVID-19) advice for public. https://www.who.int/emergencies/diseases/ novel-coronavirus-2019/advice-for-public

Yancy, C. W. (2020). COVID-19 and African Americans. JAMA, 323(19), 1891-1892. https://doi.org/10.1001/jama.2020.6548.

Zoder-Martell, K. A., Markelz, A. M., Floress, M. T., Skriba, H. A., \& Sayyah, L. E. N. (2020). Technology to facilitate telehealth in applied behavior analysis. Behavior Analysis in Practice. Advance online publication. https://doi.org/10.1007/s40617-020-00449-4

Publisher's Note Springer Nature remains neutral with regard to jurisdictional claims in published maps and institutional affiliations. 